\title{
Assessment of Net Lost Revenue Adjustment Mechanisms for Utility DSM Programs
}

Lester W. Baxter

MANAGEO BY

MARTIN MARIETIA ENERGY SYSTENS, WIC.

FOR THE UNTED STATES

DEPARTMENT OF ENERGY 
This report has been reproduced directly from the best available copy.

Available to DOE and DOE contractors from the Office of Scientific and Technical Information, P.O. Box 62, Oak Ridge, TN 37831; prices available from (615) 576-8401, FTS 626-8401.

Available to the public from the National Technical Information Service, U.S. Department of Commerce, 5285 Port Royal Rd., Springfield, VA 22161.

This report was prepared as an account of work sponsored by an agency of the United States Government. Neither the United States Government nor any agency thereof, nor any of their employees, makes any warranty, express or implied, or assumes any legal liability or responsibility for the accuracy, completeness, or usefuiness of any information, apparatus, product, or process disclosed, or represents that its use would not infringe privately owned rights. Reference herein to any specific commercial product, process, or service by trade name, trademark, manufacturer, or otherwise, does not necessarily constitute or imply its endorsement, recommendation, or favoring by the United States Government or any agency thereof. The views and opinions of authors expressed herein do not necessarily state or reflect those of the United States Government or any agency thereof. 


\section{DISCLAIMER}

Portions of this document may be illegible in electronic image products. Images are produced from the best available original document. 
ENERGY DIVISION

\section{ASSESSMENT OF \\ NET LOST REVENUE ADJUSTMENT MECHANISMS FOR UTILITY DSM PROGRAMS}

LESTER W. BAXTER

January 1995

Sponsored by

Office of Energy Efficiency and Renewable Energy

U.S. Department of Energy

OAK RIDGE NATIONAL LABORATORY

Oak Ridge, Tennessee 37831

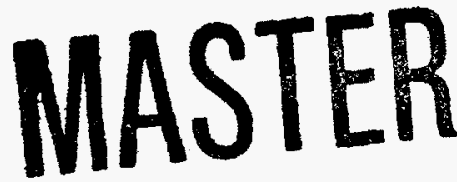
managed by

MARTIN MARIETTA ENERGY SYSTEMS, INC.

for the

U.S. DEPARTMENT OF ENERGY

under contract No. DE-AC05-84OR21400 



\section{CONTENTS}

Page

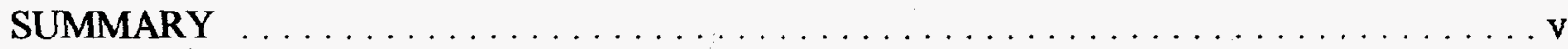

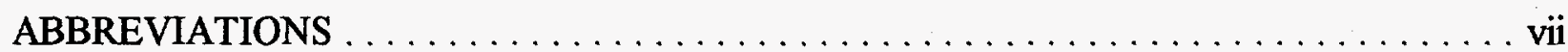

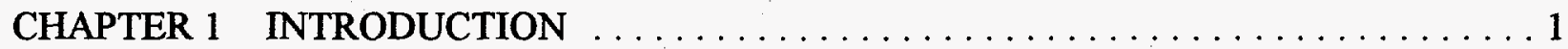

RECENT UTILITY INDUSTRY DEVELOPMENTS $\ldots \ldots \ldots \ldots \ldots \ldots \ldots \ldots$

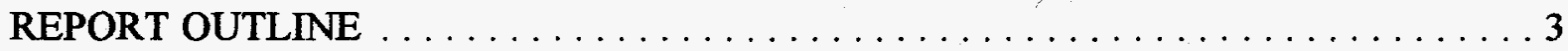

CHAPTER 2 DEFINING THE LOST REVENUE PROBLEM $\ldots \ldots \ldots \ldots \ldots \ldots \ldots$

EFFECTS OF DSM PROGRAMS ON UTILITIES $\ldots \ldots \ldots \ldots \ldots \ldots \ldots \ldots \ldots$

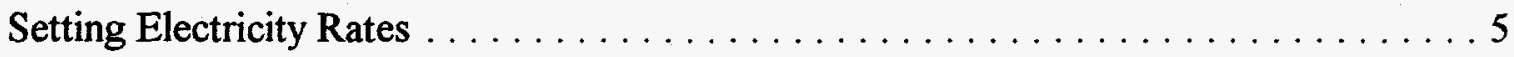

DSM Rate-making Reforms and the Effects of DSM on Utilities $\ldots \ldots \ldots \ldots \ldots 7$

Understanding Lost Revenues $\ldots \ldots \ldots \ldots \ldots \ldots \ldots \ldots \ldots$

APPROACHES TO ADDRESS LOST REVENUES FROM

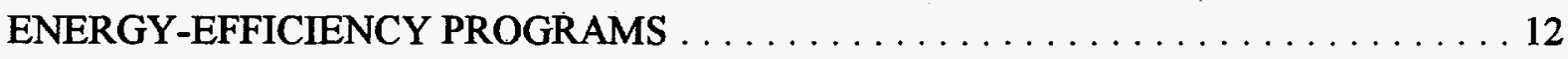

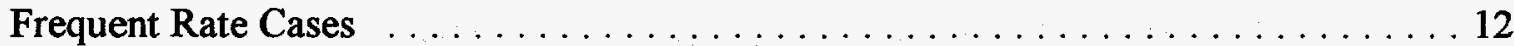

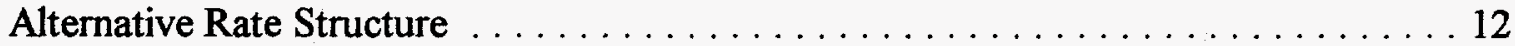

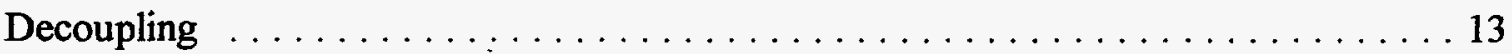

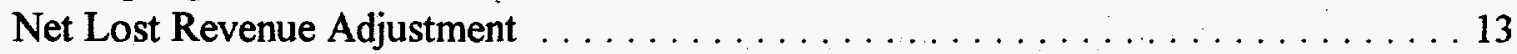

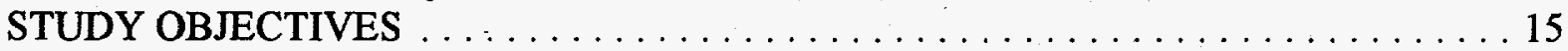

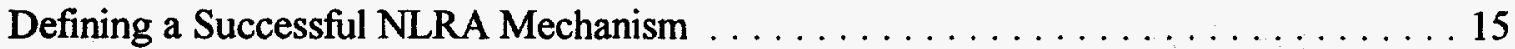

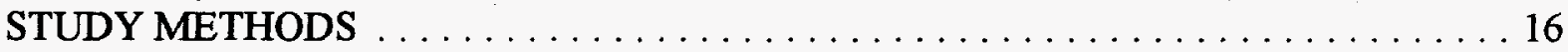

CHAPTER 3 OVERVIEW OF NLRA MECHANISMS . . . . . . . . . . . . . . . . 19

STATES ADDRESSING NET LOST REVENUE RECOVERY . . . . . . . . . . . . . . 19

STATES WITH ACTIVE NLRA MECHANISMS $\ldots \ldots \ldots \ldots \ldots \ldots \ldots \ldots \ldots \ldots \ldots$

Net Lost Revenues Recovered . ............................ 24

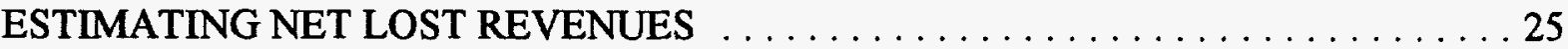

General Formula for Estimating Net Lost Revenues $\ldots \ldots \ldots \ldots \ldots \ldots \ldots \ldots$

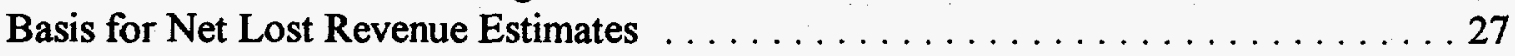

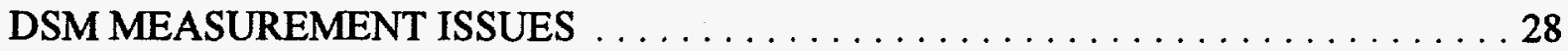

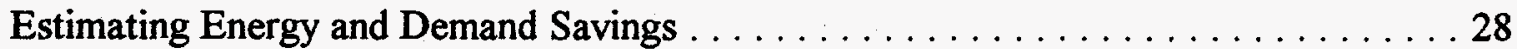

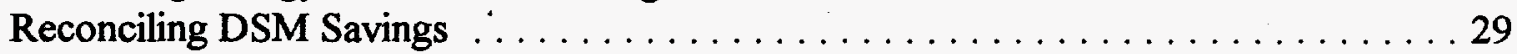

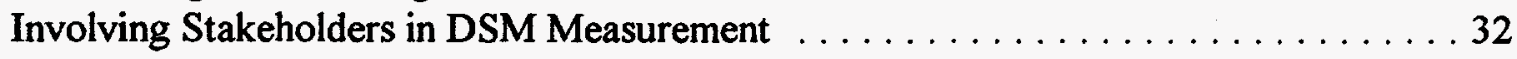

CONDITIONS PLACED ON NET LOST REVENUE RECOVERY $\ldots \ldots \ldots \ldots \ldots ., 32$

Program Preapproval . . . . . . . . . . . . . . . . . . . . . . . . 32 


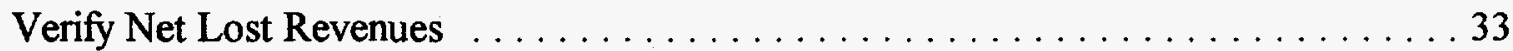

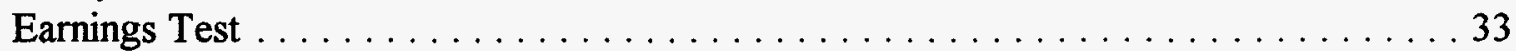

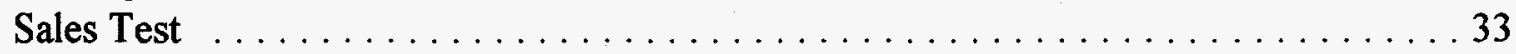

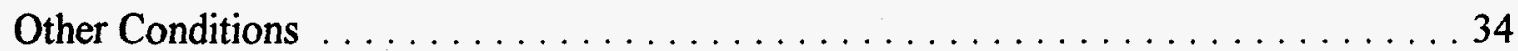

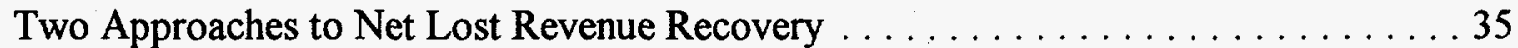

DIFFERENT TYPES OF NLRA MECHANISMS $\ldots \ldots \ldots \ldots \ldots \ldots \ldots \ldots \ldots \ldots$

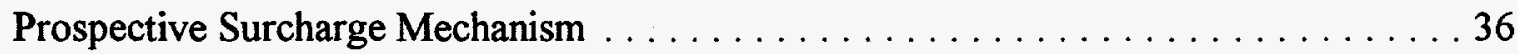

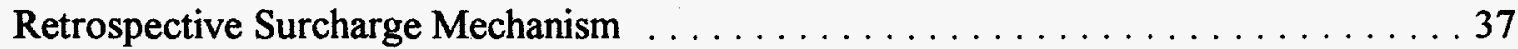

Deferred Account Mechanism . . . . . . . . . . . . . . . . . . . . . . . 37

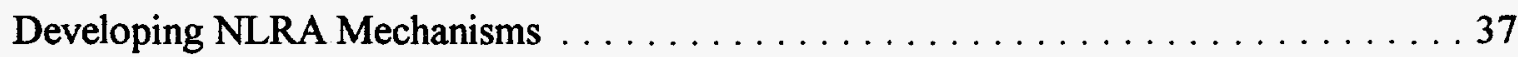

CHAPTER 4 EFFECTIVENESS OF THE NLRA APPROACH $\ldots \ldots \ldots \ldots \ldots \ldots \ldots$

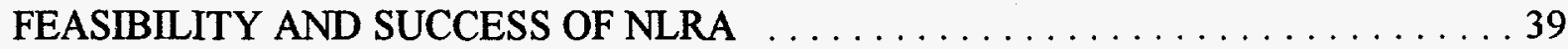

SUCCESSFUL IMPLEMENTATION OF NLRA MECHANISMS $\ldots \ldots \ldots \ldots \ldots \ldots$

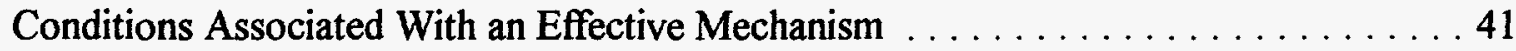

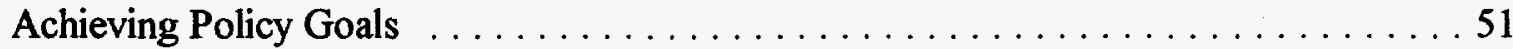

CHAPTER 5 EFFECTS OF DIFFERENT MECHANISMS ON UTILITY FINANCES . . . 57 FINANCIAL ANALYSIS OF DIFFERENT NLRA MECHANISMS $\ldots \ldots \ldots \ldots \ldots 7$

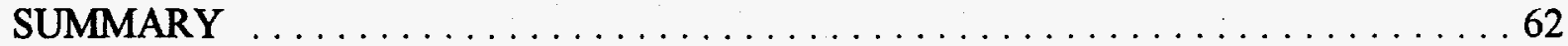

CHAPTER 6 CONCLUSIONS AND RECOMMENDATIONS $\ldots \ldots \ldots \ldots \ldots \ldots \ldots \ldots$

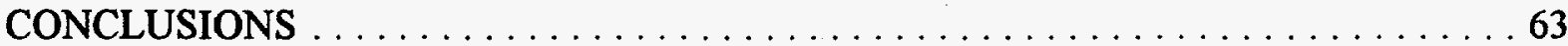

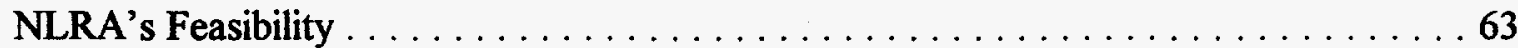

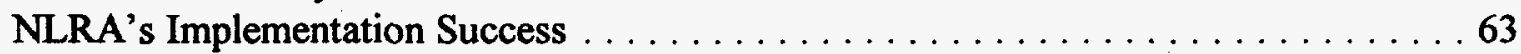

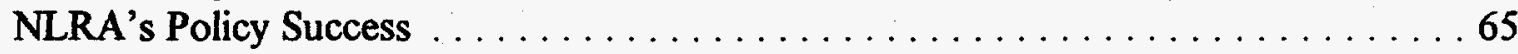

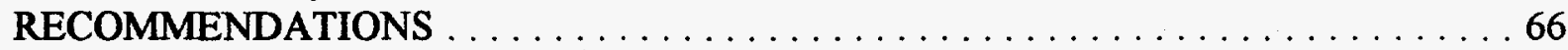

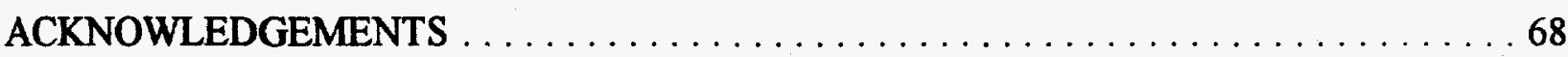

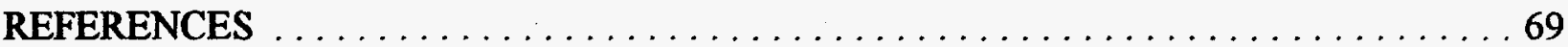

APPENDIX A STATE-SPECIFIC OVERVIEWS $\ldots \ldots \ldots \ldots \ldots \ldots \ldots \ldots \ldots$

APPENDIX B LIST OF INTERVIEWS $\ldots \ldots \ldots \ldots \ldots \ldots \ldots \ldots \ldots \ldots \ldots \ldots$ 


\section{SUMMARY}

Utility shareholders can lose money on demand-side management (DSM) investments between rate cases. Several industry analysts argue that the revenues lost from utility DSM programs are an important financial disincentive to utility DSM investment. A key utility regulatory reform undertaken since 1989 allows utilities to recover the lost revenues incurred through successful operation of DSM programs. Explicitly defined net lost revenue adjustment (NLRA) mechanisms are states' preferred approach to lost revenue recovery from DSM programs.

This report examines the experiences states and utilities are having with the NLRA approach. The report has three objectives. First, we determine whether NLRA is a feasible and successful approach to removing the lost-revenue disincentive to utility operation of DSM programs. Second, we identify the conditions linked to successful implementation of NLRA mechanisms in different states and assess whether NLRA has changed utility investment behavior. Third, we suggest improvements to NLRA mechanisms.

We first identify states with NLRA mechanisms where utilities are recovering lost revenues from DSM programs. We interview staff at regulatory agencies in all these states and utility staff in four states. These interviews focus on the status of NLRA, implementation issues, DSM measurement issues, and NLRA results. We also analyze regulatory agency orders on NLRA, as well as associated testimony, reports, and utility lost revenue recovery filings. Finally, we use qualitative and quantitative indicators to assess NLRA's effectiveness.

Contrary to the concerns raised by some industry analysts, our results indicate NLRA is a feasible approach to the lost-revenue disincentive. NLRA can be successfully implemented. Seven of the ten states we studied report no substantial problems with their approach. We observe several conditions linked to effective NLRA implementation and, for those states reporting problems, conditions linked to implementation difficulties. Table S-1 highlights the conditions associated with successful NLRA implementation. We believe the first three conditions are most important. Finally, observed changes in utility investment behavior occur after implementation of DSM rate reforms, which include deployment of NLRA mechanisms. We find that utilities in states with lost revenue recovery invest more than twice as much in DSM as do utilities in other states. 
Table S-1. Conditions Associated with a Successful NLRA Mechanism

1. Avoiding a Strict Ex Post Approach to DSM Measurement

2. Involving Stakeholders in the Process

3. Setting Conditions for Lost Revenue Recovery Related Directly to DSM Program Operation and Performance

4. Establishing a Frequent and Regular Filing Schedule

5. Allowing Flexibility for Both the PUC and the Utilities

6. Receiving Clear Legislative Authority to Set DSM Incentives and Cost Recovery

7. Addressing Cost Recovery Issues First

8. Having Previous Experience with IRP

9. Having Previous Experience with Balancing Accounts

10. Maintaining Customer Communication 


\section{ABBREVIATIONS}

ACC

ACE

APS

$\mathrm{BE}$

BGE

CAM

CE

CEL

CHG\&E

CIP

C\&LM

CL\&P

ConEd

DPS

DPU

DPUC

DSM

GRC

HVAC

IP\&L

IRP

kWh

MP

NARUC
Arizona Corporation Commission

Account Correcting for Efficiency

Arizona Public Service

Boston Edison

Baltimore Gas and Electric

Conservation Adjustment Mechanism

Commonwealth Electric (Massachusetts)

Cambridge Electric Light

Central Hudson Gas \& Electric

Conservation Improvement Program

Conservation and Load Management

Connecticut Light \& Power

Consolidated Edison (New York)

Department of Public Service (Minnesota)

Department of Public Utilities (Massachusetts)

Department of Public Utility Control (Connecticut)

Demand-Side Management

General Rate Case

Heating, Ventilating, and Air Conditioning

Indianapolis Power \& Light

Integrated Resource Planning

Kilowatt-hour

Minnesota Power

National Association of Regulatory Utility Commissioners 
NLRA

ORFIN

ORNL

OTP

PEPCO

PGE

PSB

PSC

PSI

PUC

SAVE

SIGECO

SRVC

TEP

UI

URC

WMECO
Net Lost Revenue Adjustment

Oak Ridge National Laboratory Financial Model

Oak Ridge National Laboratory

Otter Tail Power (Minnesota)

Potomac Electric Power Company

Portland General Electric

Public Service Board (Vermont)

Public Service Commission

PSI Energy, Inc.

Public Utilities Commission

Share All Value Equitably

Southern Indiana Gas and Electric Company

Short-Run Variable Costs

Tucson Electric Power

United Illuminating (Connecticut)

Utility Regulatory Commission (Indiana)

Western Massachusetts Electric Company 


\section{INTRODUCTION}

A regulatory barrier exists in many states to utility investment in demand-side management (DSM). Under traditional regulation and rate design, utility sales and revenues are linked directly with utility profits. That is, in most cases a utility's revenues and profits increase whenever it sells an additional kilowatt-hour ( $\mathrm{kWh}$ ) or therm. Likewise, the utility's revenues and profits decrease whenever a $\mathrm{kWh}$ or therm is conserved through DSM.

In a proceeding to examine rate-making practices to encourage least-cost planning and DSM investment by utilities, the New York Public Service Commission (1988, p. 40) concluded:

It is important that utilities not regard DSM programs as something that pits their customers' interests (and those of society at large) against their own. Utility reluctance to embark on cost-effective DSM programs because lost sales will reduce profitability must be brought to an end. The concern is a legitimate one for utility management, but the way to resolve it is through revised rate making, not through de-emphasis of conservation. The utilities should propose rate-making innovations ... such that DSM programs that benefit customers are also rewarding to stockholders.

The New York Public Service Commission (PSC) was identifying a fundamental tension created by utility DSM programs: DSM erodes shareholder profits while providing customers with costeffective energy options. The National Association of Regulatory Utility Commissioners (NARUC Energy Conservation Committee 1988) recognized this barrier when it passed a resolution in 1988 urging state regulatory commissions to " . . adopt appropriate mechanisms to compensate a utility for earnings lost through the successful implementation of demand-side programs and seek to make the least-cost plan a utility's most profitable resource plan."

Following NARUC's resolution, Moskovitz (1989) thoroughly explored the financial disincentives affecting DSM under traditional regulation and proposed several alternatives to address these disincentives. Shortly thereafter, DSM collaborative processes and policy reforms sprang up in several states. Many states initiated proceedings on DSM policy reform and subsequently implemented approaches to address regulatory practices that created financial disincentives to utility DSM investment. Addressing the lost revenue disincentive to utility DSM investment was a central element of these reforms, along with ensuring utility recovery of DSM program costs and, in some states, developing financial incentives to encourage further utility DSM investment.

Federal legislative initiatives also recognized the importance of lost revenues as a barrier to DSM. For example, the Clean Air Act Amendments (1990) allow those investor-owned utilities that 
invest in DSM and are provided regulatory treatment to ensure net income neutrality for DSM to receive bonus sulfur dioxide emission allowances from 1992 to 1999. In addition, the Energy Policy Act of 1992 requires state public utility commissions to consider whether their rate-making treatment of DSM provides for net income neutrality for DSM. The Act (Energy Policy Act, section 111, p.24, 1992) states:

The rates allowed to be charged by a State regulated electric utility shall be such that the utility's investment in and expenditures for energy conservation, energy efficiency resources, and other demand side management measures are at least as profitable, giving appropriate consideration to income lost from reduced sales due to investments in and expenditures for conservation and efficiency, as its investments in and expenditures for the construction of new generation, transmission, and distribution equipment.

\section{RECENT UTILITY INDUSTRY DEVELOPMENTS}

With utility DSM activities poised for continued expansion, important industry-wide forces are currently altering the DSM landscape. Due to the Public Utilities Regulatory Policies Act of 1978 and advances in generation technology, electric utilities are no longer the sole providers of generation capacity in the United States. The Energy Policy Act of 1992 mandates open and nondiscriminatory access to the transmission system for all wholesale electricity suppliers. Certain large customers want the freedom to chose their electricity provider over this open transmission system. As a result, the electric industry of the future could be characterized by widespread competition between suppliers to meet customer demands.

The future of DSM will be affected dramatically by larger policy decisions made at the federal and state levels about the future structure of both the electric utility industry and industry regulation. The most prominent industry restructuring proposal was issued in California (California Public Utilities Commission 1994). The California proposal advocates widespread competition for retail customers by suppliers. While the long-term effect of retail competition on DSM is uncertain, the short-term impact due to uncertainties about the implementation of the California proposal are clear. California's two largest utilities, Pacific Gas \& Electric and Southern California Edison, proposed large reductions in their DSM program budgets following issuance of the proposal (Electric Utility Week's Demand-Side Report 1994b and c).

Reforms to address financial disincentives to DSM investment, such as lost revenues, will also be affected by the larger changes in the utility industry. The California industry restructuring proposal, for example, recommends replacing the current cost-of-service regulation with performance-based regulation for major portions of the industry. The proposal asserts that performance-based regulation will both simplify regulation and reduce administrative burdens. With respect to DSM, a key element of the different performance-based rate-making initiatives 
proposed by California's major investor-owned electric utilities is a regulatory mechanism that severs the link between utility sales and revenues. The California industry restructuring proposal calls for those mechanisms to focus solely on lost revenues due to energy efficiency programs. Thus, regulatory changes to facilitate industry restructuring will include discussion of lost revenue adjustment mechanisms.

\section{REPORT OUTLINE}

Several states have now had one year or more of experience with lost revenue adjustment mechanisms as a means of addressing a financial disincentive to utility DSM investment. Our purpose is to study the mechanisms implemented by different states and determine if the lost revenue approach is feasible and effective. We also identify the conditions that contribute to successful applications of the lost revenue approach and those that lead to problems.

Chapter 2 more fully defines the problem of lost revenues from utility DSM and explains the methods used in our study. Chapter 3 provides overviews of lost revenue approaches in all states with active mechanisms and reports the results of our detailed interviews with regulatory and utility staff. Chapter 4 examines the feasibility of the lost revenue approach and discusses the effectiveness of the lost revenue adjustment mechanisms implemented to date. Chapter 5 presents results from our analysis on the effects of different lost revenue adjustment mechanisms on utility finances. Chapter 6 furnishes our conclusions and suggestions for improvements to these mechanisms. 


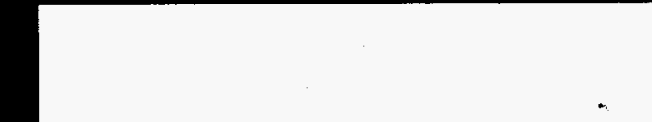




\section{DEFINING THE LOST REVENUE PROBLEM}

Chapter 2 has four objectives. First, we identify and discuss the effects of DSM programs on utilities, with particular attention to DSM's impact on utilities' fixed cost recovery. Second, we discuss approaches to address the revenues lost from utility DSM programs, including the potential problems and possible solutions utility analysts have raised about net lost revenue adjustment (NLRA) mechanisms. Third, we define this study's objectives. We conclude Chapter 2 with a description of the methods used in this study.

\section{EFFECTS OF DSM PROGRAMS ON UTILITIES}

To understand the issues surrounding financial disincentives to utility DSM programs, we must first identify the effects of DSM programs on utilities. The benefits of DSM for customers are well documented. In return for their investment of time and money in energy efficiency, customers save money, often increase comfort and productivity, and can reduce environmental damages on a local or regional scope (Brown et al. 1993; Hirst 1991; MacLeod and Haites 1994; Smith, Dykema, and Delaney 1993).

The effects of DSM programs on utilities and, in turn, utilities' motivation to pursue DSM, are related to utility regulation and rate making. Moskovitz (1989) describes three important regulatory issues affecting DSM: DSM program cost recovery, lost revenue recovery, and the incentive to increase sales under traditional regulation. Program cost recovery, insuring that utilities are compensated for their prudently incurred direct costs of running DSM programs, is important, but not the topic of our study. The remaining two issues, lost revenue recovery and the utility incentive to increase sales, are central to understanding the effects of DSM programs on utilities. To understand these two issues, we must first discuss the elements of electricity rate making.

\section{Setting Electricity Rates}

PUCs set electricity rates in general rate cases, using the test year as an important concept in rate design. The test year is the period used by regulators to assess a utility's cost of service, or revenue requirement, and the need to change rates. Test years are typically either a historic twelve-month period, in which case observed utility costs are the relevant benchmark, or a future twelve-month period, which uses a forecast of utility costs to set rates. Most PUCs rely on a historic test year to calculate the utility's cost of service or revenue requirement even though the rate case is focused on setting future rates (that is, the rates the utility will charge customers in the year(s) following the rate case). 
A fundamental principle of rate design is to set prices for utility service that enable the utility to collect the total amount of money from customers the utility needs to pay all operating and capital expenses plus a fair return on investment. In simple terms the utility's revenue requirement is defined as:

$$
\text { Revenue Requirement }=\text { Costs }+ \text { Income Taxes }+ \text { Return on Investment }
$$

- Costs include all operating costs, depreciation costs, and taxes other than income taxes.

- Return on Investment is the utility's authorized rate of return times its approved rate base. (Note that this return is not a guarantee, but is instead a ceiling the utility cannot exceed. The utility must perform to earn up to this maximum return.)

Costs have two major components:

$$
\text { Costs }=\text { Fixed Costs }+ \text { Variable Costs }
$$

- Fixed Costs include depreciation expense on plant and equipment, interest payments, taxes, and most operations and maintenance costs.

- Variable Costs include all fuel costs and certain operations and maintenance costs related to the intensity and duration of power plant operation.

For historical test year rate making (hTY), electricity rates or prices are set by dividing historical test year revenue requirements by historical electricity sales:

$$
\text { Price }=\text { Revenue Requirement }_{\mathrm{hTY}} / \text { Sales }_{\mathrm{hTY}}
$$

States that use future test year rate making (fTY) replace historical data with forecasts of future revenue requirements and future sales: ${ }^{1}$

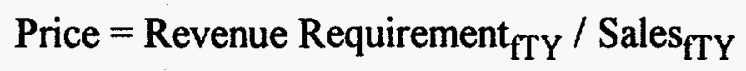

After the PUC sets the utility's rates, changes in electricity use affect utility revenues. With rates fixed between rate cases:

\section{Revenues $=$ Price $x$ Sales}

If sales are greater than assumed then the utility will overcollect revenue; the opposite is true if utility sales are less than assumed. This relationship between actual and assumed sales, and the subsequent effect on utility revenues, is important for understanding how DSM affects utilities.

\footnotetext{
${ }^{1}$ In practice, setting rates is more complicated. PUCs set different rates for residential, commercial, and industrial customers. The rate differences may depend, for example, on each group's contribution to the utility's cost of service.
} 
As a final and important point, utility and regulatory accounting practice includes a portion of fixed and variable cost recovery for each $\mathrm{kWh}$ the utility sells. Thus, even though by definition fixed costs are essentially constant and do not change over the short term with the utility's level of production, each $\mathrm{kWh}$ sold contributes to fixed cost recovery.

Fuel Adjustment Clause. Many utilities are subject to numerous rate adjustments between rate cases. The fuel adjustment clause is an important rate adjustment that, as Moskovitz (1989) notes, unintentionally has a major effect on utility DSM. This clause is a rate adjustment mechanism that allows utilities to recover through rates their fuel costs for electric generation. Fuel adjustment clauses were developed to ensure that utilities and ratepayers are not harmed by, or do not benefit from, differences between forecasted and actual fuel costs.

These clauses essentially ensure that fuel costs, which are the dominant portion of variable costs, will be recovered under almost any circumstance. If fuel costs are more than expected, the utility can raise prices to all customers to recover these costs. If costs are less than expected, the utility can reduce prices and return savings to customers. Thus, the fuel clause gives the utility little incentive to reduce fuel use. $^{2}$ As a result, the fuel clause negates what would otherwise be a tangible benefit from utility DSM - energy efficiency programs can save utilities money by reducing fuel costs. ${ }^{3}$

\section{DSM Rate-making Reforms and the Effects of DSM on Utilities}

Moskovitz (1989) develops the conceptual problems with traditional rate making and utility DSM. For utility DSM, the central problem with traditional rate making is that each $\mathrm{kWh}$ a utility sells adds to its earnings. From our discussion on setting electricity prices we can see this clearly when the electricity price is greater than the utility's short-run marginal cost ${ }^{4}$ because each $\mathrm{kWh}$ contributes to fixed and variable cost recovery, thus each $\mathrm{kWh}$ sold contributes to both components. This condition, however, also generally holds even when the electricity price is less than the utility's short-run marginal cost because the fuel adjustment clause enables the utility to recover the difference between marginal and average fuel costs. Conversely, each $\mathrm{kWh}$ saved by an energy efficiency measure reduces utility earnings, regardless of how little the measure costs.

Hirst and Blank (1993) quantify these effects for a hypothetical utility intended to represent a composite of Rocky Mountain utilities. As expected from our discussion on setting electricity

\footnotetext{
${ }^{2}$ To the extent that utilities find themselves conpeting with other suppliers on the basis of price or are subject to regulatory requirements aiming to reduce fuel use, this may change.

${ }^{3}$ Utilities save money from their DSM programs when their programs' demand reductions lead to deferral of more costly capacity additions or reduced operation of more expensive power plants. Utilities often pursue load management programs without regulatory stimulus for these reasons.

${ }^{4}$ In general, unless a utility is capacity-or energy-constrained, the utility's short-run marginal costs equal its fuel or variable costs.
} 
prices, they find that unexpected changes in electricity sales affect utility revenues and earnings. They also find that utility energy efficiency programs that affect electricity sales hurt utility earnings. We reproduce in Table 1 data from Hirst and Blank (1993) showing that utility DSM programs that reduce electricity demand also erode utility earnings. Hirst and Blank look at the effects of three different types of DSM programs on the finances of a hypothetical utility: a pilot program; a ramped-up program; and a full-scale program. Their analysis clearly shows that as programs expand to increasingly reduce energy demand, customer net benefits correspondingly grow while shareholders suffer greater earnings losses.

\section{Table 1. Effects of Different Types of Utility DSM Programs on Customers and Shareholders}

\begin{tabular}{|c|c|c|c|c|c|}
\hline \multirow{2}{*}{$\begin{array}{l}\text { Type of } \\
\text { DSM } \\
\text { Program }\end{array}$} & \multirow{2}{*}{$\begin{array}{c}\text { Percentage } \\
\text { of Energy } \\
\text { Growth }\end{array}$} & \multirow{2}{*}{$\begin{array}{l}\text { Program } \\
\text { Load } \\
\text { Factor } \\
(\%)\end{array}$} & \multicolumn{2}{|c|}{$\begin{array}{c}\text { Customer } \\
\text { Net Benefits }\end{array}$} & \multirow{2}{*}{$\begin{array}{l}\text { Shareholder } \\
\text { Effects } \\
\text { (basis points) }\end{array}$} \\
\hline & & & (millions \$) & $\mathrm{B} / \mathrm{C}$ & \\
\hline Pilot & 2 & 10 & 7 & 1.2 & -3 \\
\hline Ramp-Up & 30 & 50 & 80 & 1.8 & -90 \\
\hline Full-Scale & 68 & 68 & 174 & 2.1 & -243 \\
\hline
\end{tabular}

Source: Hirst and Blank (1993), page 1096, Table 3.

More generally, Hirst and Blank find that the greater the deviation from expected sales, the greater the impact on earnings. If sales growth is lower than expected, then earnings are hurt; the opposite is true if growth is higher then expected. Hirst and Blank also find this effect is magnified the greater the duration between rates cases. If rate cases are held annually, the effects on utility earnings are small, whether positive or negative; if rate cases are held less frequently, the effects increase. Finally, with respect to DSM programs, they note a key relationship between retail prices and short-run variable costs (SRVC): for any given difference between electricity price and SRVC, earnings decrease with increasing size of DSM programs; for any given DSM program size, earnings decrease with increasing differences between electricity price and SRVC. Thus, utilities with small programs and low retail prices relative to SRVC suffer only small earnings losses. In contrast, utilities with large DSM programs and high retail prices relative to SRVC suffer large earnings losses.

Eto, Stoft, and Belden (1994) move from Hirst and Blank's analysis of a hypothetical utility to construct a general explanation of the profitability of increasing utility sales between rate cases. They conclude that the profitability of an increase in sales goes up (1) as the variable cost fraction of total costs decreases because a larger fraction of costs is fixed and (2) as the responsiveness of 
these costs (what Eto et al. call the ratio of marginal variable to average variable costs) decreases to increases in sales. For the range of conditions characterizing the cost structure of today's electric industry, they find that costs must increase by two to three times the percentage increase in sales before earnings are negated. If costs do not increase this sharply in response to an increase in sales, then increased sales will lead to increased earnings.

Thus, we see that utility energy efficiency programs run into two fundamental and related obstacles. First, energy efficiency programs reduce utility revenues relative to what revenues would be in the absence of the programs. These revenues are typically called the "lost revenues" from utility DSM programs. Second, energy efficiency programs represent foregone potential earnings opportunities; the programs are counter to the utility incentive to increase sales between rate cases. These obstacles are rooted in the way electricity prices are set and the way fixed and variable costs are recovered through prices. We explore the concept of lost revenues in more detail below.

\section{Understanding Lost Revenues}

Lost revenues occur when actual electricity sales are less than the electricity sales level used to set electricity prices:

$$
\text { Lost }_{\text {Revenues }}=\left(\text { Sales }_{\mathrm{N}}-\text { Sales }_{\mathrm{TY}}\right) \times \mathrm{P}
$$

- Sales $_{\mathrm{N}}$ are the actual electricity sales in year N.

- Sales $_{\mathrm{TY}}$ are the electricity sales recorded (for historical test years) or forecasted (for future test years) and used to set electricity prices.

- $P$ is the electricity price set in the last rate case.

As we discussed earlier, utility and regulatory accounting practice assigns both a fixed cost and a variable cost to $P$, the electricity price. The variable cost component of electricity price represents the utility's SRVC to generate electricity. The utility does not incur this cost when electricity sales fall below the expected level. The utility's actual revenue losses are net of the SRVC to generate electricity:

$$
\text { Net Lost Revenues }{ }_{N}=\left(\text { Sales }_{N}-\text { Sales }_{T Y}\right) \times(P-S R V C)
$$

These net lost revenues represent unrecovered fixed costs to the utility. Net lost revenues can occur for many reasons. That is, there are many reasons why actual electricity sales may be less than test-year sales. These reasons include milder weather or lower economic activity than found in the test year. PUCs recognize these factors are out of the utility's control. Consequently, PUCs will generally not penalize the utility when these types of factors lead to lower than expected sales, but instead will allow the utility to recover its net lost revenues through a balancing account or some other rate mechanism. 
Net Lost Revenues From DSM. Utility DSM programs can also result in net lost revenues. Net lost revenues are the portion of a utility's net revenues lost due to utility DSM program savings, which have reduced its $\mathrm{kWh}$ sales. We present a general definition of net lost revenues from DSM below and identify differences between historical and future test year rate making in this regard. We first discuss the historical test year case.

$$
\text { Sales }_{\mathrm{hTY}}=\text { Sales }_{\mathrm{hTY}, \mathrm{w} / \mathrm{oDSM}}+\mathrm{DSM}_{\mathrm{hTY}}
$$

For this discussion, test year electricity sales include two components. The first component is electricity sales in the test year without DSM savings from that year. ${ }^{5}$ The second component is the DSM savings $\left(\mathrm{DSM}_{\mathrm{hTY}}\right)$ from new programs initiated in the test year and from new participants to existing programs in that year. ${ }^{6}$ The net lost revenues from DSM in the test year are included in the electricity sales level used to set electricity prices. Thus, the utility does not incur net lost revenues from the DSM program activities in the test year.

In the next year of DSM program activity, however, the utility will experience net lost revenues:

$$
\text { Net Lost Revenues } \mathrm{hTY}+1=\mathrm{DSM}_{\mathrm{hTY}+1} \times(\mathrm{P}-\mathrm{SRVC})
$$

These net lost revenues are linked to DSM savings from program activities in the year after the test year. These program activities include new programs and new participants to existing programs in $\mathrm{TY}+1$.

Net lost revenues will accumulate subsequent to the utility's last rate case. ${ }^{7}$ Note that in TY+2:

$$
\text { Net Lost Revenues }{ }_{\mathrm{hTY}+2}=\text { Net Lost Revenues } \mathrm{hTY}+1+\left(\mathrm{DSM}_{\mathrm{hTY}+2} \times(\mathbf{P}-\mathrm{SRVC})\right)
$$

The future test year case differs from the above in that it has a forecast of future DSM savings included in the test year sales forecast and, as a result, into rates.

$$
\begin{gathered}
\text { Sales }_{\mathrm{fTY}}=\text { Sales }_{\mathrm{fTY}, \mathrm{w} / \mathrm{oDSM}}+\mathrm{DSM}_{\mathrm{fTY}} \\
\text { Net Lost Revenues } \\
\mathrm{fTY}
\end{gathered}
$$

- DSM $_{\mathrm{fTY} \text {, est }}$ is the estimated level of program savings that actually occurred due to program activities in the future test year.

- $\mathrm{DSM}_{\mathrm{fTY}}$ is the forecasted level of program savings used to set the electricity price.

${ }^{5}$ These sales will reflect the savings from DSM actions and measures taken in previous years.

${ }^{6}$ The DSM variables in these expressions represent negative quantities.

${ }^{7}$ This specific expression assumes that the savings from TY +1 persist to $T Y+2$ and that $P$ and SRVC are unchanged. The basic principle that net lost revenues accumulate over time remains valid. 
Because the test year sales forecast (Sales $\left.{ }_{\mathrm{fTY}}\right)$ includes a DSM forecast $\left(\mathrm{DSM}_{\mathrm{fTY}}\right)$ when the actual program savings (DSM $\mathrm{fTY}_{\mathrm{fr}}$, est) equal the forecasted savings, then the utility does not experience net lost revenues beyond that already included in the electricity price. However, if the actual program savings exceed the forecasted savings, then the utility has incurred additional net lost revenues. In this case, the utility will not recover its anticipated level of fixed costs due to the operation of its DSM programs. Of course, if the actual program savings are less than the forecasted savings, the utility has "positive" net lost revenues. These positive net lost revenues represent an overrecovery of fixed costs relative to both the DSM forecast, and to the electricity sales forecast, used to set rates.

Net lost revenues can also accumulate in future-test-year rate making because all DSM activities after the test year are not included when setting rates.

$$
\text { Net Lost Revenues }{ }_{\mathrm{fTY}+1}=\text { Net Lost Revenues } \mathrm{fTY}_{\mathrm{fT}}+\left(\mathrm{DSM}_{\mathrm{fTY}+1} \times(\mathrm{P}-\mathrm{SRVC})\right)
$$

Net lost revenues from the utility's DSM programs result in lower fixed cost recovery and lower utility earnings. ${ }^{8}$ This is the net lost revenue issue that results from utility DSM programs. Utility analysts argue that net lost revenues are an important disincentive to utility DSM investment (Moskovitz 1989; Reid and Chamberlin 1990; Nadel, Reid, and Wolcott 1992).

Erosion of shareholder profits from utility DSM investment also conflicts with an important objective of integrated resource planning: considering on a consistent basis the full range of resources to cost-effectively meet customer needs (Hirst 1988). An important indicator of consistency in utility resource assessments is that the utility and its shareholders should be indifferent to alternative resource investments; that is, the utility will acquire the most costeffective resource to meet customer needs, regardless whether the resource is a power plant or an energy efficiency program. To the extent that utility DSM investment hurts utility earnings between rate cases, utilities and shareholders will not be indifferent to choices between demandside and supply-side resource additions. As a result, many states have taken steps to address the net lost revenue issue. We discuss below the options available to states to address net lost revenues and indicate those options states are currently pursuing. ${ }^{9}$

\footnotetext{
${ }^{8}$ Our discussion of net lost revenues from DSM is a simplification. Specifically, we made two simplifying assumptions. First, we assumed one price for electricity. In practice, $P$ will differ by rate class and possibly by time period or the level of energy use, or both. P may also be set to collect some portion of fixed costs through a demand charge. DSM programs that reduce demand may also affect fixed cost recovery. Second, we assume that the shortrun variable cost, SRVC, is constant (or alternatively, that the average short-run variable cost is suitable to use in estimating net lost revenues). In practice, SRVC will differ over time, depending on what plants and fuels the utility dispatches to follow load. To the extent that utility DSM savings follows the system load shape then the use of a constant average SRVC to estimate net lost revenue will give the same result as using an hourly SRVC.

${ }^{9}$ Before closing discussion on the effects of DSM programs on utilities, however, we note that the role of net lost revenues just described is not shared universally. The Georgia PSC (1994), for example, recently issued an order that concluded that no one in its proceeding on IRP and DSM issues had demonstrated that net lost revenues
} 


\section{APPROACHES TO ADDRESS LOST REVENUES FROM ENERGY-EFFICIENCY PROGRAMS}

Several approaches are available to address the net lost revenue issue. These approaches include conducting frequent rate cases, developing alternative rate structures, decoupling utility profits from utility sales, and using NLRA mechanisms. Hirst (1993) describes these alternative approaches in detail. We summarize only the basic features of these different approaches here.

\section{Frequent Rate Cases}

Because shareholders can be hurt between rate cases by revenue losses from utility investments in demand-side energy efficiency, perhaps the most straightforward correction to the lost revenue issue is to engage in frequent rate cases. The purpose of these proceedings would be to revise the utility's base rates to allow for recovery of any lost revenues due to utility energy-efficiency programs. The rate cases would have to be held frequently, perhaps annually, for this approach to effectively address the net lost revenue disincentive.

Therein lies the problem with this approach. Rate cases can be time consuming, expensive, and litigious for all parties. In principle, we believe it is possible to develop a more stream-lined ratecase approach where net lost revenue from utility DSM is the major focus of the proceeding. In practice, regulators and utilities, as well as other interested parties, may find that such a focused rate case approach is unjustified for NLRA alone and that other regulatory mechanisms, which we discuss below, accomplish much the same objectives but at far lower cost to all involved.

In addition, many PUCs are moving away from the rate case as a forum to address DSM policy issues. Many states have replaced litigation of DSM issues with collaborative groups, or similar interactive efforts, that bring together the relevant stakeholders in an effort to achieve compromise and consensus outside the formal hearing room (Schweitzer et al. 1994; English et al. 1994).

\section{Alternative Rate Structure}

If PUCs set customer rates at each utility's short-run marginal costs, utilities would have no incentive to increase sales and, therefore, no disincentive to reduce sales through energy efficiency. Under short-run marginal cost pricing, shareholder interests are essentially severed from the level of utility sales.

exist. We will also see, as we present the results of our interviews from this study, disagreement about the importance of net lost revenues to utilities. Under certain conditions, such as continuing net sales growth or achieving authorized rates of return, a few interview subjects questioned the importance or relevance of net lost revenues to utilities. We discuss these issues in Chapter 3. 
The use of marginal costs as a basis for utility pricing is the subject of continued debate by economists, a debate aptly summarized by Bonbright, Danielsen, and Kamerschen (1988). One problem with setting electricity prices using short-run marginal costs is that the utility may not collect sufficient revenue to cover all necessary utility costs. Short-run marginal costs, for example, do not include the long-term cost of generating capacity. Utilities would still need to collect revenue to cover all costs deemed prudent by regulators. As a result, utilities would need to increase substantially customer charges to offset the much lower energy and demand charges from short-run marginal cost pricing. Additionally, practical concerns, such as the instability in rates short-run marginal cost pricing might induce, limits regulators' support for this pricing approach.

\section{Decoupling}

Decoupling mechanisms are annual rate-making adjustments that provide for the collection of an agreed-upon level of revenues independent of actual sales (Eto, Stoft, and Belden 1994). In application, decoupling operates as a two-part mechanism. The first part severs the link between utility revenues and utility sales. As a result, shareholder profits are no longer positively tied to utility sales. The second part relinks utility revenues to something other than sales. Utility revenues may be instead linked to the number of customers, fixed costs, or other factors. California has long used a decoupling approach, and more recently, decoupling approaches have been implemented in Florida, Montana, New York, Washington, and Maine, although Maine no longer uses this approach. Several other states are considering the decoupling approach.

Decoupling is an involved departure from traditional rate making and we will not delve into its details here. Eto, Stoft, and Belden (1994) provide a good description of decoupling principles as well as an assessment of different methods. Decoupling addresses the net lost revenue issue because the mechanisms deployed to date are linked to utility fixed costs or the determinants of fixed costs.

Hirst (1993) develops another form of decoupling, which he calls statistical recoupling. The statistical recoupling method is also a two-step decoupling approach. The first step decouples revenues from utility sales and the second step recouples revenues to statistical estimates of electricity use. Hirst demonstrates how straightforward statistical models can be developed that link utility revenues to variables like weather, economic activity, electricity price, and number of utility customers. The statistical recoupling method is under consideration in Utah (R. Collins, Utah PSC, personal communication September 1994), Colorado (T. Woolf, Tellus Institute, personal communication November 1994), and New York (W. Mills, New York PSC, personal communication December 1994).

\section{Net Lost Revenue Adjustment}

NLRA mechanisms compensate the utility for changes in fixed cost recovery resulting from the utility's DSM programs. The basic elements of an NLRA mechanism are straightforward and 
derive from our earlier definition of net lost revenues. ${ }^{10}$ For DSM program activity not already included in base rates, the utility first determines the energy and demand savings for the year in question from its past and present DSM programs. The utility then determines the portion of retail rates for each rate class that represent fixed costs. This portion is typically the difference between the full retail rate and utility short-run costs (the fuel costs and certain operations and maintenance expenses). The product of program savings and the fixed cost portion of rates yields the utility's net lost revenues from energy and demand. These are the revenues the utility must recover if shareholders are to remain unharmed from utility DSM investments.

A recent nationwide survey of utility DSM rate reforms identified 16 locations with some type of provision for NLRA (Reid, Brown, and Deem 1993). Our more recent survey identified six additional states where NLRA mechanisms are being considered. This list will almost certainly be dated by the time this report is published because NLRA appears to be the method states prefer to address the net lost revenue issue.

Potential Difficulties with NLRA. Because NLRA is the focus of our report, we expand our discussion by summarizing potential difficulties with NLRA and conditions where the mechanism may be more effective. Investigators suggest that NLRA mechanisms may pose certain implementation difficulties or may be open to specific gaming strategies by utilities. Perhaps the key implementation issue is DSM measurement. Verifying or demonstrating that utility programs result in energy and demand savings is critical to the NLRA approach. Where program evaluations are the basis for lost revenue calculations, the NLRA approach places a substantial focus on evaluation results (Cummings 1992). Since 1990 numerous conferences devoted to DSM or DSM program evaluation have discussed the capability of the evaluation discipline as practiced to provide program impacts estimates that will satisfy the scrutiny of the regulatory arena. Of course, NLRA is not the only application of evaluation results. Other aspects of DSM cost recovery, including program costs and incentives, as well as the resource planning process itself rely on evaluations to inform regulators about DSM performance and progress toward planning objectives (Baxter and Schultz 1994). Adding net lost revenue recovery to this list of evaluation applications increases the stakes for evaluation outcomes.

NLRA mechanisms may also raise difficult administrative issues. ${ }^{11}$ Consider a utility with the potential to engage in wholesale sales. Should the lost revenues from DSM programs be at least partially offset if the utility uses its unused energy or capacity to increase wholesale sales? Alternatively, should lost revenues from demand-reducing programs be offset by revenue gains from demand-building programs? How can regulators estimate the effects of demand-building efforts on net lost revenues from DSM?

\footnotetext{
${ }^{10}$ In Chapter 3 we discuss how these different elements of an NLRA mechanism are estimated.

${ }^{11}$ We consider directly many of these administrative issues in Chapters 3 and 4.
} 
These examples of possible administrative issues also suggest that NLRA may provide opportunities for utility gaming strategies. Moskovitz, Harrington, and Austin (1992) note that NLRA may encourage utilities to operate DSM programs that appear effective on paper, but do not result in meaningful energy savings. Utilities may also have increased incentive to inflate program evaluation results with an NLRA because the greater savings estimates lead directly to increased revenue recovery.

Others have described the incentive utilities have to increase sales between rate cases (Hirst and Blank 1993; Eto, Stoft, and Belden 1994). As discussed earlier, utilities can increase net income between rate cases by increasing sales above the test-year level assumed to set base rates. The greater net income leads to higher return on equity. NLRA mechanisms have been criticized because they do not address this incentive to increase electricity sales between rate cases (Moskovitz 1992). Instead, NLRA mechanisms focus more narrowly on the financial disincentive utility DSM poses for recovery of fixed costs.

Possible Solutions to These Difficulties. Hirst (1993) suggests many of these problems can be overcome. Citing his personal communication with regulators and utilities in Connecticut and Maryland, Hirst believes that the presence of an active collaborative process facilitates the resolution of difficult DSM measurement issues. In addition, Hirst notes that utilities participating in collaboratives may have a more substantial commitment to program evaluation. With respect to NLRA, Hirst (1993, p. 11) concludes that “. . NLRAs are probably best suited for utilities that have in place an effective IRP process, are committed to acquiring cost-effective DSM resources as part of their IRP, are part of a well-functioning and ongoing DSM collaborative, and are committed to conducting competent evaluations of their DSM programs."

\section{STUDY OBJECTIVES}

We embarked on this study to assess whether the potential difficulties with an NLRA approach are being encountered by states implementing NLRA mechanisms and to determine if the possible solutions to these difficulties are effective. More specifically, the primary objective of our project is to determine if an NLRA is a feasible way to remove the lost-revenue disincentive to utility operation of DSM programs. If our research shows that the NLRA approach is feasible, we have two additional objectives. First, we want to identify the conditions that lead to successful implementation of NLRA mechanisms in different states. Second, we hope to suggest improvements to NLRA mechanisms as currently practiced.

\section{Defining a Successful NLRA Mechanism}

We define two different dimensions of success with respect to NLRA. The first dimension is the effectiveness of NLRA implementation. We consider a wide range of activities under NLRA implementation including the processes established to: (1) design and develop the initial mechanism, (2) file for lost revenue recovery, (3) review utility filings, and (4) actually recover 
lost revenues. We pursued answers to the following types of questions to gather information about implementation effectiveness:

- Is the definition of net lost revenues established and well understood?

- What conditions must the utility satisfy to file for or to collect net lost revenues?

- Is the filing process straightforward or burdensome for the utility?

- Is the review process straightforward or burdensome for PUCs and their staff?

- Do utility filings lead to substantive litigation of net lost revenue claims?

- Do utilities receive prompt decisions in response to their filings?

Our key indicator of an effective NLRA implementation is to observe if utilities are making NLRA filings, recovering net lost revenues, and doing so without regulatory or utility staff advocating substantive changes to the process.

The second dimension of a successful NLRA is its contributions to the achievement of policy goals. An NLRA mechanism is intended to remove financial impediments to the utility pursuit of energy efficiency. A policy objective of NLRA is to encourage utilities to evaluate on an equal basis the available cost-effective demand-side and supply-side options to satisfy resource needs or to meet other strategic objectives.

To the extent that utilities have underinvested in DSM due to the lost revenue disincentive, we expect to observe an increase in utility DSM investment with NLRA mechanisms. Our key indicator of NLRA's contributions to achieving its policy objective is to observe if utility DSM activity is associated with lost revenue recovery.

\section{STUDY METHODS}

Recognition of the disincentive of net lost revenue to DSM investment is recent. The development and application of specific mechanisms to allow utility recovery of net lost revenue date back only to 1990 or so. Because of the recent history of the net lost revenue issue, we found little material in the formal literature addressing either the feasibility or effectiveness of the NLRA approach. To aid our initial identification of issues, in addition to the literature we referenced in this chapter, we conducted a scoping exercise with regulatory staff, utility staff, and utility researchers. Our literature review and scoping exercise provided the foundation for the more structured interviews we conducted later in the project.

We set out to identify states with some type of policy on net lost revenue recovery. Our primary source in this task was the Reid, Brown, and Deem (1993) report, which contains basic information on the regulatory treatment of DSM as of September 1993. DSM policy-making at the state level is dynamic, however, and we relied on the utility industry trade press and colleagues (especially R. Morgan, U.S. Environmental Protection Agency, personal communications April and July, 1994) to keep us informed on changes in state policies. 
We contacted staff at the appropriate regulatory agency in each state and the District of Columbia to determine the status of NLRA mechanisms. We were particularly interested in identifying states with active policies; that is, states where utilities have filed for and recovered or received approval for recovery of net lost revenues from utility DSM programs. The states with active NLRA policies form the population for this study. We believe our information on these states is current as of October 1994.

We then conducted detailed interviews of regulatory staff in those states with active NLRA policies. We designed the interview with the assistance of Oak Ridge National Laboratory (ORNL) researchers who have extensive experience designing and conducting telephone interviews. We pretested the interview on two states with different NLRA policies. Our detailed interviews covered four major topics: history and current status of NLRA in their state; NLRA implementation issues; DSM measurement issues; and results from NLRA filings and proceedings. We also collected and reviewed regulatory agency orders and decisions on NLRA, as well as testimony, reports, and utility NLRA filings.

Based on our interviews and review of state-specific documents, we broke the ten states with active NLRA mechanisms into two groups: seven states not reporting any substantive problems and three states reporting some level of dissatisfaction with their NLRA mechanisms. We selected two states from each group for further study and followed up with detailed interviews of seven utilities in these four states. We used the same basic interview structure developed initially for state regulatory agencies, but modified it as necessary to explore issues with utility staff raised in our regulatory staff interviews. We also collected additional material from these utilities, primarily specific utility net lost revenue recovery filings and examples of how they estimated or tracked net lost revenue.

Finally, we looked for quantitative indicators of the possible effects of NLRA mechanisms on utility DSM investments. We collected data on net lost revenue recovery and DSM program expenditures from almost all utilities in the country recovering net lost revenue from DSM programs. Further, we used data on utility DSM activity in 1992 and 1993 collected by the U.S. Energy Information Administration through Schedule V of Form EIA-861 to examine differences in DSM investment (Schweitzer and Young 1994; Hadley and Hirst 1995). Finally, we used an extension of the ORNL Financial Model (Hirst and Hadley 1994) to study the impact of different NLRA mechanisms on utility finances. 



\section{OVERVIEW OF NLRA MECHANISMS}

This chapter presents an overview of net lost revenue recovery in different states as of October 1994. We first briefly discuss the states having some provision for an NLRA mechanism. The chapter concentrates on the ten states where utilities are actively recovering net lost revenue through an NLRA mechanism. We discuss the methods regulators and utilities use to estimate net lost revenues, the importance of DSM measurement issues for the operation of NLRA mechanisms, the conditions regulators place on net lost revenue recovery, and describe the different types of NLRA mechanisms now in use. Chapter 3 summarizes the more detailed presentation of state-specific NLRA mechanisms contained in Appendix A. ${ }^{12}$

\section{STATES ADDRESSING NET LOST REVENUE RECOVERY}

Since NARUC highlighted the issue of financial disincentives for DSM in 1988, many states responded by developing policies to address net lost revenue recovery. Morgan (n.d.) provides a summary of the different approaches states are using to address net lost revenue from utility DSM programs. According to Morgan, 31 locations (30 states and the District of Columbia) have some type of rate-making mechanism, either adopted or proposed, to address net lost revenue from DSM. While Morgan reports that states have adopted or proposed several types of mechanisms, including decoupling and annual rate cases, NLRA mechanisms are the most prevalent type.

We identified 22 locations (21 states and the District of Columbia) having some policy or provision for an NLRA mechanism. Figure 1 identifies these locations and divides them into two groups. The first group includes ten states where utilities had recovered net lost revenue by October 1994 and where state policy on NLRA mechanisms is clear. We refer to the mechanisms in these ten states as active NLRA mechanisms. Though a cursory survey of the 22 locations may suggest that NLRA mechanisms are widespread and that DSM regulatory reforms are proceeding apace, our more detailed survey finds that only these ten states have active NLRA mechanisms. These ten states (Arizona, Connecticut, Indiana, Maryland, Massachusetts, Minnesota, New Hampshire, New York, Oregon, and Vermont) have a well-defined mechanism, or mechanisms, where utilities are recovering net lost revenue. Much of this chapter focuses on the experiences these states report with their NLRA mechanisms.

\footnotetext{
${ }^{12}$ For the ten states where utilities are actively recovering net lost revenue through an NLRA mechanism, Appendix A presents a detailed overview of the state-specific NLRA mechanisms, including discussion of the status of NLRA, implementation issues, and NLRA results. Appendix A presents the information we gathered from interviews with regulatory and utility staff and reviews of state-specific NLRA documents.
} 


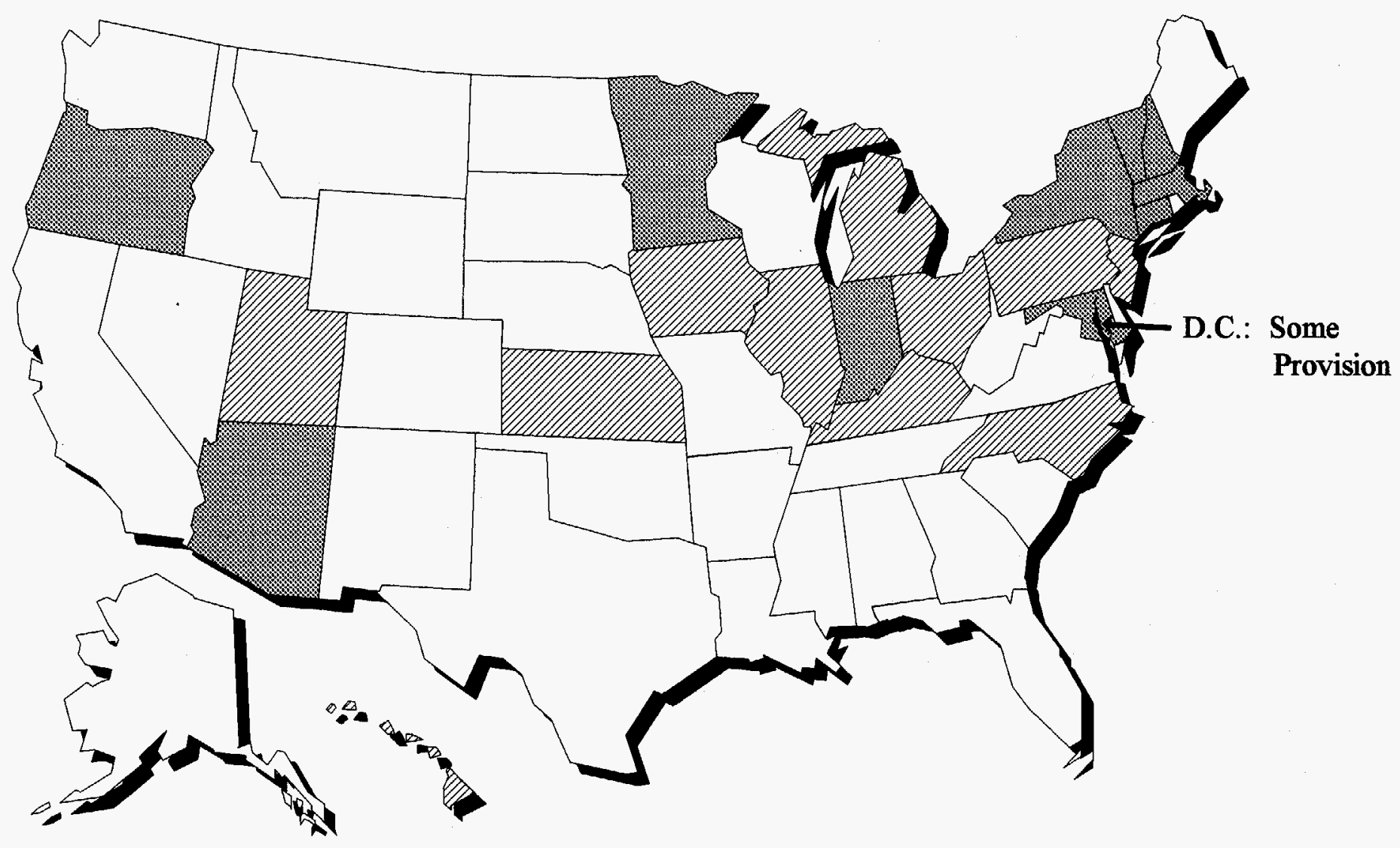

Active NLRA Mechanisms

(most NY utilities use decoupling;

CHG\&E uses NLRA)
Some Provision for NLRA: Mechanisms in

Progress, Restricted Mechanisms, or

Case-By-Case Consideration (Includes D.C.) 
The second group in Figure 1 identifies states with some provision or policy for net lost revenue recovery but, with one exception, where utilities have not yet recovered any lost revenues from DSM programs. This second group includes four states (Kentucky, New Jersey, Ohio, and Utah) with well-defined mechanisms, but utilities had not yet recovered net lost revenue by the time we completed data collection for this project in October 1994. Two states in the second group (Iowa and Michigan) have a well-defined mechanism, but with conditions that make utility net lost revenue recovery unlikely. The most important of these conditions, a sales test, is discussed in detail in this chapter. Five other locations (District of Columbia, Hawaii, Kansas, North Carolina, and Pennsylvania) have either proposed a mechanism, consider utility net lost revenue filings on a case-by-case basis, or indicate a willingness to entertain proposals for an NLRA mechanism. Finally, Illinois is the exception in the second group mentioned above. Illinois has a well-defined mechanism and Commonwealth Edison recovered lost revenues for the 1991-93 period. In 1993, however, the Illinois courts reversed the Illinois Commerce Commission's order authorizing Commonwealth Edison to recover DSM costs. Among other reasons, the Illinois courts held that the Illinois Commerce Commission engaged in single-issue and retroactive rate making. As of October 1994, neither the Illinois Commerce Commission nor the utilities had taken any action with regard to net lost revenue recovery since that ruling.

\section{STATES WITH ACTIVE NLRA MECHANISMS}

The ten states use three basic types of NLRA mechanisms: a retrospective surcharge, a prospective surcharge, and a deferred account. The surcharge mechanisms are reflected as rate changes on customer bills. The retrospective surcharge recovers revenues lost from DSM activity in a previous year or years. In contrast, the prospective surcharge recovers revenues lost as a result of the current DSM-program-year activities. The deferred account tracks and records monthly net lost revenue estimates and the utility receives authorization to recover these estimated net lost revenues at its next rate case.

Table 2 summarizes key features of the NLRA mechanisms for the ten states with active mechanisms. Five states use prospective surcharges, two states use retrospective surcharges, two states use different mechanisms for different utilities, and one state uses a deferred account.

Table 2 also identifies those elements of DSM program performance that are subject to reconciliation with DSM measurement and evaluation studies. Estimates of DSM program performance are the analytical foundation of NLRA mechanisms. Lost revenue recovery filings are based on projections or estimates of $\mathrm{kWh}$ and $\mathrm{kW}$ savings from utility programs. Most state PUCs require utilities to ultimately verify their DSM program performance estimates with DSM measurement and evaluation studies. As shown in Table 2, all states except New Hampshire require states to reconcile net lost revenue estimates. All states except Indiana and New Hampshire require utilities to verify the DSM savings estimates that support net lost revenue recovery claims by conducting DSM measurement studies. These states use DSM measurement studies in two ways to reconcile estimated or projected net lost revenue: reconciliation of 
Table 2. Overview for Ten States with Active NLRA Mechanisms

\begin{tabular}{|c|c|c|c|c|}
\hline State & $\begin{array}{c}\text { Type of } \\
\text { Mechanism }\end{array}$ & $\begin{array}{c}\text { Filing } \\
\text { Frequency }\end{array}$ & $\begin{array}{l}\text { Type of NLR } \\
\text { Reconciliation }\end{array}$ & Conditions \\
\hline Arizona & $\begin{array}{l}\text { prospective } \\
\text { (APS) } \\
\text { deferred } \\
\text { (TEP) }\end{array}$ & $\begin{array}{l}\text { annual } \\
\text { each rate case }\end{array}$ & $\begin{array}{c}\text { program } \\
\text { participation }\end{array}$ & $\begin{array}{l}\text { PUC-approved } \\
\text { programs } \\
\text { verify savings }\end{array}$ \\
\hline Connecticut & prospective & annual & $\begin{array}{c}\text { program } \\
\text { participation }\end{array}$ & $\begin{array}{c}\text { PUC-approved } \\
\text { programs } \\
\text { verify savings }\end{array}$ \\
\hline Indiana & $\begin{array}{l}\text { prospective } \\
\text { (SIGECO) } \\
\text { deferred } \\
\text { (PSI, IP\&L) }\end{array}$ & $\begin{array}{c}\text { quarterly } \\
\\
\text { each rate case } \\
\text { (net lost } \\
\text { revenue } \\
\text { estimated } \\
\text { monthly) }\end{array}$ & $\begin{array}{l}\text { program } \\
\text { participation } \\
(\mathrm{SIGECO})\end{array}$ & $\begin{array}{c}\text { PUC-approved } \\
\text { programs } \\
\text { utility must } \\
\text { estimate NLR } \\
\text { interruptible rate } \\
\text { programs } \\
\text { ineligible } \\
\text { (SIGECO) }\end{array}$ \\
\hline Maryland & prospective & annual & $\begin{array}{c}\text { program } \\
\text { participation }\end{array}$ & $\begin{array}{c}\text { PUC-approved } \\
\text { programs } \\
\text { verify savings } \\
\text { pass earnings test }\end{array}$ \\
\hline Massachusetts & prospective & annual & total savings & $\begin{array}{l}\text { PUC-approved } \\
\text { programs } \\
\text { verify savings by } \\
\text { impact } \\
\text { evaluations }\end{array}$ \\
\hline
\end{tabular}




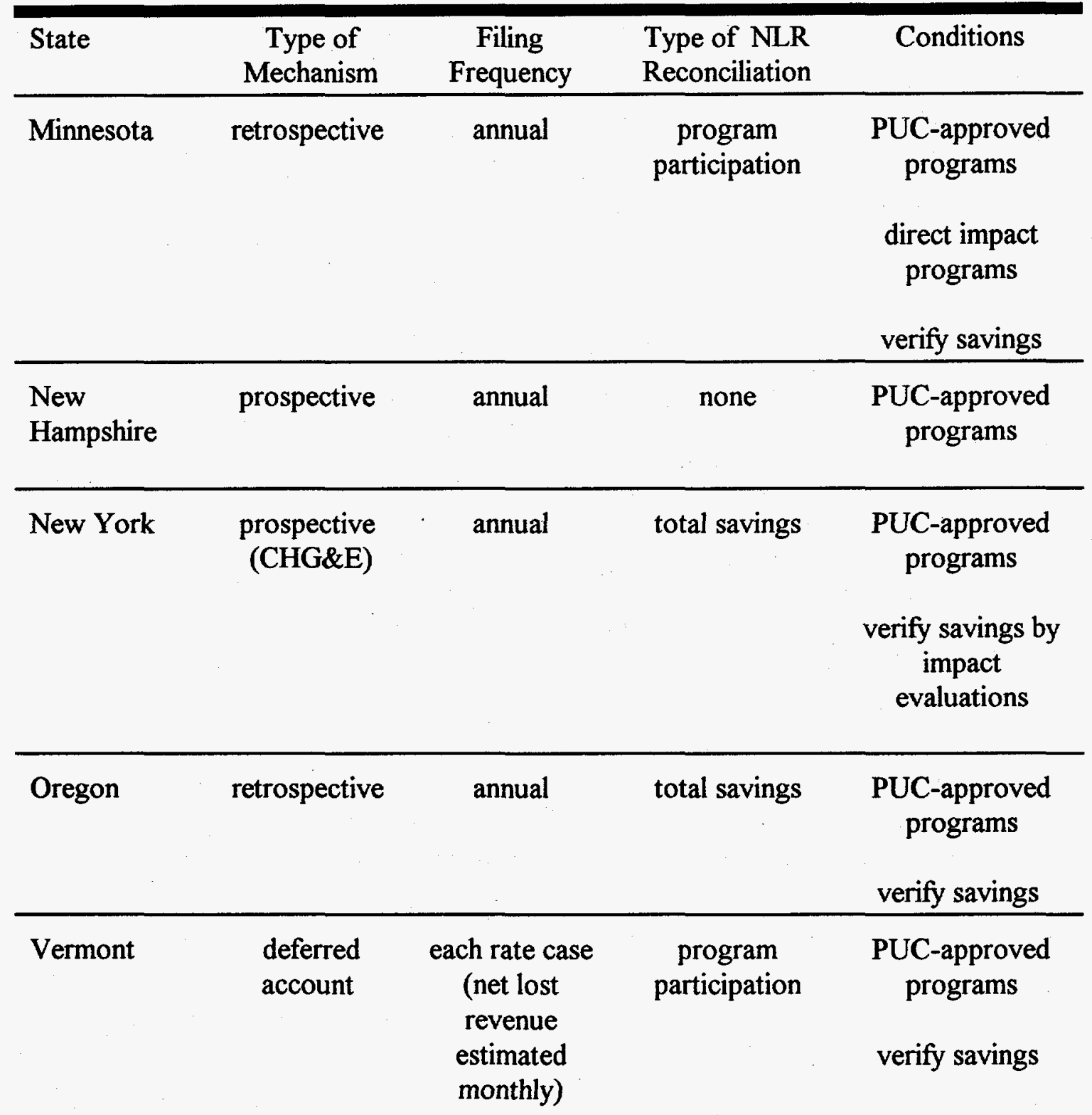

1. Verifying savings in this and other states requires utilities to demonstrate that DSM programs reduced energy or demand, or both. The rigor and comprehensiveness of this demonstration differ by state, but is related directly to the reconciliation process required by most states.

estimated to observed program participation levels and reconciliation of estimated total program savings to total program savings derived from evaluation studies (which includes counting the number of program participants and estimating the savings per participant or per measure).

Finally, all states require utilities to acquire PUC approval of DSM program plans before utilities may collect net lost revenue from those programs. As mentioned above, eight states require that utilities demonstrate or verify that they lost revenues from DSM. A few states set additional 
conditions or add qualifiers to these two conditions. For example, Massachusetts and New York specify that utilities verify DSM savings with impact evaluations. Indiana specifies for one utility that interruptible rate programs are not eligible for net lost revenue recovery. Minnesota allows lost revenue recovery only from direct impact programs, such as rebate or direct installation programs.

\section{Net Lost Revenues Recovered}

By the end of 1993, utilities in the ten states with active mechanisms had accumulated 56 years experience with NLRA and recovered about $\$ 171$ million in net lost revenues. Figure 2 shows that 31 utilities have recovered net lost revenues for at least one year, 16 utilities have recovered for at least two years, and eight utilities have recovered for at least three years. One utility, Central Hudson Gas and Electric, has recovered net lost revenues over four years.

Figure 2 also displays a common feature of NLRA mechanisms discussed in Chapter 2: the tendency of net lost revenues to grow over time. In the first year, net lost revenues average about $0.17 \%$ of utility operating revenues. By the third year, net lost revenues increase to $0.60 \%$ of operating revenues. In its fourth year of recovery, Central Hudson Gas and Electric's net lost revenues were $1.02 \%$ of operating revenues. The tendency for net lost revenues to accumulate between rate cases is a concern for regulators and utilities. In the short-term, net lost revenue recovery leads to higher rates, which many regulators and utilities are eager to avoid. In Chapter 5 , we examine in more detail the effects of different NLRA mechanisms on utility finances.

Figure 2. Net Lost Revenues Accumulate Between Rate Cases

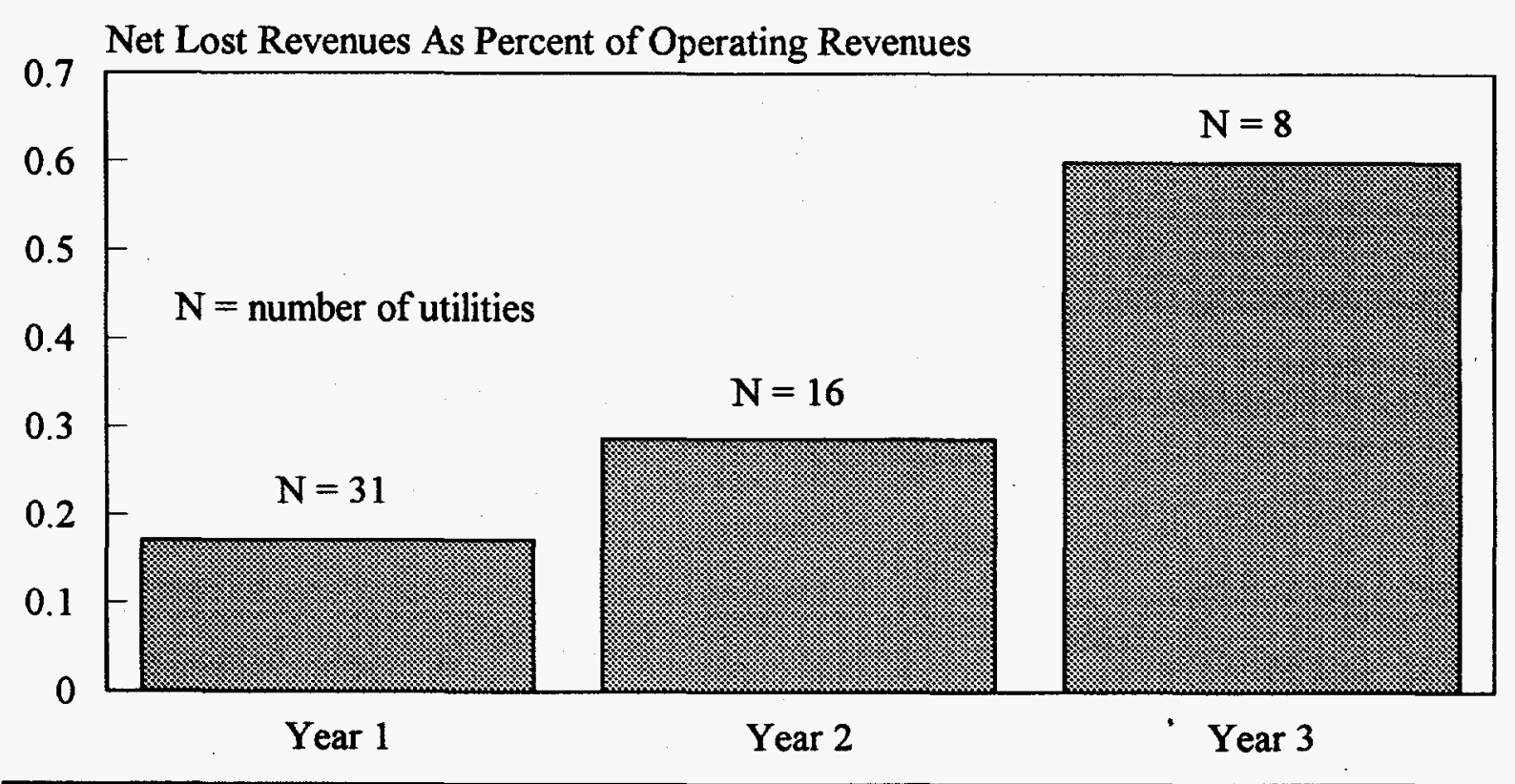




\section{ESTIMATING NET LOST REVENUES}

While the specific methods states use to estimate net lost revenues from DSM programs differ, we present a general formula below that embodies many common features of the mechanisms we reviewed. We discuss how regulators and utilities estimate the different elements of this formula and identify the important data sources used.

\section{General Formula for Estimating Net Lost Revenues}

PUCs in most states with active NLRA mechanisms have published a verbal description of how to estimate net lost revenues. PUCs in Connecticut, Indiana, and Oregon have published formulas with defined terms. The specifics of the net lost revenue estimation differ between states and, in some cases, between utilities within states. The general formula we present below is representative of how utilities in many states estimate net lost revenues and builds on the general presentation in Chapter 2:

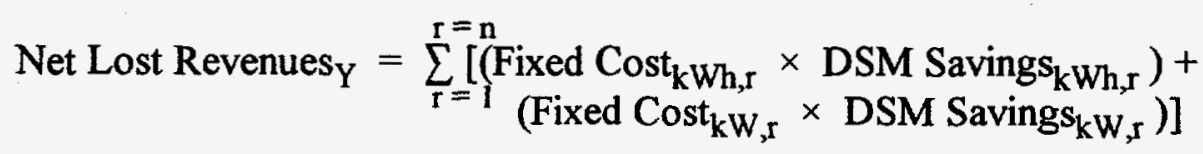

- Net lost revenues are the sum over rate classes $r=1$ to $n$ to calculate net lost revenues for the single program year $\mathrm{Y}$.

$$
\begin{aligned}
& \text { Fixed Cost }_{\mathrm{kWh}, \mathrm{r}}=\text { Retail Energy Rate }_{\mathrm{kWh}, \mathrm{r}}-\text { Short-Run Variable Cost }_{\mathrm{kWh}, \mathrm{r}} \\
& \text { Fixed Cost }_{\mathrm{kW}, \mathrm{r}}=\text { Retail Demand Charge } \mathrm{kW}_{\mathrm{k}, \mathrm{r}}-\text { Short-Run Variable Cost } \\
& \mathrm{kW,r}
\end{aligned}
$$

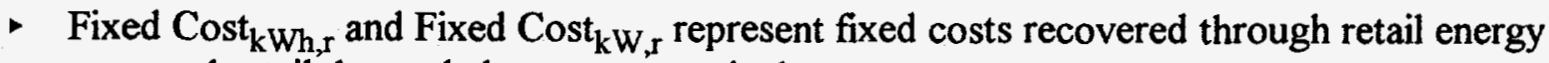
rates and retail demand charges, respectively.

$$
\begin{aligned}
& \text { DSM Savings }_{\mathrm{kWh}, \mathrm{r}}=\sum_{\mathrm{m}=1}^{\mathrm{m}=\mathrm{n}}\left(\text { Unit Energy Savings } \mathrm{s}_{\mathrm{m}, \mathrm{r}} \times \text { Participants }_{\mathrm{m}, \mathrm{r}}\right) \\
& \text { DSM Savings }_{\mathrm{kW}, \mathrm{r}}=\sum_{\mathrm{m}=1}^{\mathrm{m}=\mathrm{n}}\left(\text { Unit Demand Savings }_{\mathrm{m}, \mathrm{r}} \times \text { Participants }_{\mathrm{m}, \mathrm{r}}\right)
\end{aligned}
$$

- To calculate savings in each rate class, the last two expressions are summed over measures $m=1$ to $n$.

This net lost revenue estimation is typical for utility base rates established using an historical test year. For base rates set using a future test year, the major difference in estimating net lost revenue is that the test year DSM forecast, which is included in base rates, must be subtracted from actual DSM program performance estimates. The above example assumes that net lost 
revenues are estimated annually by rate class and that fixed costs are recovered through both energy rates and demand charges.

These simple formulas highlight the three basic steps used to estimate net lost revenues from utility DSM programs:

- First, the utility estimates savings from a single year's program activities. A standard approach is to estimate the energy and demand savings for each measure (the unit savings) and then multiply these per unit savings estimates by the number of participants (or measures) in that program year.

- Second, the utility estimates the fixed cost component of retail rates. The utility typically subtracts the short-run variable cost for each rate class from the retail energy rates and demand charges assigned to each rate class.

- Third, for each rate class, the utility multiplies the fixed cost rate for energy by the total energy savings. The utility also multiplies the fixed cost for demand by the total demand savings. The sum of these two products is the total net lost revenues from DSM program activities in that rate class. The sum over all rate classes is an estimate of the utility's total net lost revenues from program activities in that year.

Net lost revenues from DSM activities in previous program years, but incurred in the current program year (year $\mathrm{Y}$ ) are estimated using essentially the same procedure. The calculation of DSM savings may include a few additional features, which we discuss below.

Depending on the specifics of a utility's NLRA mechanism, net lost revenue estimates may be made monthly, quarterly, annually, or for the period between rate cases. Over this estimation period, the above values are typically held constant (that is, the unit savings, number of measures installed, retail rates and demand charges, and the variable costs recovered through energy and demand).

Our discussions with regulators and utilities did not identify cases in which net lost revenue estimates reflect changes in retail rates that occur within the estimation period. For example, we did not identify cases in which time-of-use rates, which can differ hourly, were used to estimate net lost revenues. The important exception is for utilities that recover some portion of fixed costs through demand charges, which may differ over the estimation period. For these utilities, the mechanisms may account for seasonal differences in demand charges. Neither did we encounter mechanisms that account for changes in short-run variable costs within the estimation period. Instead, we find utilities use average values for the estimation period or values for retail rates and variable costs as set in their last rate case.

The above formulation is typical for PUCs that want to allocate net lost revenue costs back to rate classes on the basis of each class' participation in utility DSM programs, as is the case in 
Maryland, Massachusetts, New Hampshire, and New York. A somewhat simpler formulation eliminates this rate-class-specific detail and instead estimates net lost revenues based on system average values for retail rates and variable costs. Net lost revenue recovery is then implemented using a single rate adjustment applied to all $\mathrm{kWh}$ sales, which is the procedure in Arizona, Connecticut, Minnesota, Oregon, and Vermont,

\section{Basis for Net Lost Revenue Estimates}

In the basic formulation we presented above, net lost revenue estimation requires two major pieces of data: the fixed cost portion of rates and DSM savings from utility programs. To estimate the fixed cost portion of rates, the appropriate retail energy rate and demand charge must be identified. ${ }^{13}$ For utilities with block rates, this is usually taken as the final tail block for each rate class. Individual rate adjustments or surcharges, such as a fuel adjustment clause, are subtracted from the final tail block rate. Utilities estimating a single retail rate for all customers typically use a weighted average of each rate class tail block in which the weights are estimated sales by rate class. Demand charges differ by season and these differences are reflected in the estimate if demand charges are used to recover some portion of fixed costs. The primary data sources for utility retail rates are the rate schedules adopted by PUCs at each utility's rate case.

The short-run variable cost is also typically unambiguous to calculate. For energy, the short-run variable cost is often simply assumed to be the base fuel cost, as set in the previous rate case. The utility may, however, include other costs. The most common categories for these other costs include: certain operations and maintenance costs, customer charges if these costs are treated as variable costs, and state taxes on gross revenue. For demand, short-run variable cost is defined by the accounting convention the PUC adopts in rate design. That is, the short-run variable cost portion of the demand charge is whatever fraction is intended to recover variable cost. This will typically be a relatively small fraction of any total demand charge.

A few states use the utility's short-run avoided costs as a proxy for its short-run variable costs. In principle, avoided costs equal the costs the utility avoids by not generating the next increment of power. States and utilities may have complex methods to calculate avoided costs. In simple terms, these methods multiply the utility's incremental energy rate by its electric generation fuel rate and, thus, closely resemble the earlier example of short-run variable cost estimation. Utilities often calculate avoided costs to determine payments to qualifying facilities. In these cases, the avoided costs for net lost revenue estimation are taken directly from these proceedings or from methods approved in these proceedings.

\footnotetext{
${ }^{13}$ Utility rate design is a complex topic. Phillips (1993) provides a helpful summary of electric utility rate structures. The specific rate structures differed for the utilities in the ten states we studied in detail. Many, if not most, of these utilities have rates based on some type of marginal-cost or incremental-cost concept. Thus, the general energy rate structure is either an inverted-block rate (if per-unit costs increase as sales increase) or a declining block rate (if per-unit costs decrease as sales increase).
} 
Estimating DSM savings raises more complicated measurement issues. Because of the importance of DSM measurement issues to NLRA, we discuss these issues in detail below.

\section{DSM MEASUREMENT ISSUES}

Estimating DSM savings is the analytic foundation for NLRA mechanisms. In almost all states with active mechanisms, utilities undertake considerable efforts to estimate both unit savings and participation levels. We discuss the methods to estimate the energy and demand savings used to support net lost revenue filings, placing particular emphasis on the role reconciliation plays in net lost revenue recovery.

\section{Estimating Energy and Demand Savings}

Our earlier equations illustrate that $\mathrm{kWh}$ and $\mathrm{kW}$ savings are products of unit savings and the number of measures installed. The sum of unit savings over all measures for all programs is the gross program savings for that program year.

Utilities often use engineering methods to estimate unit savings. These engineering methods combine algorithms and assumptions. The algorithms are based on thermodynamic principles, engineering standards, and laboratory tests. A building simulation model is an example of a complex engineering algorithm. The assumptions used in the engineering algorithms are based on self-reported customer surveys, on-site inspections, metering, and professional judgement. Among the most important assumptions are characterizations of baseline and measure energy use characteristics, such as operating hours, connected load, technology type and size.

The number of measures installed is based on forecasts of program participation levels. These forecasts can be derived from economic analyses and models of customer choice and behavior, DSM program potential studies, analysis of previous program experience, and professional judgement.

Most states require specific adjustments to these DSM estimates or forecasts. For example, net lost revenue recovery is based on net rather than gross measure or program savings. ${ }^{14}$ The most important adjustments to first-year program savings are for snap-back or rebound effects and free riders. ${ }^{15}$ Any adjustments for rebound effects are made to unit savings estimates. Adjustments

\footnotetext{
${ }^{14}$ Gross savings are the total change in electricity use experienced by program participants. Net savings are the portion of gross savings that can be directly attributed to the program.

${ }^{15}$ Rebound effects are changes in customer behavior resulting in greater energy use as a result of participation in a DSM program. Free riders are customers who would have adopted program-recommended actions even without the program, but who participate directly in the program.
} 
for free riders are made to participation levels. We did not identify any active NLRA mechanisms that include adjustment for free drivers. ${ }^{16}$

For net lost revenue recovery that extends beyond current program-year activities (for example, recovery of net lost revenues in 1993 due to 1992 program-year activities) two additional adjustments are frequently required. These adjustments are for useful life and measure retention. ${ }^{17}$ Both these adjustments, when required, are made to unit savings estimates. Thus, DSM program performance estimates used to calculate net lost revenue are based on net program savings and attempt to reflect certain changes in participant behavior as well as changes in equipment performance over time

As evident from Table 2, most states require utilities to verify that they incurred net revenue losses from DSM. States take a range of approaches to verification. In most states, verification relies on DSM measurement studies. The type of measurement study PUCs require most frequently for verification are DSM impact evaluations. Many states will approve net lost revenue estimates or allow utilities to collect net lost revenue based on a DSM forecast, subject to a subsequent true-up or reconciliation. A few states do not allow any recovery of net lost revenue until impact evaluations are completed and evaluation results are reviewed and approved.

\section{Reconciling DSM Savings}

Reconciliation is an effort to bring DSM savings estimates or forecasts into accord with DSM evaluation results. Reconciliation typically takes two forms. In the first form, most states retrospectively reconcile program participation levels. That is, the utility compares forecasted program participation to observed program participation. In the second form, used in three states, utilities retrospectively reconcile total program savings. That is, they reconcile to both unit savings estimates and participation levels using after-the-fact (ex post) estimates of program performance. In both cases, the objective of reconciliation is to adjust for any overrecovery (based on overly optimistic projections of program participation or unit savings) or underrecovery (based on pessimistic projections) of net lost revenue. The extent of reconciliation required by states turns out to be important to the implementation of NLRA mechanisms.

Theoretical and practical reasons exist for reconciliation to ex post estimates of total program savings. Moskovitz $(1989,1992)$ and others argue that unless net lost revenue recovery is based on measured program performance, NLRA mechanisms offer utilities perverse incentives. The utility, for example, may attempt to manipulate net lost revenue recovery by designing programs that look good on paper but do not perform well in the field. The unrealized savings included in

\footnotetext{
${ }^{16}$ Free drivers do not participate in a program but are influenced by the program and adopt program recommendations.

${ }^{17}$ Useful life is the length of time measures installed during the program year are maintained in operating condition or begin to exhibit substantial reductions in effectiveness. Measure retention is the length of time until an installed measure is removed or replaced.
} 
such estimates reward the utility twice: first with the assumed lost revenues and second with revenues from the sales not successfully saved. Analysts further argue that utilities may not promote the most efficient technologies and operate the most efficient programs. Moskovitz (1992) offers an example of an electric water heater measure to illustrate this point. He supposes that an agreement is reached by regulators and utilities that this measure results in $600 \mathrm{kWh}$ of annual savings. He then asks what happens when the utility actually achieves $700 \mathrm{kWh}$ of savings through better quality control or when the utility achieves $500 \mathrm{kwh}$ of savings due to poorer quality control. In the first instance, the utility's extra efforts go unrewarded while in the second the utility earns a lost revenue bounty for poor performance. Moskovitz asserts that the utility's profit-maximizing strategy is to select measures that test well using the measurement criteria imposed but perform poorly in practice. Under total program savings reconciliation, regulators and ratepayers can be assured that utilities are recovering net lost revenues based on the best estimates of actual program performance.

Despite the theoretical and practical arguments supporting reconciliation to ex post estimates of total program savings, we identified several problems with this approach:

- Impact evaluations seek to measure events that cannot be measured directly. Impact evaluations estimate changes in energy use and demand as a result of a DSM program by comparing energy use after program implementation to a reference or baseline. This baseline represents what program participants' energy use would have been in the absence of the program. This baseline can never be known but must be inferred. This fundamental limitation to impact evaluations has two further ramifications. First, total program reconciliation can create a considerable lag between the incurrence of net lost revenues and final recovery. The reason for this is simple: impact evaluations are expensive and lengthy. As a result, evaluation results may not be available until two or more years after the program year of interest. Second, because of the time and resources involved, conducting impact evaluations for all programs is impractical.

- An evaluation nevertheless results in an estimate of program impacts. This estimate can be compromised by sample selection biases, free ridership estimation difficulties, and other evaluation problems (Violette, Stern, and Ozog 1991).

- While ratepayers may be exposed to DSM performance-related risks, these risks are at least in part balanced by the benefits ratepayers receive (access to energy-efficiency services) and risks that work in the opposite direction (the risk of loss of benefits if net lost revenue recovery is reduced or eliminated).

- Finally, total program reconciliation increases administrative and technical burdens on regulatory and utility staff. Administrative burdens increase because program savings estimates must be tracked and reconciled over a period of years. Technical burdens increase because impact evaluations often rely on sophisticated sampling and statistical estimation techniques. The number of utility staff capable of designing and conducting 
evaluations declines, as does the number of regulatory staff capable of professionally reviewing the results, as the sophistication of the studies increases.

All the states relying on retrospective reconciliation to program participation levels but Indiana also require utilities to conduct impact evaluations or other DSM measurement studies. These states require utilities to use results of these studies prospectively in upcoming estimates or forecasts of net lost revenue. For example, an impact evaluation may suggest that a unit savings value used to estimate net lost revenues differs from an evaluation result. If the difference is significant, then the utility must use the evaluation result in its next net lost revenues estimate or forecast. Similarly, if a DSM measurement study indicates that assumptions used in an engineering analysis of measure savings are incorrect (for example, the hours of operation, connected load, or other assumptions are not representative of program participants), then the utility must use the verified assumption from the measurement study. Minnesota utilities conduct impact evaluations for their largest DSM programs and use less time and resource intensive methods to reconcile savings estimates for smaller programs

Many states argue that the above approach to evaluation and DSM reconciliation has several advantages. The approach recognizes that DSM measure performance data are imperfect and likely to improve over time as an evaluation and analysis record is assembled. This approach therefore shares the risks of over or underrecovery of net lost revenue between utilities and ratepayers when an NLRA is first implemented. ${ }^{18}$ Utilities are still required to evaluate program performance and these evaluations remain subject to scrutiny by regulators and the public. As a result, utilities have an incentive to operate effective programs. Further, the utilities understand that the evaluations will be used to prospectively improve DSM estimates or forecasts. States also find NLRA mechanisms with this type of DSM reconciliation simpler to administer than mechanisms relying on ex post reconciliation of total program savings because participation levels are easier to observe and track than unit savings. ${ }^{19}$

To conclude this discussion, we note that in the three states using total program reconciliation, either regulatory or utility staff (or both) express concerns with their NLRA mechanisms that include DSM measurement issues. Six of the seven states satisfied with their NLRA mechanisms use reconciliation to program participation levels and do not rely on strict ex post measurement criteria to reconcile total program savings.

18 These risks tilt toward ratepayers if the preponderance of initial savings estimates are biased upwards. The risks fall more on utilities and shareholders if the opposite is true. Schlegel et al. (1993) provide a useful discussion and analysis of the risk implications of systematic bias in DSM impact estimates.

\footnotetext{
${ }^{19}$ Regardless of the reconciliation approach used, the establishment and operation of an accurate program tracking system is important for NLRA mechanisims. Among other data, these systems track the number and type of measures installed, the rebates or incentives provided to the participant, and the estimated savings for each measure. Schlegel et al. (1993) and others argue that it may be more important, and feasible, to verify the accuracy of the tracking systems, through audits for example, then to engage in extensive impact evaluations of every DSM program.
} 


\section{Involving Stakeholders in DSM Measurement}

A few states emphasized the importance and benefits of involving stakeholders in the DSM measurement process. The degree of stakeholder involvement we identified ranged from the use of working groups to establish evaluation guidelines in Minnesota to the use of a DSM collaborative group to review utility DSM savings forecasts, net lost revenue estimates, evaluation plans, and evaluation results in Maryland. In certain cases, this stakeholder involvement in DSM measurement is an extension of a larger involvement in DSM rate-making reform. States and utilities attempting to involve stakeholders in these ways tend to support the contributions stakeholders make to the NLRA process. Our interviews suggest that stakeholder involvement can have the following advantages:

- allows more resources to be devoted to review complex evaluation plans and results,

- relieves PUCs from litigation of highly technical issues in net lost revenue filings,

- helps focus limited evaluation budgets on higher priority applications, and

- serves as a forum for discussion of procedural and technical issues and the resolution of these issues.

\section{CONDITIONS PLACED ON NET LOST REVENUE RECOVERY}

All states with active NLRA mechanisms set conditions for net lost revenue recovery. We describe the different conditions states impose and the implications of the conditions for the operation of NLRA mechanisms and utility pursuit of DSM.

\section{Program Preapproval}

The most common condition placed on utilities is to require preapproval of prospective DSM programs by the PUC. All states with active mechanisms require utilities to submit program plans to the appropriate regulatory agency for review and approval. Only programs approved by regulators are eligible for lost-revenue recovery. Several states have not allowed utilities to recover net lost revenues because they failed this condition.

Setting this condition has advantages. Perhaps the foremost advantage is apprising the regulators of utility intentions. Submitting plans in advance also promotes agreement between regulators and utilities (and others stakeholders if they are involved with the review) on prospective program designs and objectives. Once agreement is reached, it is the utility's obligation to fulfill the plan. If the utility makes a good faith effort to implement the approved plan, then regulators and other stakeholders are less likely to fault utility efforts, thereby reducing litigation of issues before regulators. Preapproved plans also provide a useful reference for evaluation of utility performance. 


\section{Verify Net Lost Revenues}

All states except Indiana and New Hampshire require utilities to verify or demonstrate that net lost revenues occurred. These states require use of DSM measurement studies to verify savings. Impact evaluations are the type of measurement study most frequently requested by regulators. Utilities resist this condition when required to use DSM measurement studies to retrospectively reconcile total program savings A few states also use variants of this condition. For example, Indiana disqualifies interruptible programs from revenue recovery. New York and Minnesota only allow recovery from savings attributed to installation of equipment and not behavioral changes that are easily reversible, such as lowering a thermostat in winter.

\section{Earnings Test}

The earnings test, and the remaining types of conditions we discuss below, is not well represented in our study of states with active mechanisms. Maryland, however, does have an earnings test. Under an earnings test, the utility is eligible to collect net lost revenue only during those periods when its estimated rate of return is below its authorized rate of return. The motivation for an earnings test is to ensure that if the utility is already overearning compared to its authorized return then DSM net lost revenue recovery will not be allowed to further contribute to earnings. In Maryland this test is applied monthly. While this test has not been a major issue for net lost revenue recovery in view of the other attributes of Maryland's NLRA mechanisms, Maryland utilities prefer eliminating the earnings test . One problem utilities noted about the test is that overearning may result from many factors unrelated to DSM.

\section{Sales Test}

Under a sales test, when actual sales exceed or equal test year sales, the utility is not allowed to recover net lost revenue from its DSM program operations. The sales test may include adjustments for variables such as weather when comparing actual and test year sales. No state with an active NLRA mechanism uses a sales test, although this condition is being considered in Minnesota. We did not identify any states that use the sales test condition where utilities had recovered net lost revenues. Iowa and Michigan are examples of states that use the sales test. The motivation for a sales test is to ensure that the utility does not overrecover fixed costs.

From Chapter 2, we recall that the test year sales forecast (Sales ${ }_{\mathrm{fTY}}$ ) includes a DSM forecast $\left(\mathrm{DSM}_{\mathrm{fTY}}\right)$. If the actual program savings ( $\mathrm{DSM}_{\mathrm{fTY} \text {, est }}$ ) equal the forecasted savings, then the utility does not experience net lost revenues beyond that already included in the electricity price.

From this we can illustrate the principle behind the sales test. For the historical test year case, if the difference between actual sales and test year sales $\left(\right.$ Sales $_{\mathrm{N}}-$ Sales $\left._{\mathrm{TY}}\right)$ equals actual DSM savings $\left(\mathrm{DSM}_{\mathrm{hTY}+1}\right)$ then total utility net lost revenues are zero. Similarly, for the future test year case, if the difference between actual sales and test year sales $\left(\right.$ Sales $_{N}-S_{T Y}$ Sales $_{T Y}$ ) equals the difference between actual and forecasted DSM savings $\left(\mathrm{DSM}_{\mathrm{fTY}}\right.$, est $\left.-\mathrm{DSM}_{\mathrm{fTY}}\right)$ then total utility 
net lost revenue are zero. Thus, in the sales test, if the difference between actual sales and test year sales ( Sales $_{\mathrm{N}}-$ Sales $_{\mathrm{TY}}$ ) exceeds actual DSM savings $\left(\mathrm{DSM}_{\mathrm{hTY}+1}\right)$, then the utility recovers more fixed costs than specified in the rate case. Or, if the difference between actual sales and test year sales $\left(\right.$ Sales $_{\mathrm{N}}$ - Sales $\mathrm{TY}_{\mathrm{TY}}$ ) exceeds the difference between actual and forecasted DSM savings $\left(\mathrm{DSM}_{\mathrm{fTY}}\right.$, est $\left.-\mathrm{DSM}_{\mathrm{fTY}}\right)$, then the utility also recovers more fixed costs than specified in the rate case.

\section{Other Conditions}

The other conditions we identified include revenue recovery caps, performance targets, net lost revenue offsets and time limits for recovery. An annual revenue recovery cap limits the total revenues to be collected though a DSM surcharge each year. Once the cap is reached, utilities cannot collect additional revenues. Arizona imposes a revenue recovery cap on one utility. The Arizona cap specifies a floor and ceiling for the surcharge that includes DSM program costs, shareholder incentives, and net lost revenues.

A performance target condition links net lost revenue recovery to preapproved DSM program performance goals. When estimated program performance falls below approved performance targets, the PUC either curtails or denies utility net lost revenue recovery. Minnesota imposes a performance target on one utility.

Offsets conditions involve balancing net revenue losses from energy-efficiency programs against net revenue gains from utility load-building efforts. For combined-fuel utilities, the offsets condition also applies to fuel-switching programs. An electricity fuel-switching program, for example, that encourages customers to switch from gas to electric appliances generates net revenue losses from the utility's gas operations and net revenue gains for its electricity operations. Maryland applies an offsets condition to combined-fuel utilities. The motivation for this condition is similar to the earnings and sales tests: the utility should be prohibited from overrecovering total fixed costs. This condition differs from earnings and sales tests, however, because the offsets condition considers only the utility's DSM activities. As a practical matter, most PUCs are reluctant to adopt policies or incentives encouraging utilities to pursue load-building or fuelswitching activities as part of ratepayer-funded DSM programs.

Massachusetts is considering a time limit on net lost revenue recovery. Under this condition, utilities would be able to recover net lost revenues for up to three years after each program year's activities. This condition would only apply to utilities that did not have a rate case during the three year period.

Finally, we identified several states whose NLRA policy is to review utility net lost revenue recovery requests on a case-by-case basis. These policies are effectively NLRA mechanisms without any conditions. The PUCs provide little or no guidance to utilities regarding filing requirements or procedures to recover net lost revenues. None of the utilities in states that 
consider requests on this basis have actually recovered net lost revenue from DSM program operations.

\section{Two Approaches to Net Lost Revenue Recovery}

Our review of the different conditions states place on net lost revenue recovery, particularly the earnings and sales tests, reveals two different underlying approaches to net lost revenue recovery: the regulatory approach and the DSM approach. We view these two approaches as responses to the question, When are utilities underrecovering fixed costs?

We call the first approach the regulatory approach because it is largely derived from the traditional perspective on utility regulation. The objective of the regulatory approach is to insure that the utility is made whole with respect to overall fixed cost recovery, as defined in the utility's previous rate case. Characteristics of the regulatory approach are:

- Regulators do not view DSM in isolation from the rest of utility operations.

- Regulators focus on tota! fixed cost recovery relative to the test year

- The utility can lose revenue with respect to DSM if it is gaining revenue from some other area of utility operations, such as increased sales or operational efficiency gains. These additional revenues may be due to actions beyond the utility's control, such as better than expected economic growth or more extreme weather.

The regulatory approach emphasizes placing a ceiling on fixed cost recovery. Utilities recover net lost revenue from DSM only when the utility is below this ceiling. This approach is consistent with the imposition of earnings and sales tests.

We call the second approach the DSM approach. The objective of the DSM approach is to insure that the utility does not lose revenues from DSM regardless of how revenues are affected by other aspects of utility operations. Unlike the regulatory approach, the focus is on what utility earnings would have been without the DSM program. Characteristics of the DSM approach are:

- Regulators view DSM in isolation from the rest of utility operations.

- Regulators focus on fixed cost recovery from DSM investment only.

- The utility will not lose revenue with respect to DSM investment.

The DSM approach focuses on restoring the utility's revenue recovery to what it would have been if it had not operated its DSM programs. The first two conditions we discussed, preapproved DSM programs and verifying DSM program savings, are compatible with this approach, as are load-building and fuel-switching offsets. 


\section{DIFFERENT TYPES OF NLRA MECHANISMS}

The NLRA mechanisms each state uses have unique features, but we identified three basic types of mechanisms: a prospective surcharge; a retrospective surcharge; and a deferred account. The surcharge mechanisms are reflected as rate changes on customer bills. The NLRA mechanism is typically just one component of an overall DSM surcharge that also includes program cost recovery and incentive awards. A few states include the NLRA mechanism as part of the utility's fuel adjustment clause. Under the deferred account, the utility tracks net lost revenues and receives authorization to recover these net lost revenues at its next rate case.

\section{Prospective Surcharge Mechanism}

The prospective surcharge mechanism, used by utilities in seven states, is the most prevalent NLRA mechanism. The prospective surcharge recovers revenues lost as a result of the current DSM-program-year activities. Thus, the prospective surcharge is designed to recover net lost revenue as the utility incurs these losses. Under this approach, utilities file a forecast of DSM savings and associated net lost revenues for the upcoming program year. Annual filings are most common, although Indiana requires a quarterly filing from one utility. Subject to the PUC's approval, the DSM savings and net lost revenue forecast then becomes the basis for an NLRA surcharge to customers' bills. A single surcharge may be applied to all customers or the surcharge may differ by customer class, depending upon how the PUC decides to allocate revenue recovery costs.

All the states using a prospective surcharge except New Hampshire require a subsequent reconciliation between the initial net lost revenue forecast and a subsequent assessment of DSM program performance. We discussed earlier the different approaches states take to this reconciliation. The result of this reconciliation process is also reflected in the NLRA surcharge. With this mechanism, a utility will typically include a net lost revenue reconciliation from an earlier program year with its forecast of net lost revenues for the upcoming program year. The reconciliation may result in either an increase or decrease in the surcharge for the upcoming program year, depending on whether the outcome of the reconciliation indicates an underrecovery or overrecovery of net lost revenues from the earlier program year.

The surcharge may also be designed to amortize net lost revenue recovery for the current program year over a series of years. A common time period in use is the estimated average life of the measures installed that year. States also choose time periods, however, unrelated to the average DSM measure life. Prospective surcharges that include amortization of net lost revenue recovery typically include carrying charges on each year's unamortized balance. Certain prospective mechanisms also attempt to account for the anticipated time pattern of net lost revenues over the program year. For example, certain mechanisms may concentrate net lost revenues from a new DSM program later in the program year to reflect the lower DSM savings associated with program start-up early in the program year. 


\section{Retrospective Surcharge Mechanism}

The retrospective surcharge is designed to recover revenues lost from DSM activity in a previous year or years. Thus, utility filings include annual estimates of net lost revenues from program activities in the previous year. In all other major respects, the retrospective and prospective surcharges are identical. Minnesota and Oregon use the retrospective surcharge. Reconciliation is not a major issue in Minnesota because utilities cannot recover net lost revenue from programs requiring a completed program impact evaluation until that evaluation is complete. In Oregon, the utility initially requests $50 \%$ of estimated net lost revenues from the previous program year's activities and then requests the balance once savings verification studies are complete.

\section{Deferred Account Mechanism}

The deferred account uses a tracking mechanism that records monthly net lost revenue estimates. The utility then receives authorization to recover these estimated net lost revenues at its next rate case. The deferred account mechanism may also require annual net lost revenue filings supported by DSM measurement studies. The PUC will review and approve, subject to any revisions, the annual net lost revenue amount for recovery through the new base rates established in the next rate case. More typically, the utility files an estimate of the net lost revenues incurred between rate case as part of its larger general rate case (GRC). The PUC will either require that these net lost revenue estimates be supported by DSM measurement studies or will require a reconciliation to measurement study results at the subsequent rate case. Authorized net lost revenue recovery is amortized over several years and carrying charges apply. Utilities in Arizona, Indiana, and Vermont use deferred accounts to recover net lost revenues.

\section{Developing NLRA Mechanisms}

In most states, NLRA mechanisms emerged from more general regulatory proceedings on integrated resource planning or DSM rate-making reform. Most states do not develop NLRA mechanisms in isolation. Instead, these mechanisms are developed with other DSM rate-making reforms, such as shareholder incentives and program cost recovery. Several states reported that utilities and regulatory agencies should have the flexibility to experiment with different NLRA mechanisms. Certain states also suggest that utilities should have primary responsibility for developing the cost recovery mechanism(s) that removes the disincentives to utility DSM investment, but that stakeholders should also be involved in the initial development and any subsequent revisions to the mechanisms.

Several states initiated NLRA mechanisms as pilot projects with distinct operating lives. At the end of these operating periods, the states have conducted, or will conduct, a review and assessment of each mechanism's performance. In Minnesota, for example, the PUC formed a working group of stakeholders to develop an annual DSM cost recovery mechanism suited to each utility. The PUC subsequently approved as pilot projects all the utility proposals for annual DSM cost recovery meeting the guidelines established by this group. More recently, the 
Minnesota PUC established a working group of stakeholders to assess these pilot programs and recommend the future course of these programs. 


\section{EFFECTIVENESS OF THE NLRA APPROACH}

Our interviews with regulatory and utility staff about their experience with specific NLRA mechanisms provided us with valuable information. In addition, the orders, testimony, and NLRA filings we received from states and utilities offered considerable detail about how the mechanisms were established and how they are currently operated. In this chapter, we present the results of our analysis of this material. These results are directed at this project's first two objectives:

- determine whether an NLRA is a feasible and successful way to remove the lost-revenue disincentive to utility operation of certain DSM programs; and

- if an NLRA is feasible and successful, identify the conditions that lead to the successful implementation of NLRA mechanisms in different states.

We discuss first the feasibility and success of NLRA and then the conditions associated with successful NLRA implementation. We discuss the project's third objective, to suggest improvements to NLRA mechanisms, in Chapter 6.

\section{FEASIBILITY AND SUCCESS OF NLRA}

We define a feasible NLRA mechanism as one that is capable of being carried out. A successful NLRA mechanism leads to favorable or desired results.

An NLRA approach to address the net lost revenue disincentive to utility DSM investment is obviously feasible. An NLRA mechanism of some type is being actively used by ten states. New York's Central Hudson Gas and Electric and Massachusetts's Western Massachusetts Electric have had NLRA mechanisms since 1990. Indiana, Oregon, and Vermont have used NLRA since 1991. More states are poised to implement lost revenue recovery through an NLRA mechanism, most notably Kentucky, New Jersey, Ohio, and Utah.

The only situation we identified that threatens the feasibility of NLRA is represented by Illinois. The Illinois Commerce Commission authorized Commonwealth Edison to recover costs associated with DSM, including net lost revenue. The Illinois Supreme Court (1994) reversed the Commerce Commission's order authorizing DSM cost recovery, primarily on the grounds that the Commission violated state statutes prohibiting single-issue rate making and retroactive rate making, and, in the Court's opinion, that the recovery of lost revenues does not reflect a cost of providing electric service or a cost that benefits ratepayers. As discussed in Chapter 3, Commonwealth Edison has stopped requesting net lost revenue recovery and no other utility in Illinois has requested Commission authorization for net lost revenue recovery since that ruling. 
To our knowledge, no other state has experienced a successful court challenge to net lost revenue recovery. Certain states, Minnesota for example, have passed laws that explicitly give their PUCs the authority to revise rates outside general rate cases. Where gray areas might have existed in statutes governing state public utility regulation, these laws have eliminated ambiguity about the regulatory commission's authority to implement rate-making reforms for DSM outside individual utility rate cases.

Assessing the success of NLRA is not as straightforward as judging feasibility. In large part this is because the mechanism's success is linked to achieving a broader policy goal: the comparable treatment of demand- and supply-side resource options. As a result, we will address more completely the question of NLRA's success in our upcoming discussion on the policy objectives of net lost revenue recovery. We will say now that every individual we interviewed for this project agreed that NLRA addresses an important disincentive to utility DSM. Our state-specific overviews in Appendix A contain many examples of these positive assessments. Further, many of those we interviewed reported that the NLRA mechanisms, in conjunction with other DSM ratemaking reforms, changed both utilities' attitudes and actions about DSM.

\section{SUCCESSFUL IMPLEMENTATION OF NLRA MECHANISMS}

In Chapter 2 we described two different dimensions of success. The first dimension of success refers to the process set up for design and implementation of the NLRA mechanism, including the submission and review of utility filings. The second dimension of success relates to the achievement of policy goals.

We turn initially to the first dimension of success: the effectiveness of the NLRA process itself. Of the ten states with active mechanisms, seven states (Arizona, Connecticut, Indiana, Maryland, Minnesota, New Hampshire, and Vermont) are largely satisfied with their mechanisms. Utilities are making net lost revenue filings and recovering lost revenues, and neither the regulatory staffs nor the utility staffs are advocating major changes to their current mechanisms. In Maryland and Minnesota, where we did follow-up interviews with staff from four utilities, the utilities confirmed the results of our regulatory staff interviews.

Three states (Massachusetts, New York, and Oregon) report what we judge to be substantive problems with their NLRA mechanisms. Although utilities are also making net lost revenue filings and continue to recover lost revenues, either the regulatory agencies or utility staffs are contemplating major changes in the existing mechanisms or a shift from the NLRA approach to the decoupling approach to lost revenues. Our follow-up interviews with staffs from three utilities in New York and Oregon confirmed the reports from our regulatory staff interviews. 


\section{Conditions Associated With An Effective Mechanism}

Table 3 lists the ten conditions associated with a successful NLRA mechanism that emerged from our interviews. The sequence in which we list and discuss each condition suggests a priority ranking only in the sense that the first three conditions apply more broadly and, in our view, are more important in determining the success of an NLRA mechanism than are the remaining seven. We also discuss an issue that may bear on NLRA's success, but that we did not pursue in our current research.

From an alternate perspective, the easiest way to identify the conditions associated with implementation problems is to do the opposite of what we recommend below, for example: take a strict ex post approach to measurement, omit stakeholders from the process, set conditions for net lost revenue recovery unrelated to program operation and performance, and so on.

Before beginning, we note that the type of NLRA mechanism a state applies does not appear to be related to NLRA's success. We have examples of effective NLRA implementation with all three basic mechanisms: retrospective surcharges, prospective surcharges, and deferred accounts with rate case recovery.

Table 3. Conditions Associated with a Successful NLRA Mechanism

1. Avoiding a Strict Ex Post Approach to DSM Measurement

2. Involving Stakeholders in the Process

3. Setting Conditions for Lost Revenue Recovery Related Directly to DSM Program Operation and Performance

4. Establishing a Frequent and Regular Filing Schedule

5. Allowing Flexibility for Both the PUC and the Utilities

6. Receiving Clear Legislative Authority to Set DSM Incentives and Cost Recovery

7. Addressing Cost Recovery Issues First

8. Having Previous Experience with IRP

9. Having Previous Experience with Balancing Accounts

10. Maintaining Customer Communication 
Avoiding a Strict Ex Post Approach to DSM Measurement. Table 2 shows that eight of ten states require utilities to verify that utility DSM programs result in energy savings. Utilities must satisfy this condition to file for or to collect net lost revenues. Because lost revenues from DSM are linked directly to program performance, it is perhaps no surprise that DSM measurement and evaluation is an important issue for NLRA mechanism success. The clearest indicator of NLRA effectiveness is a state's approach to DSM measurement. States that do not rely on a strict ex post approach to verify DSM savings report satisfaction with their NLRA mechanisms. States with a strict ex post approach to DSM measurement are less satisfied with NLRA.

Under a strict ex post approach, to ensure that utilities are compensated only for net lost revenues they actually incur, regulators base net lost revenue recovery on after-the-fact measurements of actual impacts. These after-the-fact measurements are from impact evaluations that focus on the statistical analysis of customer energy use data.

We believe a strict ex post approach to verify DSM program savings for net lost revenue recovery is unnecessary, particularly in the first few years an NLRA mechanism is in operation. In Chapter 3 we listed four major problems with a strict ex post approach that emerged from our analysis.

- First, impact evaluations tackle a difficult measurement problem and, because of the time and expense required to conduct evaluations, lead to delays in net lost revenue recovery ${ }^{20}$ and make evaluations for all programs impractical.

- Second, an evaluation still results in an estimate of program impacts, with all the attendant estimation difficulties this entails. ${ }^{21}$

- Third, ratepayers may be exposed to DSM performance-related risks, but these risks are at least in part balanced by the benefits ratepayers receive and risks that work in the opposite direction.

- Finally, total program reconciliation increases administrative and technical burden on regulatory and utility staff. ${ }^{22}$

\footnotetext{
${ }^{20}$ How this time lag might affect utility behavior is unclear. We examine the effects of the time lag between revenue loss and recovery on utility finances in Chapter 5.

${ }^{21}$ For example, states that require detailed longitudinal persistence studies of total program savings so that utilities can continue to include lost revenue impacts in base rates may be defining an expensive and methodologically intractable evaluation problem.

${ }^{22}$ Utility staff in New York and Oregon viewed the regulatory requirements to document net lost revenue estimates as burdensome. The utilities we interviewed in these two states were concerned about the documentation needed for the reconciliation of initial net lost revenue estimates with total program savings from measurement studies. Striking a balance between the regulators' need for information and utility staff time and resources is not a dilemma unique to DSM issues. In the case of New York and Oregon, at least, a move away from a strict ex post approach to DSM measurement might alleviate utility concerns about documentation requirements.
} 
Schlegel and colleagues (1993), in their assessment of California's DSM shareholder incentive mechanisms, reach a similar conclusion on strict ex post determination. Though their focus was on shareholder incentives, we find their conclusions are also applicable to the use of strict ex post approach for net lost revenue recovery. Schlegel et al. (1993, p. 7-44) conclude that a strict ex post approach would:

- by all accounts, be technically and administratively difficult;

- in the opinion of many utility managers ( and other interviewees as well), endanger further constructive utility responses to California's regulatory incentives;

- fail to significantly reduce any ratepayer risks that have been demonstrated to be significant to date;

- substantially increase the regulatory burden involved in overseeing the incentives;

- potentially distract both utilities and regulators from the need to use evaluation to reduce long-term resource planning risk; and

- be unnecessary for the purpose of stimulating utility commitment.

To this list we would add that a strict ex post approach will become increasingly difficult for regulators to administer as utilities move from rebate and direct installation programs to customer financing and audit programs. In addition, the strict ex post approach overemphasizes impact evaluations at the expense of other DSM measurement strategies. One important alternate strategy is verification-collecting data to determine whether measures are installed and operating and whether programs are functioning as reported by the utility (Schlegel et al. 1993). ${ }^{23}$

All states except New Hampshire require some level of reconciliation of DSM forecast estimates to DSM program measurement and evaluation results. We find that the most important characteristic of a state's approach to DSM measurement is how it decides to reconcile these initial utility estimates of program performance with later estimates of actual performance. A clear example of a strict ex post approach is the requirement by some states for utilities to retrospectively reconcile total program savings. Total program savings reconciliation involves estimating both program participation and unit savings. Unit savings are more difficult and expensive to estimate, and tracking savings estimates over time increases the administrative burden for both utility and regulatory staffs. Forecasting unit savings requires detailed understanding of the energy use and operating characteristics of both baseline equipment and the energy-efficiency measure intended to replace the baseline equipment. Because evaluation results

\footnotetext{
${ }^{23}$ Schlegel et al. (1993) provide a good description of DSM verification activities. These activities include: reviewing the appropriateness of engineering estimation procedures; reviewing the appropriateness of utility documentation; acquiring external assessments of the validity and reasonableness of evaluation studies; and making on-site inspections of measure installation, retention, and performance. The primary focus of verification, as distinct from impact evaluation, is to establish the reasonableness of data that utilities have already developed and provided to regulators.
} 
can lag program implementation by two years or more, utility and regulatory staffs must create and administer systems to track program savings over time and reconcile program evaluation results with program forecasts that can be several years old. The result of this reconciliation must then be applied to adjust current net lost revenue estimates to correct for historical overcollection or undercollection of net lost revenue.

States that require reconciliation of projected to observed program participation levels are avoiding a strict ex post approach to DSM measurement. In most cases, participation levels are administratively easy to track and, thus, to compare to projected participation. In addition, participation-level reconciliation can be done shortly after the end of each program year.

Another characteristic of avoiding a strict ex post approach to measurement commits utilities to use the best available data to estimate net lost revenue. Particularly when they initiated NLRA mechanisms, some states recognized that data on DSM program performance would improve over time as utilities and regulators put more resources into measurement and evaluation. As more evaluations were completed, some would inevitably yield unit savings results that diverged from those in the original program forecasts, which were most often made using engineeringbased methods. These states developed a policy of neither penalizing utilities when DSM evaluations indicated that realized unit savings were less than projected savings nor rewarding utilities when the reverse was evident. Instead, these states continued to reconcile participation levels and reached agreement with utilities that measurement and evaluation results are to be used, when appropriate, in subsequent net lost revenue projections. This approach strikes a compromise between a strict approach to measurement issues, where the emphasis is on getting the numbers "right" from the beginning, and an approach that largely ignores measurement and evaluation and relies instead on engineering estimates of unit savings and forecasts of program participation levels.

We want to be clear that we are not recommending a casual approach to verifying DSM program performance for net lost revenue recovery. DSM measurement is an important part of any welldesigned NLRA mechanism. ${ }^{24}$ We offer the following as an alternate to a strict ex post approach:

- Limit retrospective reconciliation to program participation.

- Use engineering algorithms and assumptions to estimate measure savings.

- Focus impact evaluation efforts on refining engineering algorithms and assumptions. Collect information on customer characteristics that matches information used in the engineering estimates. Understanding why results may be similar or different is probably

\footnotetext{
${ }^{24}$ Regardless of measurement approach, regulatory agencies must provide their staffs with adequate time and resources to review utility net lost revenue filings. Assessing the DSM measurement studies utilities use to support net lost revenue estimates requires a substantial commitment by regulatory staff and stakeholders. Providing adequate review sends a positive signal to utility and regulatory staffs, as well as all stakeholders, that net lost revenue filings should be prepared to a high standard of professional quality and will be reviewed with such a standard in mind.
} 
more important than identifying similarities and differences (Baxter 1994). This is a key finding in an initial attempt to reconcile evaluation results with engineering estimates of savings (Ignelzi, Parikh, and Mast 1994).

- Rely more on DSM verification efforts rather than impact evaluations to reduce the risks from upwardly biased program savings forecasts.

- Concentrate scarce evaluation dollars on a few large DSM programs.

- Ensure that results from completed impact evaluations and verification efforts are included in subsequent utility DSM forecasts and net lost revenue estimates.

Because of the importance of DSM measurement issues to NLRA mechanisms, we explored the question of whether establishing DSM evaluation guidelines or protocols might help anticipate and thereby reduce conflicts over measurement issues. We were especially interested in understanding if guidelines might be useful in those states that require retrospective reconciliation to total program savings. Only Massachusetts and Minnesota make use of published DSM evaluation guidelines. As we describe in Appendix A, Minnesota's guidelines emerged from the Evaluation Working Group, which appears to contribute substantially to the resolution of DSM evaluation issues. Minnesota is also generally satisfied with the NLRA mechanisms applied to their utilities. Massachusetts, which requires reconciliation to total program savings, reports some problems with DSM measurement issues despite the presence of guidelines. Thus, it appears that guidelines alone, in the absence of an alternative to a strict ex post approach to DSM measurement, do not ensure effective implementation of NLRA mechanisms.

Interestingly, though New York moved away from NLRA at least in part due to the importance evaluations played in its NLRA process, Consolidated Edison reports devoting just as many resources to evaluation under the decoupling approach as it did under NLRA. Because Consolidated Edison believes utilities must understand how DSM affects sales and revenues, Consolidated Edison continues to conduct evaluations not only to verify program performance for incentives claims but also to monitor lost revenues.

Involving Stakeholders in the Process. Involving stakeholders in the NLRA process pays dividends. The dividends are: increasing resources to review net lost revenue filings, providing a forum for discussing issues and resolving conflicts, and reducing the prospects of litigating technical issues before PUCs. Studies of DSM collaboratives clearly document the benefits of early stakeholder involvement in DSM policy and planning issues (Raab and Schweitzer 1992; Schweitzer et al. 1993).

For most states, the relevant stakeholders are utilities, regulatory agencies, consumer advocates, and environmental advocates. The degree of stakeholder involvement can be limited to a review of utility net lost revenue estimates or expanded to also include reviews of utility DSM program plans and evaluation plans and the design and implementation of the specific NLRA mechanisms. 
Connecticut and Maryland continue to use their DSM collaboratives to maintain stakeholder involvement in the NLRA process. Maryland's approach has been to seek broad participation by its collaborative, ranging from developing and implementing the initial NLRA mechanisms to review of utility DSM program plans, evaluation plans, and net lost revenue filings. The lack of regulatory staff resources to adequately review utility net lost revenue filings is reported by some states to be a burden. We find Maryland's use of its collaborative to be ingenious in this regard. Maryland not only uses its collaborative to acquire more resources to review DSM filings, but it also has effectively eliminated the need to litigate net lost revenue issues before the PUC. The addition of the collaborative parties to the review process increases both the quantity and the diversity of the resources available to assess utility evaluation studies. The collaborative thus forms the kind of multidisciplinary team necessary to review complex program evaluations (Baxter and Schultz 1994).

Collaboratives are not the only way to involve stakeholders. Minnesota has achieved many of the same benefits as Maryland through the use of three different working groups. While two of Minnesota's working groups formed under directions by the PUC, the Evaluation Working Group was more informal. According to the regulatory and utility staff we interviewed in Minnesota, the Evaluation Working Group played a valuable role in guiding program evaluation efforts and serving as a forum for the discussion and resolution of issues despite the group's lack of a formal mandate.

\section{Setting Conditions for Lost Revenue Recovery Related Directly to DSM Program}

Operation and Performance. All effective NLRA mechanisms include conditions for utility net lost revenue recovery. These conditions should be well articulated and understood by the relevant regulatory agencies and the affected utilities. The imposition of certain conditions, however, may not only increase administrative burdens on utility and regulatory staffs, but inhibit attainment of a larger DSM policy goal: the equitable treatment of demand and supply resources.

We believe that the conditions most compatible with effective NLRA mechanisms relate net lost revenue recovery directly to DSM program operation and performance. In short, we believe that conditions consistent with the DSM approach to net lost revenue recovery, described in Chapter 3 , are more likely to be associated with an effective NLRA mechanism and to support attainment of the larger DSM policy goal of equitable treatment between demand and supply resources.

All ten states with active NLRA mechanisms require the appropriate regulatory agency to review and approve DSM plans before a utility is eligible for any DSM cost recovery, including net lost revenue. In most states, the designated review agency is the state PUC. Several states and utilities emphasized the importance of getting prior approval of both DSM program plans and evaluation plans as an effective means of reducing later conflicts. Prior approval not only establishes clear expectations for utility action, but also provides a clear reference to assess utility performance. In all states but Indiana and New Hampshire, utilities are also required to demonstrate or verify that their DSM programs are achieving savings and that, as a result, they are incurring a net revenue loss. A few states explicitly omit load management or interruptible 
rate programs from net lost revenue recovery, but most do not. These latter states simply indicate that any DSM program that results in energy savings (as opposed to demand savings) is eligible for net lost revenue recovery. Most states consider only direct rebate or direct installation programs. Any impacts from education, information, or pure audit programs are generally not considered for net lost revenue recovery, primarily because the regulators believe the energy savings from these programs are more difficult to verify. To the extent that utilities shift program emphasis from rebate and direct installation programs to customer financing and audit programs, regulators will have to rethink this condition.

Conditions consistent with the regulatory approach to net lost revenue recovery, especially earnings and sales test conditions, may be more compatible with decoupling mechanisms than NLRA mechanisms. With its focus on utility total fixed cost recovery instead of DSM net income neutrality, the regulatory approach applied to NLRA mechanisms attempts to weave what is intended as a DSM regulatory reform back into the traditional approach to utility regulation and rate making. The result is that utility recovery of net lost revenues from its DSM programs is asymmetrical; that is, the utility will recover net lost revenues from DSM so long as its fixed cost recovery is lagging due to other events, such as a poor economy or milder weather. Further, this approach links net lost recovery from DSM to events outside the utility's control. Perhaps regulators most comfortable with this approach should consider decoupling instead of NLRA, particularly if their focus is going to be on the utility's total fixed cost recovery.

Earnings and sales test conditions are not common in states with active NLRA mechanisms. Maryland imposes a monthly earnings test, which we described in Chapter 3 and Appendix A, on net lost revenue recovery. The Maryland utilities we interviewed would prefer to see this condition eliminated but do not currently view the earnings test as a major problem in view of the other attributes of Maryland's net lost revenue mechanisms. The presence of this condition, however, has led the U.S. Department of Energy (1994) to deny at least one Maryland utility a "net income neutral" status with regard to demand and supply resources as provided under the Energy Policy Act of 1992. Minnesota may impose an additional condition on net lost revenue recovery linked to net sales growth. This proposal is still under discussion in Minnesota.

Massachusetts is considering a time limit on net lost revenue recovery. This condition would permit utilities to recover net lost revenues for up to three years after each program year's activities and would only apply to utilities that did not have a rate case during the three-year period. This condition may be a useful response in states where utilities do not recover net lost revenue until their rates cases, yet enter rate cases infrequently. Massachusetts, in particular, expressed concern about infrequent rate cases leading to large and growing net lost revenues over time. Infrequent rate cases can lead to an imbalance between base rates and the adjustment to base rates necessary to cover full DSM costs, including net lost revenue. Thus, they can lead to cost recovery totals through the surcharge that some may perceive to be large. Particularly in states with weak economies, regulators may find it more difficult to support substantial cost recovery amounts. 
Finally, states serious about DSM regulatory reform that propose to consider utility net lost revenue on a case-by-case basis should nevertheless establish clear guidelines about what utilities must do to file for and to collect net lost revenues. The utility is likely to perceive the absence of clear guidelines as a lack of regulatory support for DSM reform or uncertainty by the regulator on how to proceed with net lost revenue recovery. Neither situation is conducive to an effective NLRA mechanism.

Establishing a Frequent and Regular Filing Schedule. Utilities should have the opportunity to file frequently and regularly for net lost revenue recovery or for approval of net lost revenue estimates. Frequent and regular filings provide the utility with more opportunities for feedback on the adequacy of its filing and more certainty that revenues will be ultimately recovered. In addition, more frequent filings keep balancing accounts and incremental net lost revenue recovery from growing too large over time. Frequent filings can thus allow for smaller rate increases rather than larger rate increases introduced at longer intervals. Finally, because the revenues at stake are smaller, frequent filings may reduce the political burden on decision makers to approve net lost revenue recovery.

Seven states require separate annual filings for net lost revenue recovery for all affected utilities. Arizona requires a separate annual filing for Arizona Public Service, but a filing in the general rate case for Tucson Electric Power. Indiana requires Southern Indiana Gas and Electric Company to file net lost revenue quarterly, but is considering a change to a semi-annual filing. For states with separate filing requirements for net lost revenue recovery, an annual filing appears to be sufficiently frequent, particularly if regulatory staff are provided ample time to review utility filings and supporting workpapers or program evaluations.

Three states consider net lost revenue recovery as part of larger general rate case filings. Arizona and Indiana do this for select utilities and Vermont does so for all eligible utilities. We have a mixed response to the use of the GRC forum to address net lost revenue filings. For states interested in reducing the number of separate proceedings to consider single issues like net lost revenue recovery, the GRC approach has appeal. GRC proceedings are large and formal, however, which increases costs to participants and can limit the exchange of information between parties. Further, unless the utility has frequent rate cases, say every year or two (which is the case with Vermont), then unrecovered net lost revenues are likely to be substantial and result in larger incremental rate impacts. Finally, the consideration of net lost revenue recovery in rate cases defeats one of the purposes of NLRA itself, which is making utilities financially whole from DSMinduced net revenue losses between rate cases. ${ }^{25}$ One advantage of surcharge mechanisms, therefore, is that utilities do not have to enter a GRC just to achieve net lost revenue recovery.

\footnotetext{
${ }^{25}$ As Chapter 5 shows, if utilities receive interest on the unamortized net lost revenue balance and, because of established regulatory policies and practices, are certain to recover the balance and interest in the rate case, then our concern with the GRC approach is alleviated.
} 
Allowing Flexibility for Both the PUC and the Utilities. State PUCs that allow DSM cost recovery are demonstrating flexibility because they are willing to consider an alternative to traditional utility regulation. Flexibility by both state PUCs and utilities is particularly important in relatively unexplored regulatory terrain like net lost revenue recovery. No single correct approach to net lost revenue recovery exists. Utilities differ and so will their needs for DSM cost recovery.

Our observations suggest that PUCs willing to consider and experiment with different NLRA approaches fare better than PUCs that mandate an approach or apply initially a single approach to all utilities. PUC flexibility is further augmented by giving utilities the freedom to develop the cost recovery mechanism that removes the disincentives to utility DSM investment. Most states do not develop NLRA mechanisms in isolation. Instead, net lost revenue recovery is developed with other DSM rate-making reforms such as shareholder incentives and program cost recovery. Maryland and Minnesota are two examples of the benefits of flexibility. Both states experimented with different NLRA mechanisms and actively engaged the utilities and other stakeholders in the process of DSM rate-making reform.

The experience of several states also indicates that NLRA mechanisms should first be initiated as pilot projects with distinct operating lives. At the end of these operating periods, the states should conduct a review and assessment of each mechanism's performance and determine the future course of the pilots.

Receiving Clear Legislative Authority to Set Incentives and Cost Recovery. The Illinois case is a clear example of the chilling effect that ambiguity about a PUC's authority to address ratemaking reform issues can have on net lost revenue recovery. As a result, we see benefits for removing this ambiguity, particularly in states where a PUC is prohibited from addressing rate issues outside a GRC. Connecticut, Maryland, and Minnesota all cited the benefits of getting clear legislative authority to address DSM incentives and cost recovery outside GRCs.

Addressing Cost Recovery Issues First. PUCs almost always consider net lost revenue recovery along with other DSM rate-making reforms and the reorientation or redesign of utility DSM efforts. As these rate-making reforms and program redesign efforts begin, PUCs must decide which issues to address first: incentives, cost recovery, program redesign, and so on. The answer that surfaced clearly in our interviews with regulatory and utility staffs in Maryland was that PUCs should address cost recovery issues first. PUCs should first hammer out the principles and then the details on both net lost revenue recovery and program cost recovery before discussing incentives and designing new programs.

The benefits of this sequencing are plain. While incentives can be an important influence on utility behavior, net lost revenue recovery and program cost recovery often have a substantially greater impact on a utility's income statement. Once utilities are assured of being made financially whole for their DSM investments, they are more likely to undertake more aggressive DSM programs and pursue more difficult market segments. Baltimore Gas and Electric and Potomac Electric 
Power Company both reported that addressing cost recovery issues first gave them the confidence to propose and develop larger and more comprehensive programs.

Having Previous Experience with IRP. In many states, DSM rate-making reforms were preceded by more general proceedings on IRP. Connecticut, Maryland, and Minnesota found this approach helpful because the proceedings initiated a dialogue on issues such as DSM financial disincentives and introduced regulators to concepts like net lost revenue. We believe it is possible to initiate effective DSM rate-making reforms without first engaging in an IRP proceeding, but we see the benefits to setting the groundwork for reform through an exploration of IRP principles and experiences in other states.

Having Previous Experience with Balancing Accounts. Surcharges are the most common means to implement net lost revenue recovery. NLRA surcharges are associated with balancing accounts, which record the net lost revenue collected and ensure that the collected revenue does not deviate over time from the authorized amounts. Some states, like California, authorize liberal use of balancing accounts while others, like Maryland, have only recently applied balancing accounts. Maryland initiated a balancing account specifically for net lost revenue recovery. A state may feel more comfortable with the administrative technicalities of an NLRA surcharge if it has previous experience with balancing accounts. One of the most common balancing accounts is for fuel costs, where the account protects the utility from random or unforeseen deviations in short-run fuel prices.

We do not see previous experience with a balancing account as a necessary precondition to a successful NLRA mechanism, however. Maryland is a good example of a state without previous experience with such accounts that has nevertheless developed and implemented an effective set of NLRA mechanisms.

Maintaining Customer Communication. States and utilities should not overlook the customer in net lost revenue recovery in particular and DSM regulatory reforms in general. While no one reported excessive customer complaints from implementing DSM regulatory reforms, a few states indicated that some customers do call their utilities when a visible surcharge changes.

Minnesota Power reports success in communicating the utility's need for cost recovery to customers, especially its large customers. Minnesota Power believes large customers in particular are likely to understand that businesses must cover their fixed costs to survive. Minnesota Power further reports that its large customers understand a DSM surcharge is a much more costeffective way to recover these costs than the alternative-a general rate case.

Choosing Different Allocation Mechanisms for Cost Recovery. We collected data on how states allocate the costs of DSM-induced revenue losses to utility customers. We did not explore the possible effects of different allocation mechanisms on the effectiveness of NLRA. Thus, we do not include the item here as a condition contributing to NLRA effectiveness, but as a possible condition that states and utilities should consider. 
Our reasoning is that the choice of cost allocation mechanisms may affect the overall administrative burden of NLRA on regulators and utilities (D. Schultz, California Public Utilities Commission, personal communication, August 1994). The administrative burden may increase if DSM savings must be tracked at a disaggregated level for cost recovery.

Certain states elect to recover DSM costs from specific classes according to the levels of savings achieved by program participants from each rate class. These states must be able to classify participants, their lost revenues, and their DSM savings by rate class to properly allocate DSM costs. In principle such a rate-class-specific allocation mechanism results in a more detailed and burdensome accounting structure to track program participation and program impacts.

In contrast, many states allocate DSM costs to all rate classes; that is, total DSM costs are spread across all $\mathrm{kWh}$ sales so that every customer is paying the same charge per $\mathrm{kWh}$. In principle, this type of cost allocation can rely on a simple aggregate tracking of DSM program savings. The key is to develop a reasonably accurate annual estimate of total utility DSM program savings. We believe states and utilities should explicitly consider their preferred cost allocation mechanisms as they refine or develop their NLRA approach.

\section{Achieving Policy Goals}

Indicators of Achieving Policy Goals. NLRA is intended to remove a disincentive to utility investment in DSM. The larger policy goal is to make utilities indifferent to investment in demand or supply resources or, stated another way, to make demand and supply investments equally profitable. Has NLRA contributed to achieving this policy goal?

To assess NLRA's effectiveness in achieving this policy goal, we must identify indicators of effectiveness. We identify four such indicators. The first indicator is qualitative and consists of reports from our interview subjects. Our remaining indicators are quantitative and include observations about the relationship between net lost revenue recovery and utility investment in $\mathrm{DSM}^{26}$ In looking for quantitative indicators of NLRA's contribution to a policy goal, our fundamental presumption is that the prior existence of the lost revenue disincentive to DSM will lead to utility underinvestment in DSM. After the implementation of NLRA therefore, we expect to see an increase in DSM investment.

The reports from our interviews with regulatory and utility staffs are unanimous. Everyone we interviewed indicated that lost revenue recovery addresses an important disincentive to utility DSM investment. New York, which is widely cited as abandoning NLRA in favor of decoupling, reported that in the absence of decoupling, NLRA is essential to secure serious utility

\footnotetext{
${ }^{26}$ These indicators are not the only ones we considered. NLRA mechanisms might also be expected to increase the range of DSM programs utilities offer or to increase utility DSM investment over time. We did not collect individual utility program plans for detailed review; this task was outside the scope of our study. We also did not analyze individual utility DSM expenditure patterns over time because most utilities with NLRA have not had a mechanism in place for very long. This seriously constrains the observations available for any time-series analysis.
} 
commitment to DSM. When we asked if NLRA had altered their utilities' approach to DSM, and if so, how, the principal reason subjects gave was that net lost revenue recovery makes the utility financially whole with respect to demand-side investments. By making utilities revenue neutral, utility shareholders are protected. As described by several Minnesota utilities, this basic change in DSM's effect on utility finances leads to other important changes, including greater commitment to DSM by utility management, which increasingly views DSM as a business opportunity rather than a regulatory obligation.

Eight of ten states report that DSM rate-making reforms led to substantial changes in either the type or scope of programs utilities offered. Utilities that had previously focused their DSM efforts on information and audit programs subsequently designed and marketed direct installation or customer incentive programs. Utilities that had included customer incentives for certain programs expanded the scope and level of these incentives. Some utilities augmented substantially their almost exclusive focus on load management programs by marketing energy efficiency programs as well.

Connecticut and Minnesota are the reported exceptions to these trends. In Connecticut, utility DSM expenditures actually declined after the advent of DSM rate-making reforms. Connecticut utilities may have already been responding to concerns about future industry restructuring and growing competition. We will return to this point shortly. Minnesota already had extensive legislative and regulatory involvement and support for utility DSM activities. For this reason, Minnesota regulatory staff do not report substantial increases in utility DSM investments in response to NLRA or other DSM rate reforms.

The trends in utility DSM investment reported by our interview subjects are largely confirmed from data we collected on DSM expenditures. ${ }^{27}$ The tables for eight states in Appendix A (Arizona, Indiana, Maryland, Massachusetts, Minnesota, New York, Oregon, Vermont) report utility DSM expenditures for more than one year. In five of these eight states, utility DSM expenditures increase with the advent of DSM rate-making reform. In the sixth state (Arizona), DSM expenditures increase for one utility and decrease for the other. In the seventh state (Massachusetts), DSM costs rise for Boston Edison, remain steady for Western Massachusetts Electric, but decline for the smaller utilities. In New York, the eighth state, DSM expenditures increase for all utilities except Central Hudson Gas \& Electric.

ORNL completed an analysis of recent historical and projected utility DSM activity (Schweitzer and Young 1994). Using data reported by utilities to the Energy Information Administration and utility responses to an ORNL survey, Schweitzer and Young examined the relationship between utility DSM activity and states that report having regulations to allow utilities to recover lost revenues. The investigators found a significant positive relationship between these states and

${ }^{27}$ For the comparisons in the above paragraph, DSM expenditures inchude utility program costs and incentive awards (where applicable). See Appendix A for details. 
three measures of statewide DSM activity: 1992 DSM expenditures, 1992 reported energy savings, and projected 1997 energy savings.

Our study identified states where utilities are recovering lost revenues from DSM. In contrast, Schweitzer and Young examined states that report having regulations to allow lost revenue recovery. Chapter 3 demonstrates that while many states have regulations or policies about lost revenue recovery, only a subset of these states have active mechanisms. As a result, we revisited Schweitzer and Young's data. We identified twelve states where utilities recovered lost revenues from DSM program activities in 1992. Because our interest is in understanding if lost revenue recovery is related to utility behavior and not in assessing the relative effectiveness of different lost revenue recovery approaches, we grouped together states with either active NLRA or decoupling mechanisms as both provide utilities with lost revenue recovery. We compared statewide utility DSM expenditures, expressed as a percent of total statewide utility revenues, for states with and without active lost revenue recovery mechanisms. We repeated this exercise using 1993 data summarized by Hadley and Hirst (1995). By 1993, we identified thirteen states that had net lost revenues restored through either an NLRA or decoupling mechanism.

As Figure 3 shows, utilities in states with either an active NLRA or decoupling mechanism spent more than twice as much on DSM as utilities in states without these mechanisms. This difference is clearly significant in both 1992 and 1993.

Linking specific policies with specific outcomes is notoriously difficult. We cannot unequivocally state that NLRA mechanisms are the cause of increased utility DSM investments. We must remember that nine of ten states we studied implemented NLRA as part of a package of DSM rate-making reforms that included performance incentives and program cost recovery. In practice, isolating the contribution of NLRA from these other reforms is not possible. The reports from our interviews and our review and assessment of DSM expenditure patterns suggest that the expected result from DSM rate reform is consistent with reported and observed results about utility behavior. As more data on utility DSM behavior become available, researchers will be able to examine changes in utility activities over time in response to specific policies.

Conditions That Support Achieving Policy Goals. Having an administratively effective NLRA mechanisms does not necessarily ensure achieving larger utility policy goals. We describe here three conditions that support achieving policy goals and a concern shared by a number of subjects we interviewed about the prospects for making further progress on these goals.

As we described in Chapter 3, several states allow utilities to recover net lost revenues in principle, but in practice impose conditions that make actual recovery unlikely or uncertain. Morgan (n.d.) suggests that an effective way to thwart the policy goals of net lost revenue recovery is to limit recovery to instances where utility sales have declined relative to test-year sales levels. Michigan is an example of a state with a sales test condition on net lost revenue recovery. Michigan utilities apparently do not even bother to file for revenue recovery under this circumstance (G. Stojic, Michigan PSC, personal communication, April 1994). We concur with 


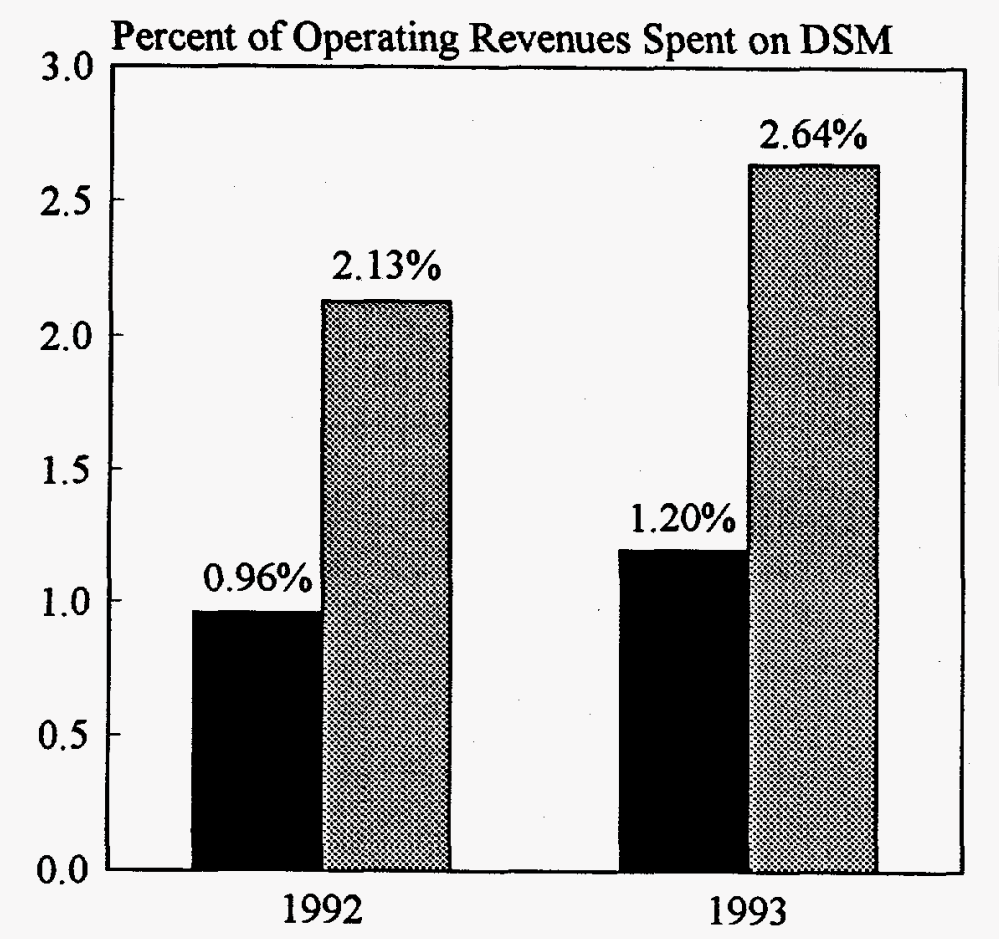

States Without NLR Recovery
States With NLR Recovery
(includes NLRA \& decoupling)

1992 Data

t-test one-tail $=3.57$

Probability $=0.0004$

1993 Data

t-test one-tail $=2.36$

Probability $=0.016$

Morgan's observation-we are not aware of any utility subject to this condition that has recovered net lost revenue from DSM programs. Developing such restrictive conditions for net lost revenue recovery thwarts the very policy goal that motivated industry experts to identify financial disincentives to utility demand-side investments.

Events in Illinois suggest that clear support from the state legislature for achieving equitable treatment of demand and supply resources is important. Regulatory staff from Connecticut, Maryland, Minnesota, and Oregon also noted that legislative support was important to achieve utility policy goals. As we noted earlier, in states where the PUC's authority to address ratemaking issues outside the GRC is ambiguous or clearly prohibited, action by the state legislature is needed to reduce the chance that achievement of policy goals will be frustrated by court challenges. Legislative support for NLRA also sends a clear signal to stakeholders that the state supports changes in the utility investment environment.

NLRA, in conjunction with other regulatory policies such as full recovery of utility program costs and the availability of utility performance incentives and rewards, can operate together to change utility behavior. Thus, states should consider implementing NLRA mechanisms as part of a more comprehensive package of DSM regulatory reforms if the objective is to motivate utilities to assess equitably demand and supply resources. 
Finally, as recent utility industry literature suggests, the prospect of industry restructuring and the increasingly competitive nature of electricity generation, may have a chilling effect on any utility investment that raises costs and rates. ${ }^{28}$ Current DSM programs in many states, with their emphasis on rebates and customer incentives, can have immediate rate impacts. Several utilities around the country are already proposing substantial reductions in DSM budgets and a reorientation from incentive programs to information and financing assistance. ${ }^{29}$ Our interviews with utilities' staffs confirm the latter trend.

The current uncertainty about the future of the electricity industry is also affecting those utilities that continue to see a role for DSM. Most of the utilities we interviewed expressed concern about the adverse rate impacts of DSM cost recovery. Because net lost revenues can accumulate between rate cases and are a major component of DSM cost recovery, these utilities were particularly concerned about the rate impacts of net lost revenue recovery. As a result, utilities concerned with rates may choose to forego net lost revenue recovery and instead recover only program costs or performance incentives.

The most sobering assessment of the likelihood of DSM continuing its current role in a more competitive utility environment was provided by a utility executive we interviewed. In his view, NLRA effectively addresses the short-term problem of revenue losses between GRCs. NLRA does not address a long-term problem, which is that energy efficiency erodes the revenue base of the utility. Ultimately, this erosion will result in fixed costs being spread across a smaller revenue base than the utility would experience without DSM. This relative erosion in the utility's revenue base will lead to rate increases. The source of the utility executive's concern is that independent power suppliers are not faced with these same upward pressures on their costs and the resulting prices they can charge for electricity.

In our view, the role of DSM will continue to develop in response to customer and industry needs. For states and utilities embarking on the restructuring path, DSM may be targeted at distribution constrained areas or at customers and loads that might otherwise leave the utility system. Regulatory and utility concern with net lost revenues may change as DSM changes. Utilities, for example, may be less concerned with net lost revenues if DSM is targeted as in our preceding example or if fuel adjustment clauses are eliminated. Meanwhile, many states and utilities are on the sidelines, observing the industry restructuring debate and perhaps wondering if restructuring will develop as quickly as some prognosticators once thought shortly after the wake of the California PUC's 1994 proposal.

For any state serious about the role of DSM in an electricity future, an NLRA or decoupling mechanism is essential to capturing utility interest and commitment to DSM. NLRA, because it

\footnotetext{
${ }^{28}$ See the April and June 1994 issues of The Electricity Journal, for example, to observe how concern with competition and restructuring currently dominates debate in the utility industry.

${ }^{29}$ See Electric Utility Week's Demand-Side Report (1994a, b, c, and d), for examples.
} 
does not entail as substantial a departure from traditional regulation as decoupling, may be the most appropriate mechanism for states beginning DSM regulatory reform. If, however, states are tempted to apply sales and earnings tests to their NLRA mechanisms, they should move to decoupling to both satisfy their concern with total fixed cost recovery and to still remove the net lost revenue disincentive to utility pursuit of DSM. 


\section{EFFECTS OF DIFFERENT MECHANISMS ON UTILITY FINANCES}

Our review of state-specific NLRA mechanisms identified three basic types with actual cost recovery. In this chapter, we examine how these different mechanisms affect utility finances. Our objective is to illustrate the relationships between each NLRA mechanism and utility cash flow and rates.

The three mechanisms described in Chapter 3 are a retrospective surcharge, a prospective surcharge, and a deferred account. The retrospective surcharge is designed to recover net lost revenue from a previous year or years. The surcharge is typically based on either estimated or verified DSM savings and net lost revenue impacts. The prospective surcharge is set to recover net lost revenue as the losses are incurred. This surcharge relies on forecasts of DSM savings and net lost revenue impacts. Net lost revenues based on DSM program estimates are later reconciled with DSM measurement and evaluation results. The deferred account approach requires the utility to maintain estimates of net lost revenue and apply for revenue recovery in an upcoming GRC. As part of the GRC process, the state PUC will revise base rates to allow for recovery of authorized net lost revenue incurred since the previous rate case.

\section{FINANCIAL ANALYSIS OF DIFFERENT NLRA MECHANISMS}

We developed an extension of the ORNL Financial Model (ORFIN) to study the implications of the three NLRA mechanisms on utility finances. ORNL researchers designed ORFIN to answer questions about the effects of utility and regulatory decisions on utility finances (Hirst and Hadley 1994). In our analysis, we are interested in the effect of net lost revenue recovery on utility cash flow and rates.

We apply ORFN to a hypothetical utility with substantial DSM programs-programs that reduce utility electricity sales by almost $3 \%$ annually. The revenue impacts of these DSM programs are not included in the utility's base rates. Table 4 presents the key assumptions in our analysis. We discuss below a few of the more important assumptions that will facilitate interpretation of the results.

Our hypothetical utility is quite stable. The utility is not experiencing any load growth or price escalation. The utility's load responds to seasonal changes in weather, with greater sales during the summer and winter. The utility's DSM programs include a combination of base-load measures affecting lights and motors as well as space-conditioning measures. The programs have a proportionately greater effect on customer demand during the summer and winter. The full annual program impacts begin in January of each year; we do not attempt to simulate the impact 
Table 4. Key Assumptions in Financial Analysis of NLRA Mechanisms

\begin{tabular}{|c|c|c|c|c|c|c|}
\hline \multicolumn{2}{|c|}{ Utility Characteristics } & & \multicolumn{4}{|c|}{ NLRA Mechanisms } \\
\hline & & & \multirow[t]{2}{*}{$\begin{array}{c}\text { Retrospective } \\
\text { Surcharge }\end{array}$} & \multicolumn{2}{|c|}{$\begin{array}{c}\text { Prospective } \\
\text { Surcharge }\end{array}$} & \multirow[t]{2}{*}{$\begin{array}{l}\text { Deferred } \\
\text { Account }\end{array}$} \\
\hline & & & & Case 1 & Case 2 & \\
\hline Total sales & $10,000 \mathrm{GWh}$ & Recovery period & 12 months & 12 months & 12 months & 36 months \\
\hline $\begin{array}{l}\text { Annual sales } \\
\text { growth }\end{array}$ & 0 & $\begin{array}{l}\text { Lag setting } \\
\text { surcharge }\end{array}$ & 9 months & no lag & no lag & no lag \\
\hline System price & $7 \notin / \mathrm{kWh}$ & $\begin{array}{l}\text { NLR forecast annual } \\
\text { accuracy }\end{array}$ & no forecast & $\begin{array}{l}100 \% \\
\text { accurate }\end{array}$ & $\begin{array}{c}50 \% \\
\text { overforecast }\end{array}$ & no forecast \\
\hline Avoided cost & $4 \notin / \mathrm{kWh}$ & Amortization period & none & none & none & 36 months \\
\hline Next rate case & January 1997 & Interest on balance & $9.00 \%$ & $9.00 \%$ & $9.00 \%$ & $9.00 \%$ \\
\hline $\begin{array}{l}\text { Interval } \\
\text { between rate } \\
\text { cases }\end{array}$ & 3 years & $\begin{array}{l}\text { Total NLR } \\
\text { recovered w/interest } \\
\left(000^{\prime} \mathrm{s} \$\right)^{1}\end{array}$ & 50,420 & 49,100 & 48,370 & 57,600 \\
\hline DSM programs & $\begin{array}{r}\text { Res/Comm: } \\
\text { HVAC and } \\
\text { weatherization } \\
\text { measures }\end{array}$ & & & & & \\
\hline $\begin{array}{l}\text { Annual DSM } \\
\text { savings }\end{array}$ & $\begin{array}{r}275 \text { GWh per year } \\
\text { for three years }\end{array}$ & & & & & \\
\hline
\end{tabular}

1. Actual net lost revenue incurred in each case is $\$ 49,050$ thousand, without interest. 
of program ramp-up over time. The programs run for three years from 1994 through 1996. For the retrospective surcharge, we assume that evaluation results are available to permit setting the surcharge nine months after the close of the initial program year. For the prospective surcharge, we assume that any change in the surcharge to include the reconciliation results takes place nine months after the end of each program year. We assume the deferred account has an amortization period of three years.

The figures that follow illustrate some of our results. We emphasize two points before we move to a discussion of these figures. First, each of these NLRA mechanisms is fixed-cost-recovery neutral relative to the no-DSM case, both in our simulation and in practice, when implemented properly. The total revenue returned to the utility in our simulations differs due to the monthly interest the utility accumulates on the unamortized monthly net lost revenue balance. ${ }^{30}$ The differences we illustrate are in the timing and magnitude of utility cash flow and rate impacts. Second, this is a simplified analysis. The exact values we generate, based on a hypothetical utility with hypothetical DSM programs, are far less important than the trends and directions the values take.

We examined many different cases, but present two here that are representative of the range of results we observed. Figure 4 presents the monthly cash flow effects of net lost revenue to the utility. We define cash flow as the monthly difference between net lost revenue recovered and net lost revenue incurred. Figure 4 presents two cases for the prospective surcharge. The first case assumes a $100 \%$ accurate annual forecast of net lost revenue for the prospective surcharge. The second case assumes the utility overforecasts net lost revenue by $50 \%$. The cash flow cycles evident for each mechanism are related to our assumptions about seasonal load and program impacts.

The retrospective surcharge and the deferred account have the same effect on cash flow until the surcharge takes effect in October 1995. After January 1997, when the utility's base rates are revised, the cash flow effects of the retroactive surcharge and the deferred account mechanism are essentially identical until October 1997. At this point, the retrospective surcharge is revised to include net lost revenues incurred due to DSM activities in the 1996 program year. Because the deferred account mechanism begins recovering net lost revenue after the retrospective surcharge, the deferred account must continue to recover lost revenues after the retrospective surcharge is set to zero.

In Figure 4, utility cash flow from the $100 \%$ accurate prospective surcharge has a much smaller standard deviation and range than the other two mechanisms. Table 5 provides a summary of the means, standard deviations, and ranges for each mechanism's monthly cash flow. The utility is

\footnotetext{
${ }^{30}$ As Table 4 shows, the prospective surcharge under the second case recovers fewer net lost revenues than actually incurred due to the unamortized interest owed ratepayers. The interest accumulates from overrecovery of net lost revenue between rate cases.
} 
Figure 4. The Effects of NLRA Mechanisms on Utility Cash Flow

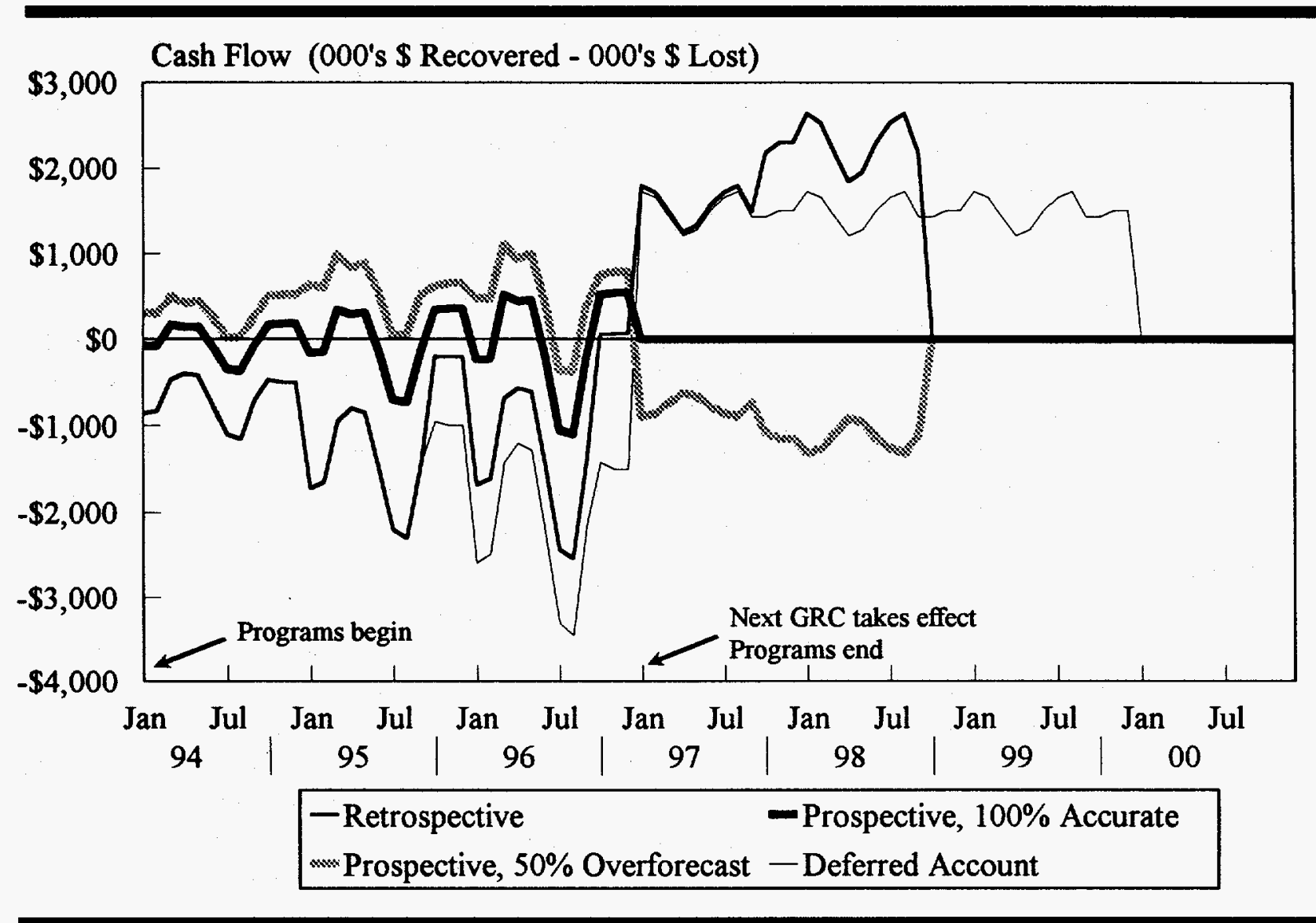

Table 5. The Effects of NLRA Mechanisms on Utility Cash Flow (000's \$)

\begin{tabular}{lccc} 
& Monthly Mean & Standard Deviation & Range \\
\hline $\begin{array}{l}\text { Retrospective Surcharge } \\
\text { Prospective Surcharge- }\end{array}$ & 119 & 1,569 & 5,189 \\
$\begin{array}{l}100 \% \text { Accurate } \\
\text { Prospective Surcharge- }\end{array}$ & 0 & 423 & 1,643 \\
$50 \%$ Overforecast & -58 & 780 & \\
Deferred Account & 72 & 1,551 & 2,433 \\
& & & 5,183 \\
\hline
\end{tabular}




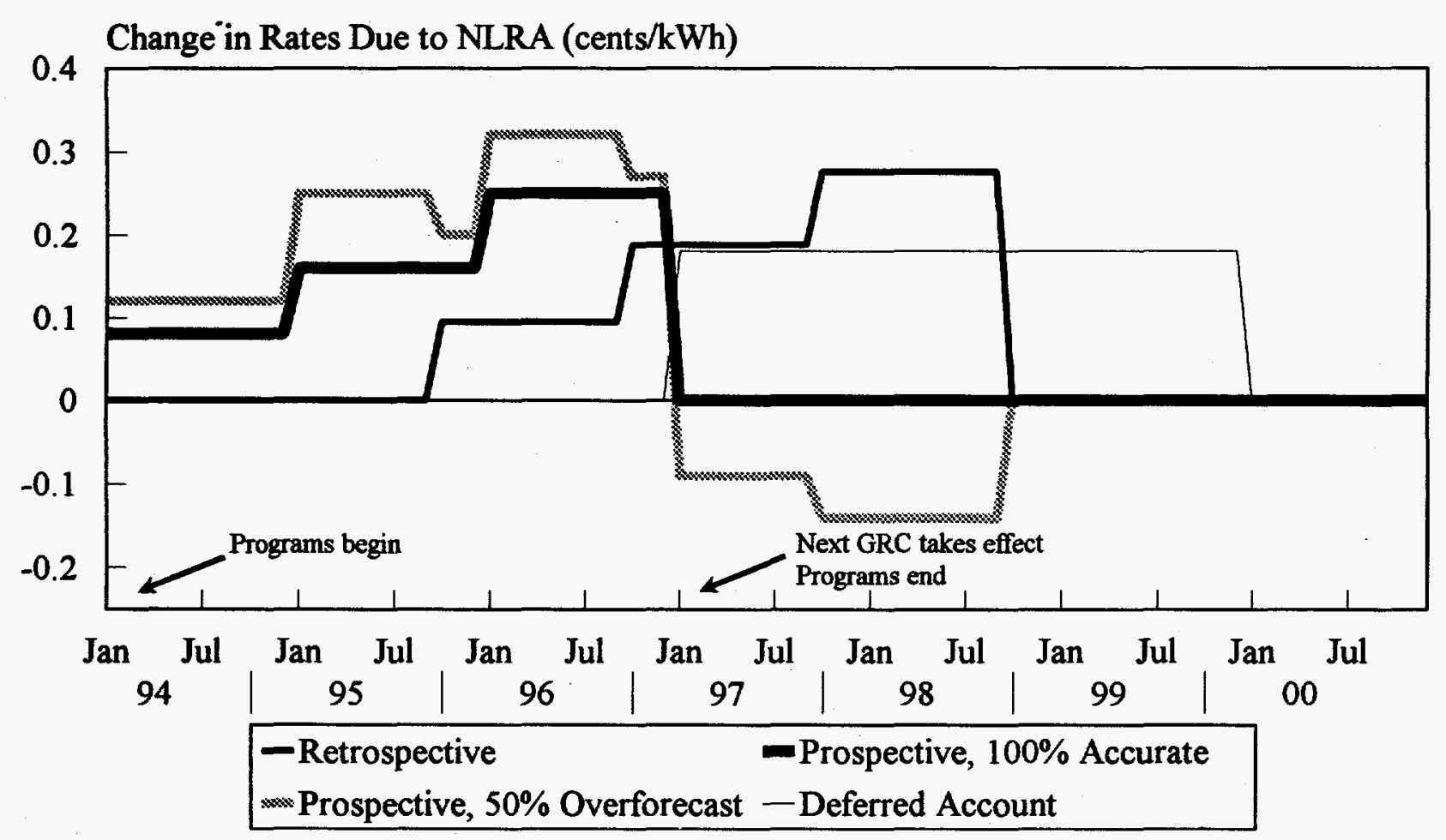

also closer to a cash-flow neutral position than with the other two mechanisms. As Table 5 shows, the mean monthly cash flow for a prospective surcharge with a $100 \%$ accurate annual forecast is zero. Forecasts of net lost revenue are unlikely to be $100 \%$ accurate, however. The second case assumes the utility overforecasts net lost revenue by $50 \%$, which we would characterize as a large short-term forecasting error. Here we see that the cash flow standard deviation and range widen due to the initial overcollection of net lost revenue and the subsequent need to return the surplus revenues to ratepayers. The volatility in monthly cash flow values for the prospective surcharge is still smaller than what we observe for the other two NLRA mechanisms.

In Figure 5 we take the same examples shown in Figure 4 and look at the effect these three NLRA mechanisms have on utility rates. The utility's base rate between rate cases is $7 \notin / \mathrm{kWh}$. The retrospective surcharge and the $100 \%$ accurate prospective surcharge have very similar effects on rates. The major difference is in the timing of the rate impact: the prospective surcharge recovers lost revenues before the retrospective surcharge. The deferred account recovers the net lost revenues incurred during three years of program operation with a single fixed rate increase that lasts for three years, which is the assumed amortization period. A longer amortization period will lead to a smaller rate increase than the one shown here. 
The maximum rate impact of the $100 \%$ accurate prospective surcharge is slightly less than the retrospective mechanism, but the rate increase occurs immediately. If the prospective surcharge is based on a $50 \%$ overforecast of net lost revenue, the initial and subsequent rate impacts are larger until October 1996. This prospective surcharge results in the largest rate impact, a $4.6 \%$ increase in base rates between January and September of 1996. As the results of the initial reconciliations are introduced to the prospective surcharge in October 1995 and 1996, the rate impact declines. Subsequent reconciliations lead to reduced rates as revenues are returned to ratepayers. We doubt that in practice a utility will repeatedly overforecast net lost revenue to this extent. As a result, we would not expect to see reconciliation effects as large as Figure 5 depicts.

\section{SUMMARY}

All three NLRA mechanisms are fixed-cost-recovery neutral; all make the utility whole with respect to net lost revenue. The prospective surcharge approach appears to expose the utility to less variation in cash flow as a result of net lost revenue. Our results show that increasing the accuracy of the net lost revenue forecast reduces the volatility in monthly cash flow. The retrospective surcharge and the deferred account approach appear to expose the utility to similar variation in monthly cash flow. The prospective and retrospective surcharges have similar effects on rates. The primary difference between these two approaches is in the timing of these effects. Compared to the prospective surcharge, the retrospective surcharge and the deferred account approach delay net-lost-revenue-induced rate increases. Overforecasts of net lost revenue in the prospective surcharge lead to relatively larger initial increases with subsequent rate reductions. 


\section{CONCLUSIONS AND RECOMMENDATIONS}

\section{CONCLUSIONS}

\section{NLRA's Feasibility}

We reviewed NLRA mechanisms in ten states where utilities have recovered, or are authorized to recover, net lost revenue from utility DSM programs. NLRA mechanisms are feasible, as demonstrated by the number of states with active mechanisms. Central Hudson Gas \& Electric in New York and Western Massachusetts Electric Company have used an NLRA mechanism since 1990, while utilities in Indiana, Oregon, and Vermont have recovered lost revenues through an NLRA mechanism since 1991. The remaining five states have had active NLRA mechanisms since 1992 or 1993. Kentucky, New Jersey, Ohio, and Utah are prepared to implement lost revenue recovery through an NLRA mechanism. NLRA mechanisms are the most prevalent approach considered by states developing policies on lost revenue recovery from utility DSM programs.

\section{NLRA's Implementation Success}

We examined two aspects of NLRA's success. The first aspect refers to the process established for design and implementation of the NLRA mechanism, including the submission and review of utility filings. The second aspect relates to the achievement of policy goals. The focus of our assessment of NLRA's success was again on the ten states with active policies.

Seven states report no substantial problems with their NLRA mechanism, while three states report problems, concerns, or dissatisfaction with some aspect of NLRA. Based on the experiences of these seven states, we conclude that NLRA mechanisms can be successfully implemented. Further, we identified ten conditions that contribute to successful NLRA implementation. The first three conditions listed below are the most important for a successful implementation.

Avoiding a Strict Ex Post Approach to DSM Measurement. The clearest indicator of implementation success is a state's approach to DSM measurement. DSM program performance is linked directly to net lost revenue incurred by a utility. In most states, a utility's initial estimate of net lost revenue is based on a DSM program savings forecast. Most states require utilities to verify DSM program savings to collect net lost revenues. This verification typically requires reconciling predicted program performance with DSM measurement and evaluation studies. States that require utilities to reconcile predicted to observed program participation levels report satisfaction with their NLRA mechanism, as do the affected utilities. States that require utilities to reconcile predicted total program savings to results from an impact evaluation study are less satisfied with their mechanisms, as are the affected utilities. A strict ex post approach to verify 
DSM program savings for net lost revenue recovery is unnecessary, particularly in the first few years an NLRA mechanism is operating.

Involving Stakeholders in the Process. Several states report substantial benefits from involving stakeholders in the NLRA process. These benefits include increasing resources available to review utility filings, providing a forum for discussing issues and resolving conflicts, and, as a result, reducing the likelihood of litigating NLRA issues before PUCs. Connecticut and Maryland use their collaborative process to maintain stakeholder participation in NLRA while Minnesota uses informal but influential working groups. Stakeholder participation at a minimum includes review of utility net lost revenue estimates but can be usefully expanded to include design and implementation of specific NLRA mechanisms and reviews of utility DSM program and evaluation plans.

\section{Setting Conditions for Lost Revenue Recovery Related Directly to DSM Program} Operation and Performance. An effective NLRA mechanism must include certain conditions for utility net lost revenue recovery. These conditions should be well articulated and understood by the relevant regulatory agencies and the affected utilities. The conditions most compatible with effective NLRA mechanisms are (1) review and approval of the utility's DSM plan by the appropriate regulatory agency and (2) requiring the utility to demonstrate or verify that its DSM programs are achieving savings and that, as a result, it is incurring a net revenue loss. The imposition of other conditions, such as sales or earnings tests, may not only increase administrative burdens on utility and regulatory staffs, but inhibit attainment of DSM policy goals.

Establishing a Frequent and Regular Filing Schedule. Utilities should have the opportunity to file frequently and regularly for net lost revenue recovery or for approval of net lost revenue estimates. Frequent and regular filings provide the utility with more opportunities for feedback on the adequacy of its filing and more certainty that revenues ultimately will be recovered. In most cases, an annual filing is sufficient to secure these benefits.

Allowing Flexibility for Both the PUC and the Utilities. Our observations suggest that PUCs willing to consider and experiment with different NLRA approaches fare better than PUCs that mandate an approach or initially apply a single approach to all utilities. PUC flexibility is further augmented by giving utilities the freedom to develop the cost recovery mechanism that removes the disincentives to utility DSM investment. Initially implementing NLRA mechanisms as pilot programs with limited operating lives also establishes a clear opportunity to assess each mechanism's performance and determine the future course of the programs.

Receiving Clear Legislative Authority to Set Incentives and Cost Recovery. The Illinois case is a clear example of the chilling effect that ambiguity about a PUC's authority to address ratemaking reform issues can have on net lost revenue recovery. As a result, we see benefits for removing this ambiguity, particularly in states where a PUC is prohibited from addressing rate issues outside a GRC. 
Addressing Cost Recovery Issues First. PUCs almost always consider net lost revenue recovery along with other DSM rate-making reforms and the reorientation or redesign of utility DSM efforts. PUCs should first hammer out the principles and then the details on both net lost revenue recovery and program cost recovery before discussing incentives and designing new programs.

Having Previous Experience with IRP. In many states, DSM rate-making reforms were preceded by more general proceedings on IRP. Connecticut, Maryland, and Minnesota found this approach helpful because the proceedings initiated a dialogue on issues such as DSM financial disincentives and introduced regulators to concepts like net lost revenue. We believe it is possible to initiate effective DSM rate-making reforms without first engaging in an IRP proceeding, but we see the benefits to setting the groundwork for reform through an exploration of IRP principles and experiences in other states.

Having Previous Experience with Balancing Accounts. Surcharges are the most common means to implement net lost revenue recovery. NLRA surcharges are associated with balancing accounts, which record the net lost revenue collected and ensure that the collected revenue does not deviate over time from the authorized amounts. A state may feel more comfortable with the administrative technicalities of an NLRA surcharge if it has previous experience with balancing accounts.

Maintaining Customer Communication. States and utilities should not overlook the customer in net lost revenue recovery in particular and DSM rate reforms in general. While no one reported excessive customer complaints from implementing DSM rate reforms, a few states indicated that some customers do call their utilities when a visible surcharge changes. Utilities should consider communicating the need for cost recovery to customers, especially large customers. Large customers may understand a DSM surcharge is a much more cost-effective way to recover these costs than the alternative-a general rate case.

\section{NLRA's Policy Success}

The second aspect of success for NLRA relates to the achievement of policy goals. NLRA is intended to remove a disincentive to utility DSM investment to help make utility investment in demand and supply equally profitable. We collected information that suggested that the expected result from DSM rate reform, which includes NLRA, is consistent with reported and observed results about utility behavior. First, all subjects we interviewed agreed that NLRA addresses an important disincentive to utility DSM investment. Eight of ten states report that DSM ratemaking reforms led to substantial changes in either the type (shifting from load management to energy-efficiency programs, for example) or scope (offering incentives on a wider range of efficiency measures, for example) of programs utilities offered.

Second, the data we collected on net lost revenues recovered and DSM program investment are largely consistent with the qualitative assessments gathered through interviews. Utility DSM 
investment increased as DSM rate reforms were implemented. Further, DSM program investments are rising more rapidly for utilities in these states than utility operating revenues.

Finally, we found that utilities in states with a mechanism for restoring net lost revenue from DSM (either an NLRA or a decoupling mechanism) invest more than twice as much in DSM as do utilities in states without such mechanisms. Our result is consistent with an earlier ORNL study, which found a significant positive relationship between states reporting regulations allowing utilities to recover lost revenues and DSM expenditures and reported energy savings.

We identified three basic NLRA mechanisms: (1) a retrospective surcharge; (2) a prospective surcharge; and (3) a deferred account. Our financial analysis demonstrated that when properly implemented, all three mechanisms completely offset the net revenue losses utilities incur through operation of DSM programs. The mechanisms differ, however, with regard to a utility's cash flow and the timing and size of the rate impacts of cost recovery. So long as the net lost revenue forecast used to determine the prospective surcharge is reasonably accurate, this mechanism exposes the utility to less variation in cash flow and a more immediate rate increase than do the other two mechanisms.

\section{RECOMMENDATIONS}

We turn now to the project's final objective: to suggest improvements to NLRA mechanisms. The following recommendations are drawn directly from the above conclusions.

Reconcile Net Lost Revenue Estimates to Program Participation: Utilities recovering lost revenues from DSM programs should verify program performance. The quality of DSM program evaluation data are likely to improve over time as utilities and regulators put more resources into this area. Recognizing this, we recommend reconciling net lost revenue estimates to observed program participation levels rather than energy and demand savings. As they become available, impact evaluation results should be used to revise measure or participant energy savings estimates in subsequent net lost revenue forecasts. Evaluation efforts should also focus on estimating free ridership and spillover effects to adjust observed program participation rates.

\section{Regulators and Utilities Should Agree on the Methods and Assumptions Used to Estimate} Measure Savings: Regulators and utilities should agree in advance on the methods and assumptions used to estimate measure savings in the first few net lost revenue filings. Pursuing such agreements is likely to greatly reduce disputes over net lost revenue estimates. The energy use characteristics of buildings and equipment are generally well understood and can be accurately estimated using thermodynamic concepts, engineering principles, and economics. The assumptions supporting energy use estimation, however, are often in error. Open discussion of these assumptions will help target evaluation efforts to key variables such as building operating hours and connected equipment load that promise to improve the accuracy of measure savings and net lost revenue estimates. 
Concentrate Scarce Evaluation Resources on the Most Important DSM Programs: DSM impact evaluations are often complex, lengthy, and expensive. Utilities should concentrate scarce impact evaluation resources on the largest and most important DSM programs. DSM savings estimates, and accompanying net lost revenue estimates, for smaller programs should be based on observed participation levels and engineering estimates of measure savings. These engineering estimates can be refined as needed based on impact evaluations the utility conducts on its larger programs. Evaluation efforts should also focus on collecting data needed to refine engineering algorithms and assumptions, with particular attention to gathering data on customer characteristics that match data used in the engineering estimates. Understanding why evaluation results and DSM forecasts may be similar or different is probably more important than identifying similarities and differences.

Rely More on DSM Verification Efforts Rather Than Impact Evaluations: DSM verification is an important alternate strategy to strict reliance on impact evaluations. DSM verification focuses on establishing the reasonableness of data on DSM performance that utilities have already developed and provided to regulators. DSM verification includes reviewing engineering estimation procedures, reviewing utility documentation, obtaining external assessments of utility evaluation studies, and making on-site inspections of measure installation, retention, and performance. Regulators must ensure that results from completed impact evaluations and verification efforts are included in subsequent utility DSM forecasts and net lost revenue estimates.

Use Stakeholders in the NLRA Process: If utilities are proposing substantial DSM programs, utilities and regulators should actively engage other relevant stakeholders in the NLRA process. Engaging stakeholders early in the process not only helps avoid later disputes, but is also a reasonable response to the demands of DSM-successful programs can be complicated to design and their evaluation often requires sophisticated and advanced analytical abilities. The collective talents of a multidisciplinary team representing stakeholders provide important resources for utilities and regulatory agencies. These resources can be harnessed to review program plans, evaluation plans, evaluation results, and net lost revenue filings.

Set Conditions for Net Lost Revenue Recovery Consistent with the Objectives of NLRA Mechanisms: Utilities should gain approval for their DSM programs from the appropriate regulatory agency. Utilities should also demonstrate or verify, through the methods we discussed above, that their programs yield energy savings. Any additional conditions on the collection of net lost revenues should be considered carefully, balancing the achievement of DSM policy goals against other policy goals. Sales tests and earnings tests, in particular, are not consistent with the objectives of NLRA mechanisms.

Implement NLRA on a Trial Basis: States should initially apply NLRA on a trial basis with an explicit provision to review the approach and results after two or three years. An NLRA trial period will encourage regulators and utilities to experiment with different approaches and conditions and reduce the risks from committing prematurely to a single approach. 
Consider a Prospective Surcharge if an Objective is to Reduce Impacts on Utility Cash Flow: A prospective surcharge is designed to recover lost revenues as incurred by the utility. The accuracy of the surcharge depends on the accuracy of the underlying DSM program forecast. A reasonably accurate annual DSM forecast results in a surcharge that reduces the variation in utility cash flow relative to a retrospective surcharge or a deferred account. The prospective surcharge will, however, immediately increase rates to utility customers.

Consider a Retrospective Surcharge or Deferred Account if an Objective is to Delay the Rate Impacts of Cost Recovery: A retrospective surcharge and a deferred account recover DSM-induced revenue losses after they occur. These mechanisms also delay the increase in customer rates relative to a prospective surcharge. The delay can be several months or years, depending on the revenue recovery timetable the regulatory agency establishes for each utility.

\section{Concluding Comment}

States serious about the role of DSM in an electricity future should consider an NLRA or decoupling mechanism as essential to capturing utility interest and commitment to DSM. NLRA, because it does not entail as substantial a departure from traditional regulation as decoupling, may be the most appropriate mechanism for states beginning DSM regulatory reform. If, however, states are compelled to apply sales and earnings tests to their NLRA mechanisms, they should move to decoupling to both satisfy their concern with total fixed cost recovery and to still remove the net lost revenue disincentive to utility pursuit of DSM. NLRA mechanisms may ultimately be best suited to a transitional strategy as the industry moves from the traditional regulation of an integrated monopoly to a new regulatory structure more in concert with a changing industry.

\section{ACKNOWLEDGEMENTS}

We thank all the individuals listed in Appendix B for participating in interviews, sharing NLRArelated documents, and responding to our subsequent telephone calls. This report is in large part a direct result of their contributions. We thank Tom Austin, Eric Blank, Gordon Dunn, Jim Gallagher, Rick Morgan, Mike Reid, and Tim Woolf for their helpful comments during our project scoping exercise. We thank Thomas Birmingham, Joe Branon, John Cutting, Steve Farmer, Stan Hadley, Eric Hirst, Tim Kelly, Mark Kumm, Craig McDonnell, Cathy O'Clair, and Stuart Ormsbee for providing additional state- and utility-specific DSM and financial data. Stan Hadley deserves special thanks for modifying ORFIN to enable us to conduct the utility financial analysis in Chapter 5. Thanks also to David Berry, Eric Blank, John Borchert, Joe Eto, Eric Hirst, David Johnston, Theo MacGregor, Bill Mills, Rick Morgan, Steve Pertusiello, Dennis Peterson, Karen Peterson, Mike Reid, Don Schultz, Marty Schweitzer, Lee Sparling, and Tim Woolf for their helpful comments on a draft of this report. Finally, we thank Virgie Sapp for editorial support and Ethel Schorn for assembling and distributing the final report. 


\section{REFERENCES}

Baxter, L. 1994, Application of DSM Evaluation Studies to Utility Forecasting and Planning (Draft), Oak Ridge National Laboratory, Oak Ridge, TN.

Baxter, L. and D. Schultz 1994, "Recent Program Evaluations: Implications for Long-Run Planning," Proceedings of the ACEEE 1994 Summer Study on Energy Efficiency in Buildings, Vol 7:23-33, American Council for an Energy-Efficient Economy, Washington, D.C.

Bonbright, J., A. Danielsen, and D. Kamerschen 1988, Principles of Public Utility Rates, 2nd Ed., Public Utility Reports, Inc., Arlington, VA.

Brown, M., L. Berry, R. Balzer, and E. Faby 1993, National Impacts of the Weatherization Assistance Program in Single-Family and Multi-Family Dwellings, ORNL/CON-326, Oak Ridge National Laboratory, Oak Ridge, TN.

California Public Utilities Commission 1994, Order Instituting Rulemaking and Order Instituting Investigation on the Commission's Proposed Policies Governing Restructuring California's Electric Services Industry and Reforming Regulation, R.94-04-031 and I.94-04-032, San Francisco, April 20, 1994.

Clean Air Act Amendments of 1990, U.S. Statutes at Large 104(1990):2601-05.

Cummings, M. 1992, "DSM Incentives and Performance Measurement," Proceedings, Fourth National Conference on Integrated Resource Planning, pp. 291-98, National Association of Regulatory Utility Commissioners, Washington, D.C.

Electric Utility Week's Demand-Side Report 1994a, "BG\&E's New Integrated Resource Plan Calls for Reducing DSM Incentives," McGraw-Hill, August 18.

Electric Utility Week's Demand-Side Report 1994b, "PG\&E Confirms Plans to Slash 1995 DSM Budget by $\$ 100$ Million," McGraw-Hill, September 1.

Electric Utility Week's Demand-Side Report 1994c, "SoCal Ed to Cut \$95 Million from DSM in Deal with PUC Ratepayer Advocate," McGraw-Hill, September 15.

Electric Utility Week's Demand-Side Report 1994d, "N.Y. Utilities Seek to Cut DSM Rebates to Restrain Rates in Competitive Era," McGraw-Hill, September 29.

Eto J., S. Stoft, and T. Belden 1994, The Theory and Practice of Decoupling, LBL-34555, Lawrence Berkeley Laboratory, Berkeley, CA. 
Energy Policy Act of 1992, Title I-Energy Efficiency, Subtitle B-Utilities, Section 111, January 3, 1992.

English, M., M. Schweitzer, S. Schexnayder, and J. Altman 1994, Making a Difference: Ten Case Studies of DSM/IRP Interactive Efforts and Related Advocacy Group Activities, ORNL/CON-378, Oak Ridge National Laboratory, Oak Ridge, TN.

Evaluation Working Group n.d., "DSM Evaluation Working Document," obtained from B. Carlson, Otter Tail Power, Fergus Falls, MN.

Georgia Public Service Commission 1994, Final Order in Docket No. 4229-U, Atlanta, GA, August 10, 1994.

Hadley, S. and E. Hirst 1995, DSM in a Changing Electric Industry: DSM Programs 1989 Through 1998 (Draft), Oak Ridge National Laboratory, Oak Ridge, TN.

Hirst, E. 1988, "Meeting Future Electricity Needs," Forum for Applied Research and Public Policy 3(3):26-34.

Hirst, E. 1991, Possible Effects of Electric-Utility DSM Programs, 1990 to 2010, ORNL/CON312, Oak Ridge National Laboratory, Oak Ridge, TN.

Hirst, E. 1993, Statistical Recoupling: A New Way to Break the Link Between Electric-Utility Sales and Revenues, ORNL/CON-372, Oak Ridge National Laboratory, Oak Ridge, TN.

Hirst, E. and E. Blank 1993, "Quantifying Regulatory Disincentives to Utility DSM Programs," Energy 18(11):1091-1105.

Hirst, E. and S. Hadley 1994, Effects of Resource Acquisitions on Electric-Utility Shareholders, ORNL/CON-387, Oak Ridge National Laboratory, Oak Ridge, TN.

Ignelzi P., K. Parikh, and B. Mast 1994, Integrating Results of Measurement and Evaluation Activities with DSM Impact Forecasts, Volume 1: Statistical Analysis, Pacific Consulting Services, Albany, CA.

Illinois Supreme Court 1994, Court Opinion on Petition for Review of Order of the Illinois Commerce Commission: A. Finkel \& Sons Company, and Citizens Utility Board v. Illinois Commerce Commission, and Commonwealth Edison Company, Springfield, IL, June 8, 1993

MacLeod G. and E. Haites 1994, "Evaluation of the Environmental Impacts of the Espanola Power Savers Program," Proceedings of the ACEEE 1994 Summer Study on Energy Efficiency in Buildings Vol. 4:177-83, American Council for an Energy-Efficient Economy, Washington, D.C. 
Morgan, R. n.d., "Stalking the Level Playing Field for Energy Efficiency," unpublished manuscript, U.S. Environmental Protection Agency, Washington, D.C.

Moskovitz, D. 1989, Profits \& Progress Through Least-Cost Planning, National Association of Regulatory Utility Commissioners, Washington, D.C.

Moskovitz, D. 1992, "Why Regulatory Reform for DSM," in S. Nadel, M. Reid, and D. Wolcott (Eds.), Regulatory Incentives for Demand-Side Management, American Council for an EnergyEfficient Economy, Washington, D.C., 1-19.

Moskovitz D., C. Harrington, and T. Austin 1992, "Weighing Decoupling vs Lost Revenues: Regulatory Considerations," The Electricity Journal 5(9):58-63.

Nadel S., M. Reid, and D. Wolcott (Eds.) 1992, Regulatory Incentives for Demand-Side Management, American Council for an Energy-Efficient Economy, Washington, D.C.

National Association of Regulatory Utility Commissioners Energy Conservation Committee 1988, "Statement of Position of the NARUC Energy Conservation Committee on Least-Cost Planning Profitability," Washington, D.C., July 26.

New Hampshire Public Utilities Commission 1990, Order 19,905 in Doc. 89-187, Generic Investigation of Financial Incentives for Conservation and Load Management, Concord, NH, August 7.

New York Public Service Commission 1988, Opinion No. 88-20 in Case 29409, Future Electricity Needs, Albany, NY, July 26.

Otter Tail Power Company 1994, “Otter Tail Power's Qualitative Response to the Future of Financial Incentives," memo to Financial Incentive Working Group, Fergus Falls, MN, April 5.

Phillips, C., Jr. 1993, The Regulation of Public Utilities, 3rd Ed., Public Utilities Reports, Inc., Arlington, VA.

Raab, J. and M. Schweitzer 1992, Public Involvement in Integrated Resource Planning: A Study of Demand-Side Management Collaboratives, ORNL/CON-344, Oak Ridge National Laboratory, Oak Ridge, TN.

Reid M., J. Brown, and J. Deem 1993, Incentives for Demand-Side Management, 3rd Ed., National Association of Regulatory Utility Commissioners, Washington, D.C.

Reid, M. and J. Chamberlin 1990, "Financial Incentives for DSM Programs: A Review and Analysis of Three Mechanisms," Proceedings of the ACEEE 1990 Summer Study on Energy 
Efficiency in Buildings, Vol 5·157-66, American Council for an Energy-Efficient Economy, Washington, D.C.

Schlegel, J., G. Edgar, R. Prahl, M. Kushler, and D. Narum 1993, Evaluation of DSM Shareholder Incentive Mechanisms, Wisconsin Energy Conservation Corporation, Madison, WI.

Schweitzer, M., M. English, E. Yourstone, and J. Altman 1993, Interactive Efforts to Address DSM and IRP Issues: Findings from the First Year of a Two-Year Study, ORNL/CON-357, Oak Ridge National Laboratory, Oak Ridge, TN.

Schweitzer, M., M. English, S. Schexnayder, and J. Altman 1994, Energy Efficiency Advocacy Groups: A Study of Selected Interactive Efforts and Independent Initiatives, ORNL/CON-377, Oak Ridge National Laboratory, Oak Ridge, TN.

Schweitzer, M. and T.R. Young 1994, State Regulation and Its Effects on Electric-Utility Use of DSM Resources, ORNL/CON-391, Oak Ridge National Laboratory, Oak Ridge, TN.

Smith B., J. Dykema, and P. Delaney 1993, "The Three E's of DSM: Evaluation, Externalities, and the Environment," Proceedings of the 1993 International Energy Program Evaluation Conference, pp. 217-22, Chicago, IL.

U.S. Department of Energy 1994, Opinion Regarding the Denial of Certification In the Matter of the Application of Potomac Electric Power Company for Certification of Net Income Neutrality, Docket No. EE-93-NINA-CERT, Application No. 007, Washington, D.C., May 5.

Violette, D., F. Stern, and M. Ozog 1991, Impact Evaluation of Demand-Side Management Programs, Vol. 2: Case Studies and Applications, EPRI CU-7179, V2, Electric Power Research Institute, Palo Alto, CA. 
APPENDIX A

\section{STATE-SPECIFIC OVERVIEWS}

The state-specific overviews in this appendix summarize important information from the interviews we conducted. We developed these summaries with the explicit goal of not interpreting or analyzing the respondents' replies, although we frequently went back to respondents to ensure clarity on matters of fact and opinion. ${ }^{31}$ The overviews for each state describe: summaries on the status of NLRA; implementation issues, including DSM measurement issues; and NLRA results, including respondents' views on the effect of NLRA on utility DSM activity and reports of net lost revenue recovered by utilities. We describe NLRA mechanisms for each state and, where appropriate, for each utility in the state. We also describe how net lost revenue estimates are reconciled with DSM measurement and evaluation studies, the conditions PUCs establish for utility net lost revenue recovery, and the key PUC orders or opinions on NLRA. The overviews differ in their depth of coverage primarily due to the amount of material we were able to obtain from each state and the amount of each state's experience with NLRA.

\section{ARIZONA \\ Status of NLRA}

On October 29, 1991, the Arizona Corporation Commission (ACC) issued an order that indicates utilities may be allowed to recover lost revenues from DSM programs (Decision No. 57589, October 29, 1991). Specific mechanisms for Arizona Public Service (APS), Tucson Electric Power (TEP), and Arizona Electric Power Cooperative were subsequently approved by the ACC within each utility's rate case. APS provides an example of how the ACC established an NLRA mechanism. The utility recommended an NLRA mechanism as part of its general rate case filing in 1991. ACC staff responded with a counter proposal and APS and staff subsequently negotiated a settlement agreement. The ACC later approved the settlement agreement and directed APS to implement the approved NLRA mechanism as part of a larger DSM cost recovery mechanism that included program costs for DSM and renewables, and a DSM incentive (Decision No. 57589).

Of the three utilities with NLRA mechanisms in place, only APS and TEP have collected net lost revenue. These two utilities have different mechanisms: the APS mechanism recovers net lost

\footnotetext{
${ }^{31}$ The views expressed in these overviews are the opinions of the individuals interviewed and not their organizations. Unless we explicitly indicate otherwise, our attribution of respondent replies to their organization (such as, the Indiana PSB believes . . . ) is purely a compositional convenience.
} 
revenue through a prospective surcharge (Decision No. 57649, December 6, 1991); the TEP mechanism tracks net lost revenue estimates with a deferred account and the total estimate, when approved by the ACC, is used to revise base rates at the utility's next general rate case. The specific mechanisms for APS and TEP are described in more detail below.

Net lost revenue for Arizona Public Service is defined as total estimated annual lost revenues resulting from reduced sales as a consequence of conservation measures implemented under the Energy Efficiency and Solar Energy Fund. These lost revenues are net of all system savings realized due to reduced sales, including variable costs such as fuel and operation and maintenance.

APS recovers net lost revenue through an Energy Efficiency Surcharge. APS estimates net lost revenue based on forecasted levels of program activity for the upcoming twelve-month period and any reconciliation of prior year net lost revenue estimates suggested by program monitoring studies. These estimates are reviewed, and revised if necessary, by ACC staff as part of the overall DSM program approval process. APS submits its annual DSM program plan by March 31. The approved estimate of net lost revenue is included as a surcharge on customer bills; thus, estimated net lost revenue are recovered as incurred. The surcharge is also the mechanism to recover approved DSM program costs and DSM shareholder incentives. The ACC sets a floor and ceiling for the total revenues to be collected through surcharge. The current floor and ceiling are $\$ 8$ million and $\$ 10$ million, respectively. The ACC increases these amounts over a period of four years until the floor and ceiling reach $\$ 14$ million and $\$ 18$ million, respectively. The overall surcharge is trued up annually based on the actual program costs and savings resulting from the approved programs and the actual revenues collected through the surcharge.

By ACC decision, APS is directed to file a revised plan of administration for the Energy Efficiency and Solar Energy Fund, subject to staff review and approval (Decision No. 58644, Docket No. U-1345-94-120, January 1, 1994). The plan must provide for a balancing account to reflect the accumulated balance of pre-approved expenditures and the annual recovery of these expenditures through the Energy Efficiency and Solar Energy Fund surcharge. The decision also directs ACC staff to convene interested parties to discuss possible capitalization and amortization of DSM and renewables costs and other cost recovery mechanisms prior to the second year of the plan administration.

Net lost revenue recovery is addressed in Tucson Electric Power's general rate case. TEP estimates test year net lost revenue and this estimate, once approved by the ACC, is included in TEP's base rates. TEP tracks net lost revenue incremental to this test year estimate. This increment includes the difference between actual and estimated net lost revenue for the test year and, for subsequent years, net lost revenue due to new participants in existing programs and new programs implemented after the test year. At the next rate case, TEP submits estimates of this 
incremental net lost revenue. Subject to review and revision, the approved net lost revenue estimates are then recovered through an adjustment in TEP's base rates. A new test year estimate of net lost revenue is also included as the net lost revenue portion of base rates.

The ACC requires that utilities meet two conditions to file for and collect net lost revenue. First, eligible DSM programs must be pre-approved by the ACC. Second, the approved programs must demonstrably save energy or reduce demand; for example, the ACC does not award net lost revenue recovery for energy education programs.

\section{Implementation Issues}

According to ACC staff the processes established by the ACC to review net lost revenue estimates and to allow net lost revenue recovery have not encountered major problems or opposition in Arizona. In staff's view, the major technical consideration is to determine the appropriate baseline efficiency levels for buildings and equipment. Assumptions about baseline efficiency levels have a substantial influence on energy savings estimates for utility DSM programs. The ACC is concerned about the precision of savings estimates reported by the utilities. Utilities currently rely on engineering methods to estimate program savings. ACC staff is recommending that utilities use load metering techniques in impact evaluations to verify engineering estimates. The ACC requires utilities to reconcile forecasted program participation levels with observed levels. The outcome of the reconciliation process can lead to revisions of the net lost revenue recovered through the surcharge or in base rates. The ACC offers no specific guidelines about program evaluation methods or measurement standards that the utilities should use in program evaluation.

\section{NLRA Results}

ACC staff report that Arizona utilities would not pursue DSM without an NLRA mechanism and that the utilities view the mechanism as removing an important disincentive to utility DSM. Before the ACC approved NLRA mechanisms for APS and TEP, staff reports these utilities were not pursuing substantial DSM programs.

As Table A-1 shows, APS and TEP received net lost revenue beginning with DSM program activities in 1992. APS's DSM costs grew by less than ten percent from 1992 to 1993 while TEP's DSM costs more than doubled. By 1993, net lost revenue recovery represents a substantial portion of total DSM costs. ${ }^{32}$ Table A-1 lists the annual operating revenues for each utility to place these DSM costs in context.

\footnotetext{
${ }^{32}$ In Tables A-1 through A-10, total DSM costs include utility program costs, incentive awards (where applicable), and net lost revenues. Net lost revenues are not, strictly speaking, an additional cost DSM cost because in principle these revenues would be recovered in the absence of the DSM program. Net lost revenues are perhaps better characterized as part of the total cost of electric service. DSM program costs and incentive awards may be estimated from these tables by subtracting net lost revenues from total DSM costs.
} 
Table A-1. Net Lost Revenues Recovered by Utilities in Arizona (000’s \$)

\begin{tabular}{rcc}
\hline Utility & 1992 & 1993 \\
\hline Arizona Public Service & & \\
Net lost revenues & 162 & 855 \\
Total DSM costs & 3,686 & 4,098 \\
Operating revenues & $1,482,053$ & $1,512,151$ \\
Tucson Electric Power & & \\
Net lost revenues & 1,327 & 2,570 \\
Total DSM costs & 2,958 & 5,410 \\
Operating revenue & 550,000 & 561,000 \\
& & \\
\end{tabular}

\section{CONNECTICUT}

\section{Status of NLRA}

Public Act 91-248 in Connecticut encourages the development of conservation and load management technologies. The Act also authorizes the use of rate adjustment clauses to encourage implementation of DSM programs and authorizes the Connecticut Department of Public Utility Control (DPUC) to approve rate amendments outside general rate cases to encourage DSM programs. As a result, the DPUC directed utilities to propose an NLRA mechanism. DPUC approved cost recovery mechanisms for Connecticut Light and Power (CL\&P) Company (Docket No. 92-07-09) and United Illuminating (UI) (Docket No. 92-04-01) in 1992. Only CL\&P has actually recovered net lost revenue. UI's application was under review by the Connecticut DPUC at the time we prepared this report.

CL\&P includes lost revenues from DSM in its test-year forecast. These revenues are recovered in base rates in the first year following a rate case. Lost revenues in subsequent years are recovered through a prospective surcharge called the Conservation Adjustment Mechanism (CAM), which also includes cost recovery for DSM expenditures and DSM shareholder incentives. Both the test year forecast and subsequent year forecasts are based on engineering estimates of unit energy savings and forecasts of program participation levels. A reconciliation is performed at the end of each year and focuses on differences in forecasted and realized participation levels. Over or under collection of net lost revenue is then factored into the following year's CAM surcharge. The CAM surcharge is also based on an eight-year amortization period for DSM costs. 
To file for or collect net lost revenue, utilities must have their DSM programs approved by the DPUC and must demonstrate that energy savings actually occur. All utility conservation and load management programs are eligible to be considered for net lost revenue recovery through CAM.

\section{Implementation Issues}

DPUC staff report no major problems with the NLRA mechanisms. Staff also believe its discussions with utilities during the implementation of the mechanism resulted in better cooperation between utilities and the DPUC.

DSM program impact measurement does not appear to be a major issue in Connecticut for net lost revenue recovery. The DPUC does not require impact evaluations nor has it issued guidelines or directions on evaluation methods or measurement criteria. Both utilities have evaluation efforts underway. DPUC staff expressed a preference for impact evaluations that use billing analysis rather than load metering because of concerns over the expense of metering.

DPUC staff offered the following reasons for Connecticut's success with NLRA:

- DPUC sponsored an investigation on integrated resource planning that helped parties understand the relationship between utility DSM and lost revenues;

- in implementing the CAM surcharge, the DPUC was responding to directions from the state legislature;

- Connecticut established a collaborative process that enabled stakeholders to engage with utilities at an early stage of DSM policy and program development;

- the collaborative is used by parties as the forum for review of utility draft program plans and net lost revenue estimates, thereby avoiding the DPUC litigation of technical details; and

- DPUC gave both utilities the flexibility to develop an overall DSM plan and cost recovery mechanism, including net lost revenue, that best met each utilities' needs

\section{NLRA Results}

DPUC staff report that the net lost revenue mechanism has not altered the types of DSM programs implemented by the two utilities with approved mechanisms. Staff believes it is difficult to isolate the impacts of NLRA from other DSM reforms that occurred during the same time in Connecticut. The DPUC implemented the CAM surcharge, for example, as a complete package that included program cost recovery and an incentive mechanism, as well as NLRA.

The rate impact of DSM cost recovery is becoming a major concern in Connecticut. DPUC staff reports that the Connecticut economy is not healthy, which reduces the utilities' inclination to raise rates to recover DSM costs. This may be one reason why staff reports that CL\&P has steadily reduced its DSM efforts since 1992 and why UI plans to reduce its efforts. 
CL\&P initially recovered net lost revenue for DSM activities in the 1992 program year, as shown in Table A-2. CL\&P continues to receive net lost revenue, but data for more recent years are not available.

Table A-2. Net Lost Revenues Recovered by Utilities in Connecticut (000's \$)

\begin{tabular}{rc}
\hline Utility & $1992^{\mathrm{l}}$ \\
\hline Connecticut L\&P & \\
Net lost revenues & 698 \\
Total DSM costs & 46,000 \\
Operating revenues & $2,012,000$
\end{tabular}

1. Net lost revenue recovery continues beyond 1992, but final data for CL\&P are not available.

\section{INDIANA}

\section{Status of NLRA}

In October 1991 the Indiana Utility Regulatory Commission (URC) released orders authorizing PSI Energy, Inc. (Order in Cause No. 38986) and Southern Indiana Gas and Electric Company (Order in Cause No. 39201) to collect lost revenues from utility DSM programs. Indiana URC staff report that the Indiana URC also recently approved lost revenue recovery for Indianapolis Power and Light, which is initiating programs in 1994.

The Indiana URC has approved two NLRA mechanisms, a deferred account mechanism and a monthly prospective surcharge. The deferred account mechanism for PSI Energy, Inc. (PSI) and Indianapolis Power \& Light (IP\&L) requires these utilities to make monthly estimates of net lost revenues. The net lost revenues are incremental to the level included in the test-year demand forecast from each utility's previous rate case. In a subsequent rate case, the utility puts forward its net lost revenue estimates and requests recovery through a revision of base rates. PSI recovers approved net lost revenue amounts over a four-year amortization period that includes a carrying charge. The Indiana URC has not yet decided on a recovery period for IP\&L.

The settlement agreement for PSI in Cause No. 38986 defines lost revenues as the component of fixed costs that will not be recovered due to retail sales losses resulting from prudent implementation of DSM programs. The settlement agreement further specifies that the calculation of lost revenues will be based on: (1) the $\mathrm{kW}$ or $\mathrm{kWh}$ impacts of DSM programs; (2) the number of participants or installations, as appropriate; and (3) the fixed cost components of the applicable rates. The utility calculates the fixed cost component of rates by subtracting the 
base fuel cost per $\mathrm{kWh}$ in each rate from the tail-step rate. ${ }^{33}$ PSI reports it uses the tail-step price because it is the lowest rate in each rate class and thus helps ensure that the utility does not overstate the amount of net lost revenue.

The mechanism applied to Southern Indiana Gas and Electric Company (SIGECO) uses a monthly prospective surcharge. The utility makes quarterly filings that the Indiana URC uses to set the surcharge. The utility's quarterly filing includes a net lost revenue projection for the coming quarter and any difference between projected and observed program participation rates from earlier quarters. Thus, the SIGECO mechanism is designed to recover lost revenues as they occur. SIGECO uses the following formula to estimate lost revenues.

$$
\begin{gathered}
L M_{r}-\left(R M_{k T h, r} \times L U_{k W h, r}\right)+\left(R M_{k w, r} \times L U_{k w, r}\right) \\
R M_{k W T, r}=R S P_{k T h, r}-B F C_{r} \\
L U_{k T h, r}-U E S_{m} \times N_{m}
\end{gathered}
$$

$\mathrm{LM}_{\mathrm{r}}=$ lost margins for rate class $\mathrm{r}$,

$\mathrm{RM}_{\mathrm{kWh}, \mathrm{r}}=$ revenue margin $(\mathrm{kWh}$ or $\mathrm{kW})$ for rate class $\mathrm{r}$,

$\mathrm{LU}_{\mathrm{kWh}, \mathrm{r}}=$ lost usage $(\mathrm{kWh}$ or $\mathrm{kW})$ for rate class $\mathrm{r}$,

$\mathrm{RSP}_{\mathrm{kWh}, \mathrm{r}}=$ rate-tail step price $(\mathrm{kWh}$ or $\mathrm{kW})$ for rate class $\mathrm{r}$,

$\mathrm{BFC}_{\mathrm{r}}=$ base fuel cost for rate class $\mathrm{r}$,

$\mathrm{UES}_{\mathrm{m}}=$ unit energy savings for measure $\mathrm{m}$,

$\mathrm{N}_{\mathrm{m}}=$ number of installed measures for measure $\mathrm{m}$.

To file for and collect lost revenues, utilities must receive Indiana URC approval of their DSM programs and provide the lost margin estimates. The Indiana URC does not allow SIGECO to recover any lost revenues from interruptible rate programs.

\section{Implementation Issues}

The quarterly filings made by SIGECO may prove unnecessarily frequent and Indiana URC staff may recommend in a future proceeding changing to semi-annual filings. The rate case approach the Indiana URC uses for PSI and IP\&L is untested in Indiana, although PSI is in the midst of a rate case as of the time of this writing. One reason Indiana is experimenting with the rate case

33 Step rates use a per-unit price that depends on the step into which a customer's total electricity use falls. The appropriate step rate is then applied to the customer's total electricity use to calculate the total bill. The step rate typically declines as use increases; for example, a utility will charge a price of $\$ 0.05$ per $\mathrm{kWh}$ if total use is between 0 and $500 \mathrm{kWh}$ and a price of $\$ 0.04$ per $\mathrm{kWh}$ if the total use if greater than $500 \mathrm{kWh}$. 
approach stems from a concern with monitoring the proliferation of tracking mechanisms if more utilities used the SIGECO approach. Indiana URC staff report that neither process has generated any controversy, perhaps because the lost revenue amounts are small relative to other DSM costs.

The Indiana URC has not issued guidelines on program evaluation methods or required the utilities to use specific measurement and evaluation techniques. The Commission does require utilities to monitor, evaluate and record the results of all DSM programs on an ongoing basis and submit annual reports to the Indiana URC. Net lost revenue estimates rely on projected participation rates and engineering-based unit energy savings estimates. The reconciliation procedure included in SIGECO's surcharge attempts to correct for the difference between projected and realized program participation levels. To the extent that program evaluations suggest substantive problems with the unit energy savings estimates, the utility uses the evaluation results to revise the program savings projections underlying its next quarterly surcharge. The Indiana URC does not require SIGECO to retrospectively reconcile unit energy savings.

\section{NLRA Results}

Indiana URC staff indicate that Indiana utilities strongly support use of the NLRA mechanisms. Table A-3 shows that PSI began tracking lost revenues in 1991 and SIGECO began recovering lost revenues in 1992. IP\&L has not filed for lost revenue recovery because the utility is just beginning to implement its DSM programs.

Table A-3. Net Lost Revenues Recovered by Utilities in Indiana (000’s \$)

\begin{tabular}{lccc}
\hline Utility & 1991 & 1992 & 1993 \\
\hline PSI Energy & & & \\
Net lost revenues & 33 & 397 & 2,428 \\
Total DSM costs & 3,511 & 16,127 & 29,243 \\
Operating revenues & 916,451 & 893,051 & 953,547 \\
SIGECO & & & \\
Net lost revenues & ineligible & 25 & 215 \\
Total DSM costs & n/a & 2,714 & 5,879 \\
Operating revenues & n/a & 243,077 & 258,405 \\
& & & \\
n/a: not applicable & &
\end{tabular}


Regulatory staff do not report differences in the type of DSM programs implemented by the utilities as a result of net lost revenue recovery. Both utilities increased their DSM expenditures since NLRA mechanisms have been in place.

\section{MARYLAND}

\section{Status of NLRA}

Maryland's DSM rate-making reforms were developed through a collaborative process. Maryland established a collaborative process in 1990 for Potomac Electric Power Company and in 1991 for Baltimore Gas and Electric. The first issue addressed in these collaboratives was DSM cost recovery, including the recovery of lost revenues. In August 1991 the collaborative parties filed a cost recovery mechanism for Potomac Electric Power Company, which was subsequently adopted by the Maryland PSC. After this mechanism became effective, the collaborative parties filed cost recovery mechanisms for Baltimore Gas and Electric, Conowingo Power, Potomac Edison, and Delmarva Power \& Light.

Utilities must meet three conditions to recover lost revenues in Maryland. First, the DSM program must be approved by the Maryland PSC (the exception is for any program initiated before the collaborative process began in Maryland). Second, the utility must demonstrate that revenues were lost as a result of the DSM program. Finally, the utility must pass an earnings test to collect lost revenues.

The NLRA mechanism in Maryland is a prospective surcharge on customer bills. ${ }^{34}$ The application of the surcharge differs somewhat between major utilities in Maryland, primarily due to differences in the application of the earnings test condition. We describe below the NLRA mechanisms for each Maryland utility.

Rates for service under each of Baltimore Gas and Electric's (BGE's) rate schedules are subject to a surcharge to recover eligible lost revenues from DSM. The surcharge also includes program costs, program incentives, and imbalances, which are differences between cumulative costs eligible for recovery and revenues collected through the surcharge as of June 30 of each year, and is in effect for twelve months beginning on July 1 of each year. The surcharge is determined for each rate schedule by dividing eligible costs by the $\mathrm{kWh}$ sales projected for that rate schedule over the upcoming twelve-month period.

Lost revenues for BGE are defined as monthly base rate revenues not billed because of lost sales from approved conservation programs. Lost revenues are determined using current base rates and include program impacts (demand and energy) incremental to the historical test-year level

\footnotetext{
34 Examples of recent surcharges are E-6, Supplement 298, issued October 29, 1993 for Baltimore Gas and Electric and DSM Surcharge, issued May 20, 1993 for Potomac Electric Power Company.
} 
used in the utility's most recent general rate case. Lost revenues are subject to offset by additional electric base rate revenues generated by gas conservation programs included in the utility's gas conservation surcharge.

An annual reconciliation is made based on the differences between projected and observed program participation levels. BGE conducts DSM measurement and evaluation studies to verify program performance. The evaluations for major DSM programs include estimates of DSM measure savings, but these estimates are not used to retrospectively reconcile total program savings. If impact evaluations suggest that the measure savings estimates BGE uses to project its annual net lost revenue require revision, then the utility is expected to use the impact evaluation estimate in its next DSM program performance forecast. The Maryland PSC applies the same reconciliation approach to all Maryland utilities. Maryland PSC staff's view is that holding utilities to their program participation forecast, rather then to their total program savings forecast, spreads the risks of projecting program performance between shareholders and ratepayers.

BGE's earnings test is performed on the first day of each month. The test is met when the utility's actual rate of return for electric service is below the most recently authorized rate of return. Lost revenues and program incentives collected during months when the earnings test is not satisfied are returned to customers with interest at the rate of the utility's most recent authorized rate of return.

Potomac Electric Power Company's (PEPCO's) DSM surcharge is calculated annually and includes program costs, estimated lost revenues, shared savings, and an amortization calculation based on a five-year period. The surcharge, effective June 1, 1993, is revised by April 1 of each year. The utility may continue to collect program costs when the calculated rate of return is greater than the allowed rate. It may not collect other DSM costs until the calculated rate of return is below the authorized rate. The surcharge is computed by dividing the total amount to be recovered by PEPCO's forecasted Maryland retail sales.

PEPCO's estimated annual lost revenue is determined by reference to the conservation program effects contained in the most recent short-term sales forecast for the current year and reflects reductions in demand and energy use associated with each program. Beginning in 1994, and each year thereafter, the utility will calculate lost revenues for the previous year reflecting actual program participation. The utility will adjust the surcharge in 1994 and each subsequent year to reflect any over or under recovery of lost revenues in the previous year.

The prospective surcharges for Potomac Edison and Conowingo Power are similar to BGE's and PEPCO's. The surcharges are calculated annually and include program costs, lost revenues, performance incentives, and any adjustments needed from the previous year. The application period is twelve months and begins on November 1 each year. The earnings test for Potomac Edison and Conowingo Power is a comparison of the overall rate of return for the twelve-month period prior to the application period versus the rate of return allowed in the utility's last general 
rate case. If the estimated rate of return exceeds the authorized return then no lost revenue will be recovered for the current year.

\section{Implementation Issues}

With regard to conditions for recovery, representatives from BGE and PEPCO find the first two to be reasonable (PUC must approve programs and utility must demonstrate that DSM program results in net lost revenues). The utilities also report that they do not find the documentation required by the Maryland PSC to satisfy these two conditions to be unreasonable or burdensome. The utilities expressed reservations about the earnings test condition. While PEPCO does not find the earnings test unreasonable, the utility would prefer to eliminate the test. PEPCO occasionally fails the test, but the utility would be more concerned with the test if failure was the rule rather than the exception. BGE points out that it has been overearning for the past year and as a result has returned net lost revenues and incentives. BGE's problem with the test is that many causes of overearning (warmer summers, for example) or underearning (cool summers) are unrelated to DSM. Despite these concerns, both utilities agree that the earnings test is not a major issue at this point.

Regulatory and utility staff report that the collaborative parties play an important role in Maryland's NLRA process. Utilities submit draft net lost revenue recovery filings to the collaborative parties for review. The draft filings contain a projection of net lost revenue for the coming year and a reconciliation for the previous year(s). The collaborative parties discuss each utility's draft filing until the parties reach consensus. The utilities revise their drafts, if necessary, and then file the drafts with the Maryland PSC. The collaborative parties also review each utility's program evaluation plan and the results of specific evaluation studies.

Regulatory staff, and representatives from BGE and PEPCO agree that the NLRA process in Maryland works well. They agree that the calculation of net lost revenue is straightforward and the estimates are not litigated. PEPCO and Maryland PSC staff emphasize the importance of addressing cost recovery issues initially in the collaborative process. Settling the cost recovery issues gave utilities confidence to proceed with important design changes in their DSM programs. All agreed that the collaborative is an effective forum to address issues and resolve conflicts without resorting to litigation, although BGE notes that reaching consensus is not always an easy task. BGE further suggests that utilities may wish to revise programs in the wake of greater industry competition and achieving future consensus on certain DSM issues may be more difficult.

In addition to the positive role of the collaborative parties, Maryland PSC staff point to several additional reasons for the success of NLRA in Maryland. The previous work on IRP in Maryland made it clear to utilities and regulators that lost revenues are real and should be addressed. The Maryland PSC was also supportive of the collaborative parties' efforts to address cost recovery and program design issues. In addition, the Maryland PSC has been willing to experiment with different NLRA mechanisms to determine which is most effective. The Maryland PSC is 
motivated to ease the utilities' administrative burden and ensure better predictability of customer rates.

Maryland PSC staff and utilities agree that measurement issues have been an important part of the implementation process, and the subject of much discussion in the collaborative, but have not been the source of major controversy. The Maryland PSC's objective is to estimate net lost revenue with the best available information at the time an estimate is made. The Maryland PSC does not specify measurement guidelines or recommended evaluation methods. Instead, the Maryland PSC relies on the collaborative parties to pursue the Commission's objective of using the best available data to estimate net lost revenue.

The collaborative parties also oversee the net lost revenue reconciliation process. The collaborative parties acknowledged that data on the performance of early utility programs were unlikely to be as robust as data from more recent programs. Thus, the collaborative recognized that unit savings estimates for early programs would be based on engineering methods rather than impact evaluations. Over time, the collaborative expects that evaluation results will provide improved data to support engineering-based estimation methods or, where results dictate, revisions to the engineering estimates themselves.

PEPCO and BGE agree that estimating net lost revenue through program monitoring and impact evaluation is important. PEPCO in particular cites the willingness of the collaborative parties to take a reasonable approach to evaluation and to recognize that DSM measurement and evaluation does not always lead to precise results as a major reason for the utility's support and enthusiasm for the NLRA mechanism. BGE notes, however, that program evaluation results showing substantially different unit savings than those derived from engineering methods could lead to future controversy.

\section{NLRA Results}

Maryland PSC staff report that before DSM cost recovery the utilities operated only direct load control programs and less comprehensive programs that focused on single end uses, such as commercial lighting. After cost recovery, staff believes the utilities pursue a broader range of programs. After NLRA was established, PEPCO reports offering many more measures to customers and at higher rebate levels. Maryland PSC staff and utilities agree that NLRA has removed a fundamental disincentive to utility DSM and that it has encouraged utilities to pursue DSM more vigorously. Table A-4 reports net lost revenue recovered, total DSM costs, and operating revenues for Maryland utilities in 1993.

While the Maryland PSC has no plans to make major changes to the NLRA mechanism, Maryland PSC staff and utilities expressed concern about the role of NLRA in a more competitive utility environment. Specifically, staff from the PSC, BGE, and PEPCO are concerned about the effect of cost recovery on rates. BGE prefers to change its program designs to move away from rebates. BGE's ideas for new programs include an array of energy efficiency services including 
audits, design assistance, technical advice, and contracted energy services. These programs may not be eligible for net lost revenue recovery, but the utility views the programs as more compatible with its desire to keep rates low in the more competitive industry environment.

Table A-4. Net Lost Revenues Recovered by Utilities in Maryland (000's \$)

\begin{tabular}{rcc} 
Utility & 1992 & 1993 \\
\hline BGE (electric only) & & \\
Net lost revenues & 6,021 & 9,424 \\
Total DSM costs & 33,285 & 51,954 \\
Operating revenues & $1,967,923$ & $2,115,155$
\end{tabular}

Conowingo

$\begin{array}{rcc}\text { Net lost revenues } & \mathrm{n} / \mathrm{a} & 0 \\ \text { Total DSM costs } & \mathrm{n} / \mathrm{a} & 180 \\ \text { Operating revenues } & \mathrm{n} / \mathrm{a} & 75,058\end{array}$

Potomac Edison

Net lost revenues

$\mathrm{n} / \mathbf{a}$

7

Total DSM Costs

$\mathbf{n} / \mathbf{a}$

796

Operating revenues

n/a

417,620

PEPCO

Net lost revenues

0

5,402

Total DSM Costs

15,256

37,806

Operating revenues

818,983

884,450

Southern Maryland Elec Coop

Net lost revenues

n/a

Total DSM costs

n/a

1,743

Operating revenues

n/a

166,994

1. PEPCO exceeded its authorized rate of return during 1991 and 1992. As a result, though PEPCO's had an NLRA mechanism during this period, the utility was not eligible to recover net lost revenues. 
BGE further notes that one of the major benefits of DSM is to avoid the need to build or purchase supply-side resources. Yet the capacity benefits of DSM often only materialize in the long run. In the long run, however, supply-side investments are less like to be made by the utility and thus less likely to be included in the utility's rate base. Thus, the long-term benefit of DSM, to lower the present value of utility revenue requirements, does not address the utility's concerns about rate impacts and cross subsidies in an emerging competitive environment. Based on this concern, BGE recommends decreasing reliance on the total resource cost test as the sole determinant of DSM cost effectiveness and increasing the reliance on the rate impact measure test (Letter from C. Poindexter, BGE's Chairman, to F. Heintz, Maryland PSC's Chairman, dated July 15, 1994). Any DSM program that fails the rate impact measure test will lead to higher present value rate impacts on non-participating customers over the program's life cycle than if the utility had acquired the least-cost supply-side option.

PEPCO makes a similar point: NLRA addresses the short-term problem of revenue loss between rate cases, but the larger problem is the loss of long-term sales from DSM. Over the long term, the utility must therefore allocate fixed costs over reduced total sales (or sales growing at a slower rate) due to DSM, resulting in higher rates. PEPCO is also concerned about maintaining stability in regulatory policy toward DSM cost recovery in Maryland as the membership of the PUC changes over time.

\section{MASSACHUSETTS}

\section{Status of NLRA}

Massachusetts allows net lost revenue recovery for both electric and gas utilities. Only the electric utilities have recovered lost revenues so we focus our discussion on the mechanisms the Massachusetts Department of Public Utilities (DPU) has approved for electric utilities.

Massachusetts established net lost revenue recovery mechanisms as an outgrowth of an investigation on integrated resource planning regulations (Order 86-36-F). The investigation recognized that utilities may need rate adjustments between rate cases to compensate them for significant sales erosion and associated revenue loss caused by successful DSM programs. In Order 89-260, the Massachusetts DPU approved an NLRA mechanism proposed by Western Massachusetts Electric Company. The Massachusetts DPU subsequently approved NLRA mechanisms for Boston Edison (Order 90-335), Fitchburg Gas and Electric Light (Order 92-181), and Cambridge Electric Light and Commonwealth Electric Companies (Order 93-15/16).

Massachusetts uses a prospective surcharge, but calculates net lost revenues in two different ways. The first calculation, which applies to Boston Edison (BE) and Fitchburg Gas and Electric Light, multiplies kWh savings by base-rate demand and energy charges calculated for major rate-class groupings. The second net lost revenue calculation, which applies to Western Massachusetts Electric Company (WMECO), Commonwealth Electric (CE) and Cambridge 
Electric Light (CEL), multiplies kWh savings by the per $k$ Wh charge for each rate category. The $\mathrm{kWh}$ charges are estimated by taking total test-year revenue, deducting fuel and customer charge revenue, and dividing the remainder by test-year $\mathrm{kWh}$ sales.

All utilities file annually as part of the total DSM cost recovery process. DSM cost recovery is through a surcharge; no DSM costs are in base rates. The net lost revenue portion of the DSM surcharge is based on an annual forecast of DSM savings. Each year the surcharge includes a two-part reconciliation with the utility's net lost revenue estimates from the previous two years. The reconciliation's first part is between the forecasted program savings and the program savings based on the program's tracking system. The tracking system includes observed program participation, observed types of measures installed, and estimated measure savings. The reconciliation's second part, which applies to the year before last year, is between forecasted program savings and program savings based on program impact evaluations. The purpose of this second part is to reflect any differences between program savings estimates from the tracking system and the impact evaluation, with the latter used as the reference. Thus, the net lost revenue portion of DSM surcharge for 1994 will include the following: a DSM savings forecast for 1994; the difference between the savings forecast for 1993 and a revised forecast based on a reconciliation to the program tracking system; and the difference between the revised DSM savings forecast for 1992 and a forecast based on a reconciliation to estimated program savings from program impact evaluations.

To be eligible for net lost revenue recovery, DSM programs must be approved by Massachusetts DPU and the program savings must ultimately be demonstrated by impact evaluations. Load management programs are only eligible if program operation leads to lost revenue.

\section{Implementation Issues}

Massachusetts is reviewing its current approach to net lost revenue recovery for possible future revisions. Massachusetts DPU described several concerns that are prompting this review. First, net lost revenue is becoming a substantial portion of overall DSM costs for some utilities. Massachusetts DPU staff is concerned that if total DSM budgets are relatively constant, then the dollars collected for net lost revenue recovery will reduce the available dollars for DSM programs. Massachusetts DPU staff explained that net lost revenue are a large share of total DSM costs because the utilities have not had a rate case since Massachusetts first implemented NLRA in 1991-92. As a result, base rates for the utilities have not been revised to reflect changes in revenues required to cover fixed costs. Furthermore, some utilities do not anticipate entering a rate case until the end of this decade.

Second, DPU staff is worried about the short-term rate impacts of DSM programs. As utility DSM activities increase, so do the estimates of net lost revenue. Recovering the growing net lost revenue leads to higher rates for consumers. This concern, as well as the previous staff concern, leads regulators and utilities to pull back on DSM activities to mitigate the rate impacts of DSM. 
Third, Massachusetts DPU staff is concerned that utilities may not be experiencing unrecovered fixed costs due to utility DSM, especially given the length of time between rate cases for these utilities. In Massachusetts DPU staff's view, net revenue losses should be a short-term problem. However, if utilities go several years between rate cases Massachusetts DPU staff is concerned that the assumptions governing the revenue requirements to cover fixed costs may no longer apply. In other words, the utility may have already reduced its overall costs, thus eliminating the need to collect lost revenues resulting from DSM programs conducted several years earlier. DPU staff suggests that a rolling recovery period, reflecting the average filing time between utility rate cases, may be one way to address this concern.

Fourth, certain customers, primarily large customers, have expressed dissatisfaction with the conservation charge. These customers believe they pay twice for DSM: first when they pay for all or part of a measure and second when they pay, through the net lost revenue portion of the charge, for a part of the energy savings achieved by others in their rate class.

In addition, DSM measurement issues are gaining importance, particularly in the state's retrospective reconciliation to total program savings. Over time the impact evaluations increase in quality and complexity. As a result, evaluation review and the reconciliation process take up substantial Massachusetts DPU staff resources. Massachusetts DPU staff began using consultants in 1994 to assist them with utility program evaluation review.

The Massachusetts DPU has established guidelines for program evaluations and standards of evaluation review. The guidelines indicate the evaluation methods appropriate to use for different program types, but do not require utilities to use a specific evaluation approach. The guidelines require utilities to estimate free riders, rebound effects, and savings persistence. Massachusetts DPU Order 90-335 establishes a desired measurement precision level for impact evaluations. Massachusetts DPU staff reports that achieving this level has proven costly and, in response, the Massachusetts DPU instructed utilities to ensure that the value of the information gained by meeting this precision level does not exceed the costs.

As a result of these problems, Massachusetts DPU staff has four suggestions to revise the current NLRA process in Massachusetts.

- Utilities and Massachusetts DPU staff need to better define and disaggregate the components of fixed and variable costs. Utilities and Massachusetts DPU staff will then better understand how specific costs are affected by DSM program savings.

- Utilities should not wait too long between rate cases. More frequent rate cases will allow net loss revenue effects to be reflected sooner in base rates. Where utilities do not file rate cases, the Massachusetts DPU may only allow utilities to file for net lost revenue recovery for the first three years after a DSM program year's activities. For example, for net lost revenues incurred due to DSM activities in the 1992 program year, a utility will be able to file for net lost revenues that result in 1993, 1994, and 1995, but not in 1996. 
- Net lost revenue recovery should be tied more closely to the time period when revenue losses are likely to be experienced. Under the existing mechanisms, utilities recover revenue immediately even though some DSM programs may not go into effect for several months.

- Massachusetts should eventually shift from a more narrowly focused NLRA approach to a broader decoupling or statistical recoupling approach. Although Massachusetts DPU staff would still review evaluations for shareholder incentive awards, the evaluation review would not be as time-consuming as it is currently when both incentive awards and lost revenue estimates must be considered.

\section{NLRA Results}

Massachusetts DPU staff report that net lost revenue recovery has been a very effective approach to attract utility attention to DSM. Table A-5 shows that since NLRA's implementation, WMECO's DSM costs have remained stable, CE's and CEL's have decreased, and BE's has increased. Staff report that CE's and CEL's DSM costs decline because the Massachusetts DPU did not preapprove these utilities' DSM programs. Table A-5 also shows that WMECO and CE anticipate net lost revenue recovery for 1993 that are over $40 \%$ of their total DSM costs, one source of Massachusetts DPU staff's concern with the current mechanism. Massachusetts DPU staff does not believe NLRA has influenced the types of DSM programs the utilities implement. Although utilities have moved from load management to energy efficiency programs, Massachusetts DPU staff attributes this to the current capacity surplus in the area.

\section{MINNESOTA}

\section{Status of NLRA}

This overview concentrates on Minnesota's electric utilities, primarily because the gas utilities developed NLRA mechanisms more recently and, therefore, have less experience with their operation.

On February 28, 1991 the Minnesota Public Utilities Commission issued an order requiring all investor-owned electric utilities serving more than 500 Minnesota customers to file plans for financial incentives to promote DSM (Docket No. E-999/CI-89-212, February 28, 1991). The Minnesota PUC's 1991 Order was precipitated by an earlier investigation into integrated resource planning (Docket No. E-999/R-89-201). Investor-owned electric utilities subsequently developed and filed DSM financial incentive plans with the Minnesota PUC. By 1992 the Minnesota PUC had reviewed and approved financial incentive pilot projects for Northern States Power (electric only), Minnesota Power (MP-Docket E-015/M-91-458, March 12, 1992), Otter Tail Power (OTP-Docket E-015/M-91-457, March 12, 1992), and Interstate Power Company (electric 
Table A-5. Net Lost Revenues Recovered by Utilities in Massachusetts (000’s \$)

\begin{tabular}{|c|c|c|c|}
\hline Utility & 1991 & 1992 & 1993 \\
\hline \multicolumn{4}{|l|}{ Boston Edison } \\
\hline Net lost revenues & 2,973 & 3,384 & 5,656 \\
\hline Total DSM costs & 40,966 & 55,632 & 63,775 \\
\hline Operating revenues & $1,349,356$ & $1,406,556$ & $1,477,117$ \\
\hline \multicolumn{4}{|l|}{ Cambridge Electric Light } \\
\hline Net lost revenues & ineligible & ineligible & 43 \\
\hline Total DSM Costs & $\mathbf{n} / \mathbf{a}$ & 3,185 & 2,777 \\
\hline Operating revenues & $\mathrm{n} / \mathbf{a}$ & 103,321 & 113,241 \\
\hline \multicolumn{4}{|l|}{ Commonwealth Electric } \\
\hline Net lost revenues & ineligible & ineligible & 1,758 \\
\hline Total DSM costs & $\mathbf{n} / \mathbf{a}$ & 11,255 & 5,854 \\
\hline Operating revenues & $\mathrm{n} / \mathfrak{a}$ & 374,801 & 404,693 \\
\hline \multicolumn{4}{|l|}{ Fitchburg $G$ and $E$} \\
\hline Net lost revenues & ineligible & ineligible & 272 \\
\hline Total DSM costs & 642 & 556 & 693 \\
\hline Operating revenues & 37,658 & 38,905 & 43,222 \\
\hline \multicolumn{4}{|l|}{ WMECO } \\
\hline Net lost revenues & 3,683 & 5,954 & 7,536 \\
\hline Total DSM costs & 22,024 & 23,431 & 26,036 \\
\hline Operating revenues & 409,840 & 410,720 & 415,055 \\
\hline
\end{tabular}

n/a: not applicable

only-Docket E-001/GR-91-605, June 12, 1992). Except for Northern States Power, all these pilot projects have some provision for recovery of net lost revenue. 
The Minnesota PUC also began an investigation into DSM financial incentives for gas utilities on April 10, 1991. Gas utilities developed and filed plans and by 1993 the Minnesota PUC had approved financial incentive pilot projects, including recovery of net lost revenue, for Northern States Power (gas only), Interstate Power Company (gas only), Great Plains Natural Gas, Northern Minnesota Utilities, and Minnegasco.

DSM cost recovery is managed through the Conservation Improvement Program (CIP) account, which is a retrospective surcharge. The surcharge includes net lost revenue (called "lost margins" in Minnesota), program costs, and incentives. The Minnesota PUC defines net lost revenue as all unrecovered non-variable costs within a specific rate as a result of utility DSM programs.

Each April, the utilities file with the Minnesota PUC annual estimates of lost revenues from program activities in the previous year. The annual estimates are supported by program impact evaluations that have been reviewed and approved by the Department of Public Service (DPS). DPS also has responsibility to review and approve each utility's DSM program plan and evaluation plan. Thus, a key element of DPS's review of impact evaluation results is to determine if the utilities have faithfully executed their approved program and evaluation plans. Utilities cannot recover net lost revenue from programs that require a completed program impact evaluation until the evaluation is complete.

Prior to 1994, all utilities recovered CIP account balances, including net lost revenue, at their next rate case. Changes in Minnesota law in 1993 allow the Minnesota PUC to revise rates outside a general rate case for conservation costs. Several Minnesota utilities are now proposing to recover conservation costs through a monthly surcharge applied to customer bills. The Minnesota PUC will annually set the surcharge after reviewing each utility's April DSM cost recovery report. The Minnesota PUC anticipates revising the surcharge in late summer or early autumn of each year.

The Minnesota PUC initially approved the DSM financial incentive plans for each utility as pilot projects. By 1994 most electric utilities are in the third year of their pilot program. Minnesota PUC staff, under direction from the Minnesota PUC, has formed a DSM Financial Incentives Working Group. This Group is to assess the performance of the pilot projects and develop recommendations about the future course of DSM financial incentives in Minnesota.

The conditions utilities must satisfy to file for and collect net lost revenue are that DSM programs must be approved by the DPS, the utilities must verify savings from these programs, and the programs must generally be direct impact programs (that is, programs that lead to the direct installation of energy efficiency measures). Minnegasco's net lost revenue recovery is conditioned on meeting approved performance targets. The other utilities are eligible for full recovery of approved net lost revenue without regard to meeting performance targets. 


\section{Implementation Issues}

Minnesota PUC staff and representatives from two utilities, MP and OTP, agree that NLRA implementation and administration issues have gone smoothly. Minnesota PUC staff believe the implementation process has been effective because the Minnesota PUC's integrated resource planning investigation resulted in clear regulatory recognition that utilities earn profits primarily from selling, rather than conserving, $\mathrm{kWh}$. If regulators encourage utilities to pursue DSM without removing disincentives then utilities will lose sales and profits. Staff also notes that many utilities had experience with the type of tracker account that is fundamental to Minnesota's DSM cost recovery mechanisms.

Utilities must acquire prior approval from DPS for DSM program and evaluation plans. MP and OTP staff agree that if utilities faithfully abide by these plans, the prospects for disputes about subsequent net lost revenue filings are greatly reduced. Further, both utilities have experienced little in the way of intervention in rate cases from customers about net lost revenue recovery.

MP, a utility with several large customers, believes its strategy of openly sharing utility motivations for net lost revenue recovery with customers has been effective. The customers understand the utility must somehow recover lost fixed costs due to DSM and large customers in particular prefer the surcharge to a rate case for this purpose because the participation costs are typically high in rate cases. OTP also cites the strong support from the legislature and DPS for DSM as contributing to an effective process. In addition, OTP believes that Minnesota's low rates may make the rate impacts of DSM a less immediate concern for the state.

Minnesota has had three working groups involved with different aspects of DSM cost recovery, including net lost revenue. The first group, the Implementation Working Group, was formed under the direction of the PUC to develop an annual DSM cost recovery mechanism suited to each utility. Membership in this group included DPS staff, PUC staff, utilities, Office of Attorney General, the Isaac Walton League, and other interested parties. The PUC subsequently approved all utility proposals for annual DSM cost recovery that met the guidelines established by this group.

The second group, the Evaluation Working Group, is an informal group without an explicit charge from either DPS or the PUC. The Evaluation Working Group formed to guide program evaluation efforts and to be a forum for the discussion and resolution of evaluation problems and issues. The group, with a membership similar to the Implementation Working Group, published a working document on DSM evaluation. The working document is a set of guidelines that identify key issues and criteria for utilities, regulators, and other parties to consult when planning and conducting evaluations. The Group's philosophy on evaluation is spelled out in a section of the working document on evaluation budgets (Evaluation Working Group n.d., p. 9):

There is no standard amount that must be spent on evaluation. The overriding goal should be to strike a balance between the cost and 
overall effectiveness of DSM evaluation. This is dependent on the type of evaluation, the objectives of the evaluation, and the availability of resources and data. Ultimately, the determining factor of evaluation budget should be the expected impact of both the project and the project evaluation.

While Minnesota PUC staff, MP, and OTP agree that program impact evaluation is an important issue for net lost revenue recovery, all agreed that the Evaluation Working Group has been fundamental in shaping both the state's and the utilities' approach to evaluation. For large DSM programs, utilities conduct impact evaluations that rely on an analysis of participant electricity use before and during the project and a comparison of participants with a control group. For some programs, utilities use engineering-based methods for unit energy savings and recorded participation levels to estimate program savings. The engineering estimates are spot checked and adjusted, if necessary, by metered data. Both utilities describe the current approach to evaluation as balanced and reasonable, and one that focuses scarce evaluation dollars on important programs. Of course, because Minnesota requires a completed program evaluation before approving net lost revenue, reconciliation is not an issue.

The third group, the DSM Financial Incentives Working Group, formed at the direction of the PUC. This group's responsibility is to assess the DSM financial incentive pilot programs and recommend the future course of these program in Minnesota. Group membership is identical to the other two working groups.

Minnesota PUC staff suggested several possible changes to Minnesota's current approach to NLRA. These changes include: establishing a DSM Financial Incentives Working Group for gas utilities; setting common reporting dates for utility net lost revenue filings to reduce the administrative burden of tracking the different elements of the cost recovery for multiple utilities; and setting largely common reporting requirement and NLRA mechanisms while preserving important utility-specific features. For example, some utilities may want DSM cost recovery to only include net lost revenue while others may want to exclude net lost revenue recovery. The latter option would address in part the concern MP and OTP have with the rate impacts of net lost revenue recovery given the uncertainty surrounding the role of future industry competition.

The DSM Financial Incentives Working Group is considering the effects of sales growth on net lost revenue. The Group may recommend an adjustment to the NLRA mechanism to reduce net lost revenue recovered if a utility experiences net sales growth. Sales growth is an issue because part of the Group believes that if DSM does not completely offset sales growth, then the utility is receiving some new revenue that at least partially compensates it for revenues lost due to DSM. This new revenue should at least partially compensate the utility for DSM-induced revenue losses. Others in the Group believe that NLRA is intended to make utilities whole from utility DSM so the issues of sales growth and net lost revenue are separate and should remain separate. 


\section{NLRA Results}

Minnesota PUC staff report that the NLRA mechanism has not changed the types of programs utilities pursue in Minnesota because the state legislature and PUC exercise considerable control over utility activities. The legislature requires, for example, electric utilities to spend at least $1.5 \%$ of their annual revenues on DSM programs. Staff believes the combination of NLRA and financial incentives has had two positive effects on utilities: first, utilities are more enthusiastic about DSM and second, management is more focused on DSM.

MP and OTP both report that in the past few years their utilities have moved from education and audit programs to direct impact programs. Because financial incentives and NLRA were implemented jointly in Minnesota, both utilities indicate singling out the effect of NLRA on program design is difficult. OTP also noted the strong support for direct impact programs from DPS contributed to the shift from information programs.

The available data on DSM program expenditures from MP and OTP, reflected in Table A-6, reveal a substantial expansion from 1992 to 1993 . In addition, as part of the Financial Incentives Working Group's assessment of incentive pilot projects, utilities responded to the following question: "What changes have occurred at your utility since receiving the incentive?"

The response from OTP (Otter Tail Power Company 1994) is representative of responses we reviewed from other Minnesota utilities:

There is much more acceptance of CIP within Otter Tail Power since incentives were first established. Financial incentives have had a positive impact on how the Company views CIP from a financial perspective. This has opened the door to other benefits on investing in CIP:

- The Company is now seeing customer and utility value in most energy efficiency programs.

- The Company's focus is on the customer and how they can use electricity efficiently.

- The Company is much more accepting of promoting energy efficiency.

- The Company has allocated more resources to DSM activities.

- The Company views DSM as a viable resource option and puts DSM on a level playing field with supply-side options. 
During the interviews we conducted for this project, both MP and OTP expressed concern with the rate impacts of lost margin recovery. MP would prefer to strike a balance between education programs (including audits) and direct impact programs. MP would also prefer that DSM result in positive benefits to shareholders while maintaining rates as low as possible. OTP is considering how to reduce the overall utility cost of DSM programs and, as one option, is discussing a reduction in incentive levels. OTP may also increase reliance on the rate impact measure test when developing future DSM programs.

Table A-6. Net Lost Revenues Recovered by Utilities in Minnesota (000's \$)

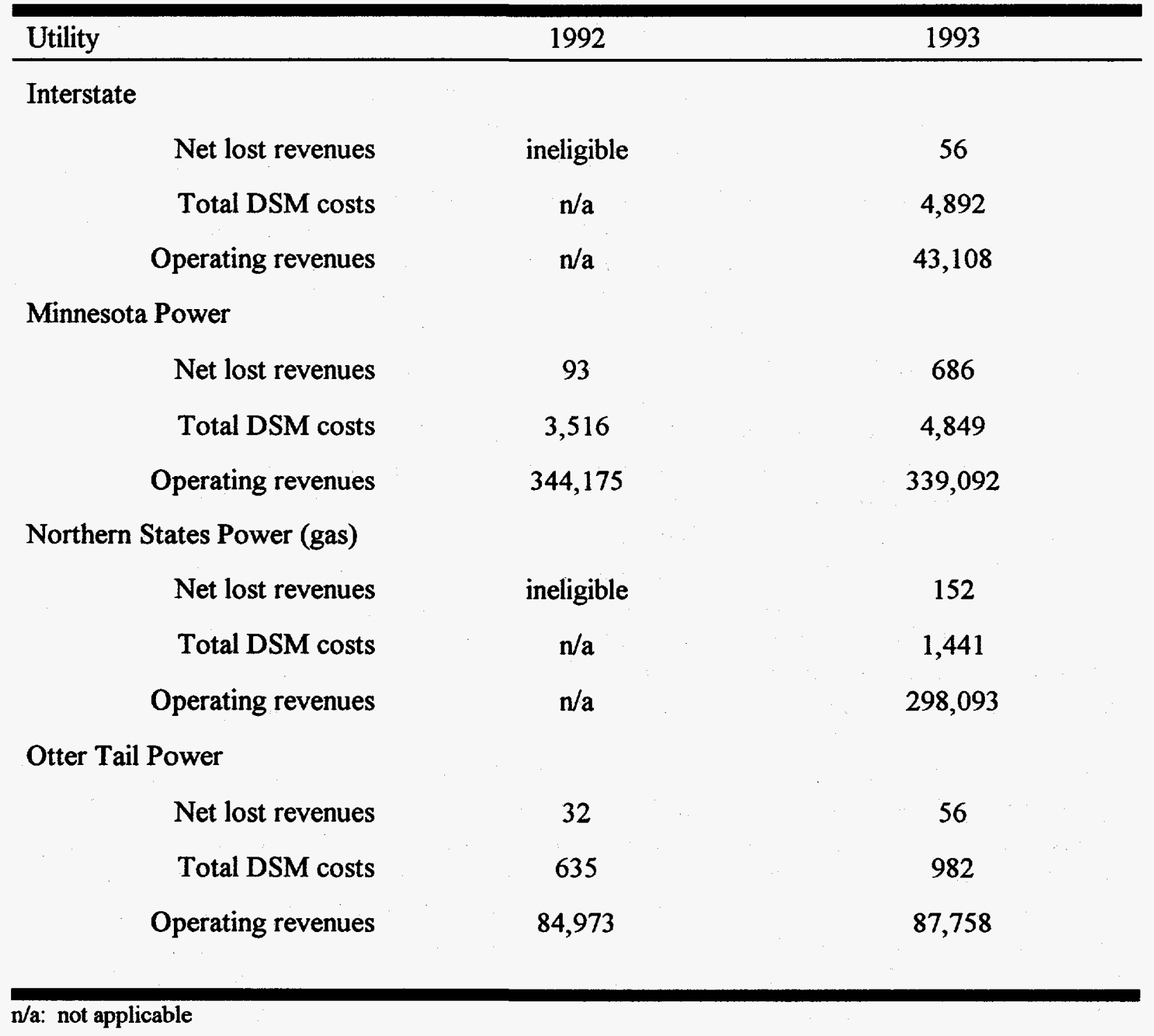




\section{NEW HAMPSHIRE}

\section{Status of NLRA}

In October 1989 the New Hampshire PUC opened an investigation into financial incentives for utility conservation and load management (C\&LM). The Commission opened the investigation in response to a CL\&M cost recovery proposal filed by Granite State Electric Company on September 1, 1989. On August 7, 1990, the Commission decided that lost revenues (called "lost fixed costs" in New Hampshire) are a recoverable cost to utilities of CL\&M program implementation (Order 19,905 in Docket 89-187, August 7, 1990). The New Hampshire PUC (1990, pg 12) also adopted a definition of lost revenues recommended by Northeast Utilities Service Company and Public Service Company of New Hampshire:

... the term "lost revenues" (also known as "lost fixed cost
recovery") means the net revenue impact of documented reduced
sales due directly to utility CL\&M programs. Lost revenues equate
to the portions of utility rate prices that contribute to recovery of
utility fixed costs. In calculating a utility's lost revenues, the impact
of any applicable automatic rate adjustment mechanisms ... must
be taken into account. The intent of the calculation of lost revenues
is to restore the utility's net income to the level that would have
occurred without the loss of sales from utility CL\&M programs.

Connecticut Valley Electric (Order 20,359 in Docket 91-024, December 31, 1991), Granite State Electric Company, Public Service Company of New Hampshire, Concord Electric, and Exeter \& Hampton Electric (Order 20,477 in Docket 91-158, May 12, 1992) are eligible to recover net lost revenue. The New Hampshire PUC administers an identical prospective surcharge for all these utilities. The utilities file DSM plans, annual program savings forecasts, and net lost revenue estimates in October of each year. Utility net lost revenue projections are based on engineering estimates of measure savings and measure installations. This filing covers planned activities for the coming year. The net lost revenue forecast for the coming year includes any cumulative lost revenues accrued from program activities in the current and previous years.

The net lost revenue are recovered as part of the CL\&M surcharge. Lost revenues are calculated by multiplying the lost $\mathrm{kWh}$ sales by the base rate for each program and customer class. The base rate is unique to each utility, and reflects that utilities' base rate demand and energy charges by customer class. At present, utilities do not reconcile net lost revenue forecasts with either participation levels or unit energy savings. The New Hampshire PUC plans to reconcile net lost revenue estimates to observed participation levels in the October 1994 utility filings. This reconciliation would compare projected to observed program participation levels for 1993 . The adjustment for any difference would occur in the 1995 C\&LM surcharge charge. 
Utility programs must be approved by the New Hampshire PUC before any lost revenues can be recovered. New Hampshire is the only state with an active NLRA mechanism that does not also require some type of reconciliation of net lost revenue estimates with DSM measurement and evaluation studies.

\section{Implementation Issues}

New Hampshire PUC staff report that the implementation of the mechanism is simple if utility program savings estimates are accepted. The PUC recognizes the need for program evaluations, but the strategy in New Hampshire is to focus DSM budgets on programs. Staff indicates that evaluations are expensive and current utility efforts focus on making selective use of evaluation data from neighboring states where parent utilities are operating programs similar to ones being offered in New Hampshire. The PUC has not established guidelines for how utilities should measure or verify savings. Staff intends to focus more on DSM measurement issues in 1995.

Staff has a concern that the current NLRA mechanism has a built-in bias favoring utilities. In the increasingly competitive environment utilities face, staff questions whether utilities would make the $\mathrm{kWh}$ sale lost due to the DSM program. This concern has not led to litigation of utility net lost revenue estimates.

The first litigation of utility net lost revenue estimates in New Hampshire occurred in 1994. Connecticut Valley Electric Company argued that the dollar value of net lost revenue should be based on the avoided costs of the parent utility. Staff argued that net lost revenue be priced at the wholesale rate of the parent utility. The New Hampshire PUC decided in favor of staff's position (Order in Docket 93-151, April 4, 1994).

\section{NLRA Results}

Staff notes that historically some utilities have resisted PUC encouragement to actively pursue DSM opportunities. From this standpoint, staff views the NLRA mechanism as a success because these same utilities are pursuing DSM without the level of resistance to PUC policy previously observed.

Table A-7 contains net lost revenue data from 1993 for New Hampshire utilities. The revenues recovered are small. Granite State Power, though eligible to recover lost revenues, has never requested recovery. Based on our review of DSM program expenditures for 1992 and 1993, New Hampshire utilities spent only about $0.4 \%$ and $0.7 \%$, respectively, of total annual revenues on DSM. This is about a quarter of the DSM investment level for states with policies that restore net lost revenues from utility DSM. Utilities in states without a policy to restore net lost revenues spent an average of about one percent of revenues on DSM programs. 
Table A-7. Net Lost Revenues Recovered by Utilities in New Hampshire (000's dollars)

\begin{tabular}{rc}
\hline Utility & $1993^{1}$ \\
\hline Connecticut Valley & \\
Net lost revenues & 54 \\
Total DSM costs & 360 \\
Operating revenues & 16,699
\end{tabular}

Granite State

Net lost revenues not claimed

Total DSM costs

Operating revenues

62,745

Public Service Co of NH

Net lost revenues

Total DSM costs

Operating revenues

Concord, Exeter \& Hampton

Net lost revenues 25

Total DSM costs

Operating revenues 90,599

1. Utilities did not recover net lost revenues prior to 1993 because they were not operating DSM programs or were not operating Commission-approved DSM programs.

\section{NEW YORK}

\section{Status of NLRA}

On July 26, 1988, the New York PSC (Opinion No. 88-20, p. 40) directed electric utilities to "propose rate-making innovations such that [demand side management] programs that benefit 
customers are also rewarding to stockholders." By 1990, all investor-owned electric utilities had implemented rate-making proposals that included net lost revenue recovery.

Until recently, all New York utilities were eligible to collect lost revenues through a specific NLRA mechanism. New York defines lost revenues from DSM programs as net of avoided fuel costs, taxes, and variable operation and maintenance costs. In 1991 Orange \& Rockland became the first utility in the state to move to a decoupling mechanism. By the end of 1993, all the utilities but Central Hudson Gas and Electric had moved to revenue decoupling (Opinion 93-2, Case 89-E-176, February 2, 1993).

Over time, New York used two different NLRA mechanisms, a deferred account mechanism and a prospective surcharge. The deferred account mechanism relied on a tracker account. Utilities filed annual estimates of net lost revenues. These estimates were reviewed by the PSC and the utility recovery of approved amounts was deferred until the utility's next rate case. At the rate case, the utility recovered approved net lost revenues in base rates. The second mechanism, a prospective surcharge, allowed utilities to recover approved net lost revenues, and other DSM costs, as part of a fuel adjustment charge included in monthly bills. Initial net lost revenue recovery was based on annual program participation projections and pre-approved measurement criteria. ${ }^{35}$ The pre-approved measurement criteria were the engineering algorithms used to estimate per measure energy savings. Reconciliation of net lost revenue estimates to total program savings occurred when utilities completed program evaluations. The New York PSC deferred treatment of over- or under-recovered net lost revenue until the utility's next rate case.

Central Hudson Gas and Electric's (CHG\&E's-Case 89-E-186, January 4, 1990) NLRA mechanism is of the second type described above. The utility estimates net lost revenue annually and, subject to PSC review and approval, is then authorized to collect estimates of net lost revenue through annual adjustments of base rates. The annual DSM cost recovery filing CHG\&E makes to the PSC also includes a reconciliation with previous net lost revenue estimates. The reconciliation is based on recorded participation levels and the results of impact evaluations. The PSC's annual review and approval process also addresses reconciliation. Any over- or underrecovery of net lost revenue from earlier filings is deferred until CHG\&E's next rate case. At the rate case, net lost revenue impacts are included in base rates, subject to the PSC's approval.

CHG\&E's programs must be approved by the New York PSC, reduce utility sales, and the net lost revenue estimates must be reconciled with impact evaluations. CHG\&E is also eligible to recover net lost revenue from DSM programs established through competitive bidding.

\section{Implementation Issues}

New York's switch to decoupling is prompted by several considerations, only some which are direct concerns with NLRA. PSC staff concerns with NLRA center on DSM measurement and

\footnotetext{
${ }^{35}$ Not all utilities used pre-approved measurement criteria to estimate per measure energy savings.
} 
evaluation issues. New York PSC staff views program evaluation as a critical part of NLRA. The NLRA mechanisms in New York relied on retrospective reconciliation of both program participation and unit energy savings. New York PSC staff noted that over time the program evaluations tended to become more sophisticated. This growing evaluation sophistication developed at least in part to increase the confidence of the PSC about program performance. New York PSC staff also believes, however, that more sophisticated evaluations approaches were applied because of the importance evaluations play in ultimately determining net lost revenue recovery. Staff suggested that the NLRA mechanism elevated the importance of accurate evaluations because errors in net lost revenue estimates are passed through to ratepayers on a dollar-for-dollar basis. The evaluation stakes are not as high in incentive awards because these awards typically represent only a small fraction of the value of total program savings. Finally, the growing sophistication of evaluations was making greater demands on PSC staff and utility resources. In particular, as evaluations became more complicated, staff observed that fewer regulatory staff are capable of assessing the reliability of evaluation methods and results.

PSC staff view the move to decoupling as a way to reduce the importance of DSM evaluations in DSM cost recovery. For all utilities except CHG\&E, the PSC now uses evaluations only to determine incentive payments. Staff also views NLRA as a specific technical fix to a much larger regulatory problem: the linkage of utility profits to sales. In New York PSC staff's view, decoupling better addresses this larger problem, strengthens utility commitment to IRP, and makes utilities indifferent to using demand-side or supply-side resources to meet customers' electricity needs.

CHG\&E has retained its NLRA mechanism in part because of problems the utility sees with decoupling. CHG\&E does not support a complete separation of sales from profits. The utility further believes decoupling may invite greater oversight by the PSC on utility management decisions. In CHG\&E's view, increased regulatory oversight is incompatible with increasing competitive pressures in the industry. Finally, the utility is concerned that under decoupling, the PSC might eventually establish performance goals that are stringent enough to reduce the company's investment return.

CHG\&E believes its NLRA mechanism has been implemented effectively, although implementation requires a considerable amount of documentation. CHG\&E describes the documentation of net lost revenue savings as somewhat burdensome, but that the utility would likely do much of this work anyway for DSM program performance assessments. A representative from Consolidated Edison Company (ConEd) makes a similar point; namely that while moving to decoupling has eliminated the need to file the net lost revenue portion of its overall DSM reporting requirement with the PSC, the utility still needs to understand the effect of DSM on lost sales. ConEd still does all the analysis required for the NLRA mechanism in order to understand the impact of DSM on rates, bills, and revenue.

CHG\&E would prefer that the PSC broaden its definition of DSM to include programs other than direct impact programs. For example, CHG\&E believes education and audit programs affect 
utility sales and that their effects can be evaluated. Because the utility is allowed to collect net lost revenue from these programs only where claimed savings can be demonstrated, CHG\&E believes a disincentive still exists for design and implementation of more broadly focused programs. $^{36}$

Because of the emphasis on program evaluations to support retrospective reconciliation of total program savings, CHG\&E views program evaluation costs as an important part of total utility DSM costs. As a result, CHG\&E is attempting to implement less costly evaluations, but is uncertain if the results will withstand PSC review. CHG\&E also reported a timing problem with retrospective reconciliation. Program evaluations are often not complete until two to three years after a program is first implemented. As a result, $\mathrm{CHG \& E}$ must reconcile net lost revenue estimates that date back several years. CHG\&E supports the use of pre-approved measurement criteria to estimate net lost revenues and suggests their application would help mitigate the timing problem with retrospective reconciliation. CHG\&E also believes measuring the persistence of savings is a looming issue. CHG\&E is concerned that the PSC will require documentation of net lost revenue from earlier programs. For example, for measures installed in 1990, CHG\&E is concerned that in order to claim the lost revenues in a future rate case from the 1990 measures, it will be required to conduct program evaluations to show that measures are still in place and producing savings. If the utility evaluations do not demonstrate persistent savings, then the net lost revenue collected in base rates will be reconciled to a lower level.

ConEd no longer has an NLRA mechanism, but did note the benefits of using pre-approved measurement criteria to estimate net lost revenue. In ConEd's NLRA mechanism, the preapproved measurement criteria were the assumptions included in engineering algorithms used to estimate per measure energy savings. ConEd used the measurement criteria with an annual forecast of units or measures installed to estimate program energy savings. The focus of program evaluation efforts was to verify assumptions used in the engineering algorithms, such as connected load, hours of operation, and load diversity. The measurement criteria allowed the utility and PSC staff to agree on unit energy savings and focus on monitoring program participation levels for both net lost revenue estimates and DSM incentives. ConEd's primary motivation to develop pre-approved measurement criteria was to expedite accounting and eliminate the need to conduct retrospective reconciliation for both unit energy savings and participation levels.

\section{NLRA Results}

PSC staff report that prior to New York's implementation of NLRA, utilities focused their DSM efforts on load management programs. NLRA promoted the development and implementation of energy efficiency programs. Without NLRA, utilities could be expected to continue with a load management focus because energy efficiency programs would reduce utility revenues. New York

\footnotetext{
${ }^{36} \mathrm{CHG \& E}$ is eligible for net lost revenue recovery from programs that lead to verifiable hardware installations, but not for programs that may lead to changes in customer behavior.
} 
PSC staff views an NLRA mechanism to be essential to an effective utility DSM policy in the absence of decoupling.

Under the current NLRA mechanisms, CHG\&E reports it offers more direct rebate and direct equipment installation programs. In addition, CHG\&E does not believe it would be pursuing DSM as aggressively without NLRA. ConEd reports that because the lost revenue issue was settled up front in New York's approach to DSM rate-making reform, the utilities were assured of having lost revenues addressed. From this perspective, ConEd believes the DSM performance incentive played a greater role to encourage utility DSM.

Table A-8 documents the substantial increase in DSM program expenditures by New York utilities from 1990 to 1993. Total DSM costs in New York have been increasing since at least 1985 , but the absolute increase in annual costs from 1990 (the first year comprehensive DSM rate-making reforms took effect) to 1993 is over $\$ 260$ million.

Table A-8 also shows that CHG\&E's program expenditures declined from 1992 to 1993. CHG\&E is concerned about the rate impacts of DSM and attributes part of the decline in DSM expenditures as a response to this concern.

Table A-8. Net Lost Revenues Recovered by Utilities in New York (000’s \$)

\begin{tabular}{rcccc}
\hline Utility & 1990 & 1991 & 1992 & 1993 \\
\hline CHG\&E & & & & \\
Net lost revenues & 93 & 1,191 & 3,400 & 5,272 \\
Total DSM costs & 5,103 & 12,067 & 13,734 & 12,090 \\
Operating revenue & 503,608 & 494,737 & 523,559 & 517,373
\end{tabular}

ConEd

$\begin{array}{ccccc}\text { Net lost revenues } & 2,446 & 12,745 & 5159^{1} & \text { decoupling } \\ \text { Total DSM costs } & 34,543 & 116,239 & 150,899 & 183,468\end{array}$

Operating revenue $\quad 5,455,889 \quad 5,589,975 \quad 5,635,655 \quad 5,955,387$

Long Island Lighting

Net lost revenues

17,988

$25,075^{1}$

decoupling

decoupling

Total DSM costs

51,803

58,741

39,032

39,145

Operating revenue

$2,856,045$

$2,574,367$

$2,634,174$

$2,911,549$ 


\begin{tabular}{ccccc}
\hline Utility & 1990 & 1991 & 1992 & 1993 \\
\hline NY State E\&G & & & & \\
Net lost revenues & 704 & 3,586 & 11,824 & $14,535^{1}$ \\
Total DSM costs & 15,092 & 42,496 & 65,491 & 74,559 \\
Operating revenue & $1,496,780$ & $1,555,815$ & $1,691,689$ & $1,800,150$ \\
Niagara Mohawk & & & & \\
Net lost revenues & 1,867 & 10,077 & 21,417 & decoupling \\
Total DSM costs & 24,163 & 62,779 & 99,085 & 39,829 \\
Operating revenue & $3,131,406$ & $3,358,294$ & $3,676,314$ & $3,904,834$ \\
Orange \& Rockland & & & & \\
Net lost revenues & 450 & decoupling & decoupling & decoupling \\
Total DSM costs & 6,023 & 11,728 & 14,010 & 20,424 \\
Operating revenue & 501,017 & 515,839 & 543,580 & 577,716 \\
Rochester G\&E & & & & \\
Net lost revenues & 472 & 1,600 & 5,391 & $3,711^{1}$ \\
Total DSM costs & 4,904 & 9,152 & 18,881 & 16,700 \\
Operating revenue & 828,730 & 859,548 & 902,970 & 935,452 \\
& & & & \\
\hline
\end{tabular}

N/A: not available

1. Represents net lost revenues for part of the year for before decoupling became effective.

\section{OREGON}

\section{Status of NLRA}

In 1989 Oregon Public Utility Commission staff began an investigation of DSM incentives for Oregon's electric utilities. In January 1991, the Oregon PUC approved Portland General Electric's Share All Value Equitably (SAVE) program (Order No. 91-98). The SAVE program contains both a lost revenue recovery mechanism and an incentive provision. The Oregon PUC initially authorized SAVE for three years (1991-93) and later extended the program one year to cover 1994. In Juiy 1991 the PUC staff issued a report that led to the opening of Docket 
UM 409 by the Oregon PUC. The Oregon PUC's goal in this proceeding was to develop policies to encourage utilities to acquire all cost-effective demand-side resources. The Oregon PUC's subsequent order committed to removing institutional and policy barriers to equal treatment of demand-side and supply-side resources (Order No. 92-1673). In addition, the Oregon PUC directed Pacific Power \& Light and Idaho Power to propose rate-making initiatives similar to the SAVE program already adopted for Portland General Electric.

By 1994 two electric utilities and three gas utilities were eligible for lost revenue recovery in Oregon. To date, only Portland General Electric (PGE) has filed and collected lost revenues. PGE's lost revenue recovery takes place through a retrospective surcharge, the Energy Efficiency Adjustment, that also includes a shared savings incentive, DSM program costs, and an adjustment account to recover over- and under-collections. PGE places lost revenue estimates in an interestearning balancing account. The utility initially requests $50 \%$ of estimated lost revenues and then requests the balance once savings verification studies are complete.

PGE's lost revenue recovery is calculated for kWh savings from energy efficiency measures not included in the utility's base rates that accrue between general rate cases. The Oregon PUC defines PGE's lost revenues as the net revenue lost from the reduction in $\mathrm{kWh}$ sales to retail customers from energy efficiency measures installed during the previous calendar years. The reduction in $\mathrm{kWh}$ sales is incremental to the amount included in PGE's test-year demand forecast used to determine PGE's base rates. In future base-rate adjustments, the test-year demand forecast will contain all kWh savings previously achieved by PGE's energy efficiency programs. As a result, $\mathrm{kWh}$ savings from energy efficiency programs are eligible for lost revenue recovery until new base rates are established in a general rate case; the $\mathrm{kWh}$ base is then reset to equal the amount of energy savings assumed in developing the new base rates. Lost revenue recovery may be positive or negative. Negative lost revenues will occur if actual kWh savings are less than estimated in setting base rates.

The specific formula PGE uses to calculate net lost revenue for each program category follows:

$$
L R_{i}-C L S_{i} \times\left(R_{i}-(S R M C+W H M)\right)
$$

$\mathrm{LR}_{\mathrm{i}}=$ lost revenues associated with program category $\mathrm{i}$,

$\mathrm{CLS}_{\mathrm{i}}=$ cumulative lost sales which are annual verified $\mathrm{kWh}$ savings produced by energy efficiency measures in the preceding calendar years in program category $\mathrm{i}$ minus any $\mathrm{kWh}$ savings already included in the most recently approved rate case,

$\mathrm{R}_{\mathrm{i}}=$ weighted average of retail rates in program category $\mathrm{i}$ calculated at the applicable tail block rate,

SRMC = PGE's short-run marginal cost,

WHM = PGE's short-run wholesale sales margin. 
Total lost revenues are the sum of lost revenues from PGE's four program categories. The shortrun marginal cost is from PGE's most recent avoided cost filing. PGE estimates its wholesale sales margin using methods consistent with those it uses to calculate avoided costs.

Annually in mid-February, PGE files all supporting material to estimate lost revenues, including program evaluations, as well as the other components of the Energy Efficiency Adjustment. The annual filing includes estimates of program impacts for the previous year as well as reconciliations for net lost revenue estimates from earlier years. The PUC acts on PGE's filing during a regularly scheduled business meeting in mid-April. The PGE NLRA mechanism is a retrospective surcharge with reconciliation to both program participation levels and unit energy savings.

PGE must have its DSM program approved by the PUC and must verify program savings to file for and collect lost revenues.

\section{Implementation Issues}

Oregon PUC staff reports problems with the NLRA mechanism that center on DSM measurement issues and the time required to review utility filings. Oregon PUC staff indicates that the two months (mid-February to mid-April) allotted to review PGE's annual filing is too limited to determine if program savings have been adequately measured. To compound the time shortage problem, the initial utility filing may not be final and is often followed with revised assumptions and modeling corrections. The utility may be compelled to file these updates because the midFebruary filing date does not always coincide with completion of the relevant program evaluations. Oregon PUC staff has recommended extending the review period to mid-May and having the utility submit the reconciliation portion of the net lost revenue filing before midFebruary.

The PUC has not set guidelines regarding how utilities are to verify program savings. Oregon PUC staff reports that PGE and Pacific Power \& Light have established evaluation groups comprised of experts who provide the utilities comments on their evaluation plans, evaluations in progress, and evaluation results.

Oregon PUC staff notes that the PUC may move to a decoupling mechanism for PGE sometime in 1995. While the PUC would not base a change to decoupling on administrative reasons, staff believes a decoupling mechanism would remove some administrative burdens associated with the NLRA mechanism. In particular, Oregon PUC staff would not devote the same level of resources to DSM evaluation review under a decoupling mechanism that it devotes under the NLRA mechanism.

While PGE's lost revenue filings have not resulted in litigation, PGE finds the detail and documentation required to support program savings estimates burdensome. In particular, PGE believes the regulatory requirements for retroactive reconciliation of both program participation levels and unit energy savings to be especially burdensome. For example, PGE is required to 
reconcile participation estimates and unit savings for program activities that occurred four years ago. PGE notes that this level of retroactive reconciliation makes tracking lost revenues difficult and complicates the annual lost revenue filing. As a result, PGE would prefer to eliminate the reconciliation provision from its NLRA mechanisms. PGE is willing to collect fewer lost revenues than it believes it is actually incurring so long as it collects this lower estimate with certainty. PGE does not believe that PUC-approved guidelines on program evaluations would be especially helpful so long as the PUC's focus on evaluations is for retroactive reconciliation.

PGE is also opposed to the decoupling concept for three reasons. First, PGE does not believe decoupling stimulates utility investment in energy efficiency. Second, because PGE is concerned with increasing industry competition and the possibility of stranded investment, the utility wants as much pricing flexibility as possible. From this perspective, PGE views decoupling as preserving extensive utility regulation. Third, a switch to decoupling will not eliminate PGE's need to perform expensive program evaluations because evaluations are still needed to support shareholder incentives.

\section{NLRA Results}

Oregon PUC staff finds it difficult to assess the effect of NLRA in isolation because the NLRA mechanism was adopted as a package with DSM incentives and at the same time IRP was being implemented in Oregon. Staff does not believe NLRA has changed the types of DSM programs utilities are pursuing, though staff is concerned that utilities may promote their programs at the expense of supporting building energy efficiency codes and standards.

PGE indicates that prior to 1991 it was only pursuing mandated energy efficiency programs, but is now marketing a broad portfolio of DSM programs. PGE describes a changing role for DSM. In 1991, PGE and regulators viewed DSM as a resource. The motivation for NLRA was to remove DSM incentives and let the utilities acquire as much cost-effective DSM as possible. PGE's current approach to DSM has changed. PGE views DSM first as a customer service-if a customer wants DSM then PGE will provide this service. DSM still provides the customer resource benefits, but customer value is becoming the driver of the utility's DSM decisions. In addition, PGE is reluctant to maintain utility-sponsored rebates at historical levels due to stranded investment concerns. The utility may not capture the full benefits of its current DSM investment if industry regulation changes in the next few years. Because of possible changes in the industry, PGE's current planning horizon for DSM extends only to the next year or two. PGE is planning to capture DSM through market transformation initiatives and other approaches that do not disadvantage the company's competitive position. As a result of these considerations, PGE prefers an NLRA mechanism because these mechanisms are targeted at specific financial disincentives to DSM rather than a more broadly-based decoupling mechanisms.

Table A-9 reports PGE's net lost revenue, total DSM costs, and operating revenues from 1991 to 1993 PGE's total DSM costs have doubled since the Oregon PUC approved the utility's SAVE program in 1991. 
Table A-9. Net Lost Revenues Recovered by Utilities in Oregon (000's \$)

\begin{tabular}{rccc}
\hline Utility & 1991 & 1992 & 1993 \\
\hline Portland General & & & \\
Net lost revenues & 0 & 1,537 & 4,755 \\
Total DSM costs & 9,013 & 10,704 & 18,148 \\
Operating revenues & 833,000 & 838,000 & 863,000 \\
\hline
\end{tabular}

\section{VERMONT}

\section{Status of NLRA}

In April 1990 the Vermont Public Service Board (PSB) established IRP rules and rate-making guidelines for utility recovery of investments in DSM (Order in Docket No. 5270, April 16, 1990). The order also established the Account Correcting for Efficiency (ACE). ACE is a deferred account mechanism that addresses net lost revenues from approved DSM programs. Unlike adjustment mechanisms in the other nine states, ACE includes only net lost revenues. DSM program cost recovery is addressed in rates. Utilities operating in Vermont do not receive incentives for DSM program performance.

At least five utilities have filed for and been awarded lost revenue recovery in Vermont: Central Vermont Public Service, Green Mountain Power, Citizen Utilities Company, Burlington Electric Department, and Washington Electric Cooperative. The ACE mechanism is used for all these utilities. ACE is intended to reflect the amount by which approved DSM programs reduce customer bills in the short term net of the utility's direct savings in fuel, capacity costs, other short-term variable costs, and the utility's off-system sales. Any DSM program that reduces utility revenues is eligible for net lost revenue recovery through ACE. The utility must update its ACE monthly. The account accrues a finance credit until the revenues are reflected in the utility's base rates. The utility recovers the accrued costs in the ACE account over a period to be decided in future rate cases. Negative entries can be entered in the account if estimated lost revenues are below test-year levels. Rate cases for Vermont utilities are held as needed depending on each utility's revenue situation. A typical interval between rate cases is one to one and a half years.

\section{Implementation Issues}

Under ACE, the utilities must establish that program savings occur. According to PSB staff this condition focuses debate on DSM measurement issues. PSB orders released after establishing 
ACE indicate that DSM programs must be accompanied by evaluations. At this point, Vermont utilities rely primarily on engineering estimates of unit energy savings. The PSB has not issued guidelines or defined measurement and evaluation protocols, although PSB does encourage evaluations that rely on end-use analysis and metering. PSB staff reports that engineering-based unit energy savings estimates are reconciled with program impact studies, but not in a formal proceeding. Instead, the PSB designates responsibility for ensuring that net lost revenue are incurred to Vermont's collaborative process. The Vermont Department of Public Service also provides an independent review of utility net lost revenue estimates.

PSB staff reports that obtaining reliable measurements of program savings is a concern. In particular, staff views the small size of Vermont utilities as an impediment to obtain sufficiently large evaluation samples for adequate estimation. PSB staff indicates that concerns with measurement have so far been successfully addressed by the collaborative process and the Vermont DPS. The PSB encourages utilities to make filings for net lost revenue recovery that reflect the consensus of the collaborative parties about the utilities' net lost revenue estimates.

\section{NLRA Results}

PSB staff believes the ACE removes an important disincentive to utility DSM. As a result, utilities now seriously pursue DSM and market a full suite of programs, including retrofit, rebate, and new construction programs. Despite what staff sees as a successful ACE policy, staff is concerned that larger regulatory and industry impediments exist to achieving comparable treatment of demand and supply-side investments. Specifically, each utility's rate base is still overwhelmingly tied to supply and the overall rate structure still encourages the utility to make incremental sales. This is especially true when marginal costs are less than embedded costs. Thus, PSB staff sees a mismatch between societal objectives, at least partially embodied in IRP, and the institutional objectives of utilities, which are motivated to generate profits.

Table A-10 provides net lost revenue recovered by Vermont's two largest utilities. Central Vermont remains eligible for net lost revenue recovery, but has not completed a rate case since 1992. Green Mountain Power's revenue recovery grew substantially from 1991 to 1993 . This growth paralleled the expansion in the utility's total DSM costs. 
Table A-10. Net Lost Revenues from DSM for Utilities in Vermont (000's dollars)

\begin{tabular}{rccc}
\hline Utility & 1991 & 1992 & 1993 \\
\hline Central Vermont & & & \\
Net lost revenues ${ }^{1}$ & 51 & pending & pending \\
Total DSM costs & 2,200 & 4,000 & 10,000 \\
Operating revenues & 226,530 & 267,953 & 293,000 \\
Green Mountain & & & 854 \\
Net lost revenues ${ }^{2}$ & 565 & 854 & 8,000 \\
Total DSM costs & 1,080 & 5,000 & 129,174 \\
Operating revenues & 117,430 & 123,363 & \\
\end{tabular}

1. Central Vermont Power recovered $\$ 135$ thousand for lost revenues in 1990-91; \$51 thousand is our estimate of those revenues recovered due to program activities in 1991. A Vermont PSB decision is pending on Central Vermont Power's current general rate case, which would cover net lost revenues for 1992-93 (F. Weston, Vermont PSB, personal communication October 1994).

2. These are annual estimates of revenues recovered due to program activities during the calendar year. Green Mountain Power recovered approximately $\$ 479$ thousand for lost revenues in 1990. 



\section{LIST OF INTERVIEWS}

\begin{tabular}{|c|c|c|}
\hline State & Organization & Contact \\
\hline Arizona & Arizona Corporation Commission & David Berry \\
\hline Connecticut & Department of Public Utility Control & $\begin{array}{l}\text { Cindy Jacobs } \\
\text { Mark Quinlan }\end{array}$ \\
\hline Illinois & Illinois Commerce Commission & $\begin{array}{l}\text { Mary Selvaggio } \\
\text { Steve Tuma }\end{array}$ \\
\hline Indiana & Utility Regulatory Commission & David Johnston \\
\hline Iowa & Utilities Board & Gordon Dunn \\
\hline Maryland & $\begin{array}{l}\text { Public Service Commission } \\
\text { Baltimore Gas \& Electric } \\
\text { Potomac Electric Power }\end{array}$ & $\begin{array}{l}\text { Mary Elizabeth Tighe } \\
\text { Sheldon Switzer } \\
\text { Ed Mayberry }\end{array}$ \\
\hline Massachusetts & Department of Public Utilities & Theo MacGregor \\
\hline Minnesota & $\begin{array}{l}\text { Public Utilities Commission } \\
\text { Minnesota Power } \\
\text { Otter Tail Power }\end{array}$ & $\begin{array}{l}\text { Betsy Engelking } \\
\text { Dennis Peterson } \\
\text { Brian Carlson }\end{array}$ \\
\hline New Hampshire & Public Utilities Commission & George McCluskey \\
\hline New York & $\begin{array}{l}\text { Public Service Commission } \\
\text { Central Hudson Gas \& Electric } \\
\text { Consolidated Edison }\end{array}$ & $\begin{array}{l}\text { William Mills } \\
\text { John Borchert } \\
\text { Stephen Pertusiello }\end{array}$ \\
\hline Ohio & Public Utilities Commission & Steve Puican \\
\hline Oregon & Portland General Electric & $\begin{array}{l}\text { Lee Sparling } \\
\text { Lynn Plamondon } \\
\text { Ed Busch } \\
\text { Kathy Phillips-Israel }\end{array}$ \\
\hline Vermont & Public Service Board & Frederick Weston \\
\hline
\end{tabular}




\section{INTERNAL DISTRIBUTION}

ORNL/CON-408

1. D. Bauer

2. L. Baxter

3. V. D. Baxter

4. L. Berry

5. D. S. Bjornstad

6. R. Braid

7. M. A. Brown

8. J. B. Cannon

9. F. C. Chen

10. J. Christian

11. G. Courville

12. T. R. Curlee

13. P. D. Fairchild

14. S. Hadley

15. L. J. Hill

16. E. Hillsman

17. E. Hirst

18. P. J. Hughes

19. M. A. Kuliasha
20. R. Lee

21. P. Leiby

22. J. M. MacDonald

23. V. C. Mei

24. D. E. Reichle

25. D. T. Rizy

26. A. C. Schaffhauser

27. M. Schweitzer

28. R. B. Shelton

29. J. Tomlinson

30. B. E. Tonn

31. J. Van Dyke

32. J. VanCoevering

33. J. M. Veigel (ORAU)

34. T. J. Wilbanks

35. ORNL Patent Office

36. Central Research Office

37. Document Reference Section

38. Laboratory Records (RC)

39-41. Laboratory Records Dept.

\section{EXTERNAL DISTRIBUTION}

42.

43.

44.

45.

46.

47.

48.

49. -50 .

51.

$52 .-800$
Dr. Douglas R. Bohi, Director, Energy and Natural Resources Division, Resources for the Future, 1616 P Street, N.W., Washington, DC 20036

Dr. Thomas E. Drabek, Professor, Department of Sociology, University of Denver, Denver, CO 80208-0209

Dr. Stephen G. Hildebrand, Director, Environmental Sciences Division, Oak Ridge National Laboratory, Post Office Box 2008, Oak Ridge, TN 37831-6037

Calvin MacCracken, President, Calmac Manufacturing Corporation, 101 West Sheffield Avenue, P. O. Box 710, Englewood, NJ 07631

Jacqueline B. Shrago, Director, Office of Technology Transfer, 405 Kirkland Hall, Vanderbilt University, Nashville, TN 37240

Mr. George F. Sowers, P. E., Senior Vice President, Law Companies Group, Inc., 114 Townpark Drive, Suite 250, Kennesaw, GA 30144-5599

Dr. C. Michael Walton, Ernest H. Cockrell Centennial Chair in Engineering and Chairman, Department of Civil Engineering, University of Texas at Austin, Austin, TX 78712-1076 OSTI, U. S. Department of Energy, P. O. Box 62, Oak Ridge, TN 37831

Office of Assistant Manager for Energy Research and Development, DOE/ORO, P. O. Box 2001, Oak Ridge, TN 37831-8600

External Energy and Global Change Analysis Section distribution mailing list and extra copies to E.M. Schorn, 4500N, H-19A 